\title{
A Simulation Study of the Effect of Injecting Carbon Dioxide with Nitrogen or Lean Gas on the Minimum Miscibility Pressure
}

\author{
by \\ Hussain R. Saoyleh \\ A Thesis \\ In \\ Petroleum Engineering
Submitted to the Graduate Faculty of Texas Tech University in
Partial Fulfillment of
the Requirements for
the Degree of
MASTER OF SCIENCE \\ Dr. Talal Gamadi \\ Chair of Committee \\ Dr. Habib Menouar \\ Dr. Hossein Emadibaladehi \\ Mark Sheridan \\ Dean of the Graduate School
}

December, 2016 
Copyright 2016, Hussain R. Saoyleh 


\section{ACKNOWLEDGMENTS}

This master thesis work and report would not be completed without all of the uncountable support, guidance, and assistance of many people. I would like to thank and express a great appreciation to my research supervisor, Dr. Talal Gamadi, who was encouraging and supportive of me throughout my research. I appreciate the time he spent helping me finish my research and the effort he put to guide me in my work. I would also like to thank my committee members, Dr. Habib Menouar and Dr. Hossein Emadibaladehi for their help and advice to improve my work on the research.

I also would like to express a deep thanks to my friends for motivating me to do the best I could in the research. All of the work and the ideas they gave me to improve my research and its results were very helpful. Finally, I would like to express my appreciation to my family and especially my parents for all of the countless prayers, the support and the love throughout my life and academic journey. 


\section{TABLE OF CONTENTS}

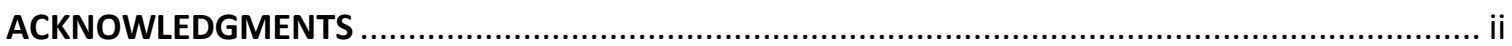

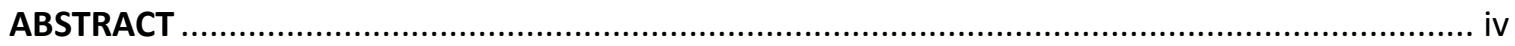

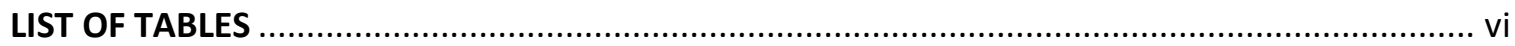

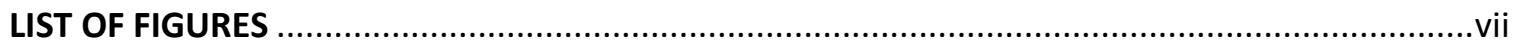

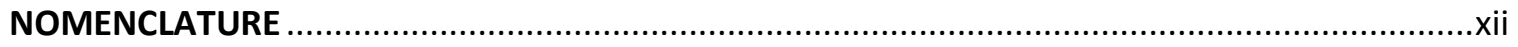

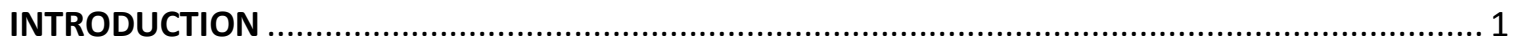

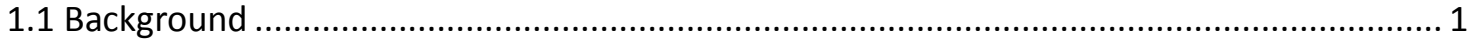

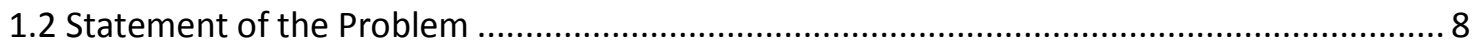

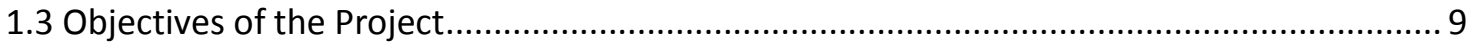

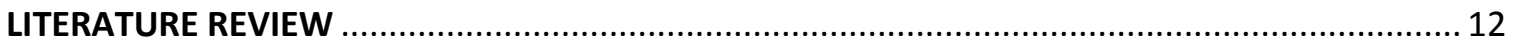

2.1 Minimum Miscibility Pressure and Its Measurement Methods ....................................... 12

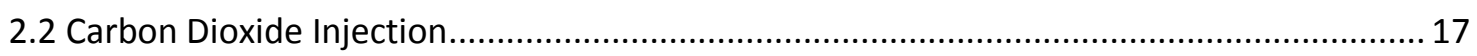

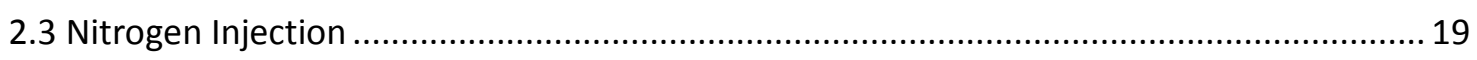

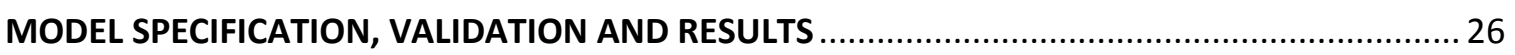

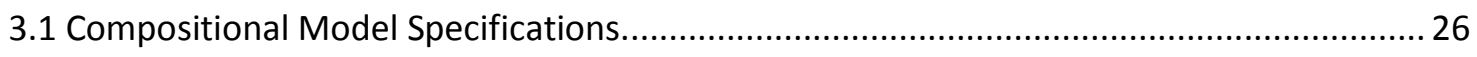

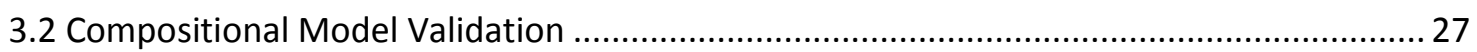

3.3 Carbon Dioxide and Lean Hydrocarbon Gas Mixture Results ............................................ 34

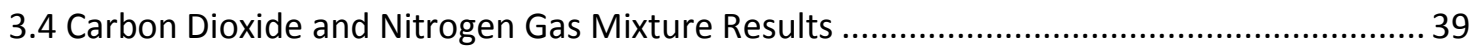

3.5 Reservoir Temperature Effect on the Minimum Miscible Pressure ................................... 45

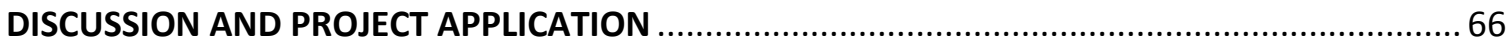

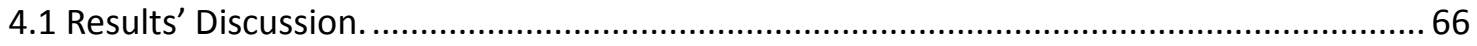

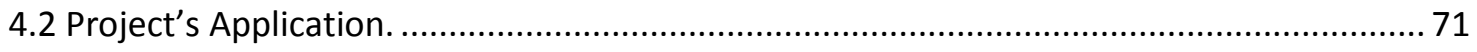

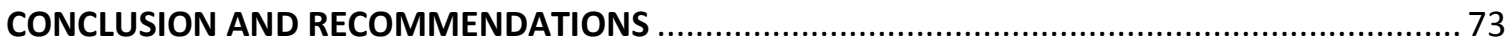

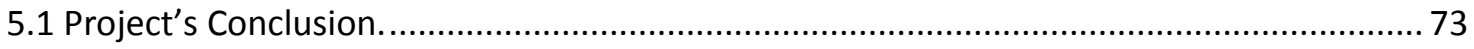

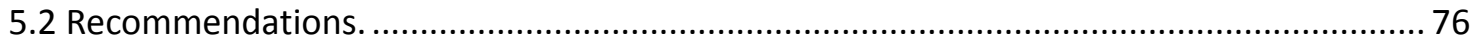

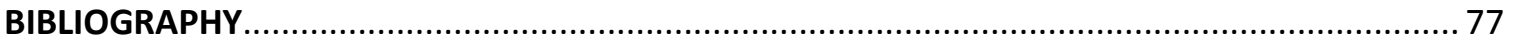

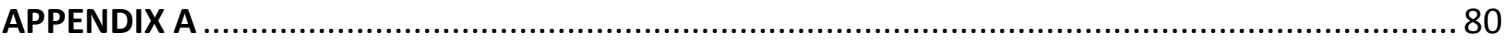

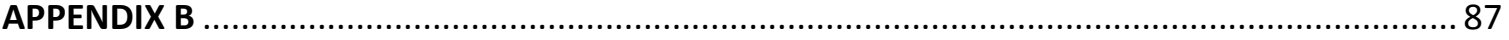




\section{ABSTRACT}

Gas injection projects are used for enhanced oil recovery purposes. Many gases are used as injected gas such as carbon dioxide, nitrogen, and lean gas. The minimum miscibility pressure of the carbon dioxide is low compared to the other injection gases. Moreover, carbon dioxide injection reduces its concentration in the atmosphere, which makes it environmental solution. However, capturing and storing carbon dioxide is not economical. Thus, lean gas can be used as an injection gas. Instead of storing lean gas, which raises the cost of the gas injection project, lean gas can be re-injected instead of carbon dioxide. This process of re-injection of lean gas lowers the cost but raises the cost of the injection project due to its high minimum miscibility pressure compared to the carbon dioxide. Moreover, nitrogen is also used as an injection gas. Nitrogen is available everywhere, which makes the use of nitrogen more favorable. Nonetheless, nitrogen has an extremely high minimum miscibility pressure, which is much higher than carbon dioxide and lean gas. Therefore, nitrogen's high minimum miscibility pressure is one of its biggest disadvantages. In reservoirs with high pressure, nitrogen is a good gas to be injected.

When carbon dioxide is used in injection gas projects, the availability of carbon dioxide is not enough to complete the project; therefore, some additional gases can be mixed with the available amount of carbon dioxide. In the first part of this project, different mixture of carbon dioxide and lean gas with different percentages are simulated using Schlumberger Eclipse 300 to measure the minimum miscibility pressure 
values. Based on the result, mixing carbon dioxide to the lean gas lowers the minimum miscibility pressure of the $100 \%$ lean gas. A small amount of total gas is required to be injected to produce a good amount of oil compared to the other mixtures.

The second part of the project is using nitrogen instead of lean gas to be mixed with carbon dioxide. The minimum miscibility pressure was simulated and compared to the result of the minimum miscibility pressure of the $100 \%$ carbon dioxide and $100 \%$ nitrogen. Unlike the $50 \%-50 \%$ carbon dioxide and lean gas mixture, the $50 \%-50 \%$ carbon dioxide and nitrogen mixture has a high minimum miscibility pressure, but not as high as the $100 \%$ nitrogen's minimum miscibility pressure. Even though the amount needed of the total gas injected (nitrogen mixture) is not high compared to the other mixtures, the amount of oil produced is too low.

This project also studies the effect of temperature on injection gas mixtures' minimum miscibility pressure consisting of two or more gases. It is found that the higher the temperature is, the higher the minimum miscibility pressure is, in general.

Temperature has more effect on the $100 \%$ lean gas's and $100 \%$ nitrogen minimum miscibility pressure than the minimum miscibility pressure of the $100 \%$ carbon dioxide. Therefore, in carbon dioxide - lean gas and carbon dioxide - nitrogen mixtures, the higher the amount of lean gas or nitrogen in the injected gas mixture results in a higher effect of the reservoir temperature on the minimum miscibility pressure. 


\section{LIST OF TABLES}

1.1. The recent projects of carbon dioxide in the field (Kossack, 2013.)..................................... 5

3.1. Lean gas and carbon dioxide gas mixture's minimum miscibility pressure at $250 \mathrm{~F} \ldots \ldots \ldots \ldots . . . . .38$

3.2. Nitrogen and carbon dioxide gas mixture's minimum miscibility pressure at $250 \mathrm{~F} \ldots \ldots \ldots \ldots . . . . .44$

3.3. Carbon dioxide - lean gas mixture' minimum miscible pressure at $160 \mathrm{~F}, 200 \mathrm{~F}$, and $250 \mathrm{~F} \ldots .64$

3.4. Carbon dioxide - nitrogen mixture' minimum miscible pressure at $160 \mathrm{~F}, 200 \mathrm{~F}$, and $250 \mathrm{~F} . . .65$

4.1. Summary of the results of the total gas injected and the amount of gas needed of each component in the injected gas mixture of the five cases.................................................... 71

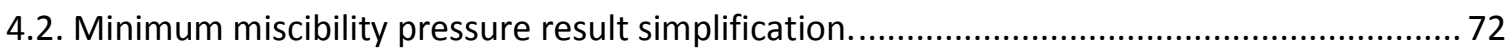




\section{LIST OF FIGURES}

1.1. The oil produced in stock tank barrel of the different enhanced oil recovery types (Kossack, 2013.)

1.2. The number of projects performed for each of the three main enhanced oil recovery methods throughout the years (Kossack, 2013.)

1.3. The oil produced in stock tank barrel (y-axis) of the different enhanced oil recovery types (Kossack, 2013.)

1.5. Primary, secondary and tertiary recoveries' diagram (Kossack, 2013.)................................. 6

1.6. The miscible carbon dioxide stages in the reservoir (Kossack, 2013.).................................. 7

2.1. The apparatus that are used in the lab to measure the minimum miscibility pressure using the slim tube (Matthew, 2012.).

2.2. Example of the intersection between two lines in the plot of the oil recovery factor as a function of the pressure.

2.3. Another example of the intersection between two lines in the plot of the oil recovery factor as a function of the pressure (Adel, 2016.)

2.4. All of the MMP values when nitrogen is used are higher than the methane ones.

2.5. Comparison of Hannsen correlation with experimental data (Sebastain, 1992.)

2.6. Comparison of Flroozabadl correlation with experimental data (Sebastain, 1992.).............. 23

2.7. Comparison of NIPER correlation with experimental data (Sebastain, 1992.) ....................... 24

2.8. Comparison of Glaso correlation with experimental data (Sebastain, 1992.)....................... 24

3.1. Relative Permeability Curves

3.2. Simulator result of the minimum miscibility pressure of $100 \%$ carbon dioxide at $250 \mathrm{~F}$

3.3. The oil recovery factor of $90 \%$ at 1.2 pore volume injected vs. the pressure $(100 \%$ carbon dioxide at 250F)

3.4. Simulator result of the minimum miscibility pressure of $100 \%$ lean gas at $250 \mathrm{~F}$.

3.5. The oil recovery factor of $90 \%$ at 1.2 pore volume injected vs. the pressure ( $100 \%$ lean gas at 250F).

3.6. Simulator result of the minimum miscibility pressure of $100 \%$ nitrogen at $250 \mathrm{~F}$. 
3.7. The oil recovery factor of $90 \%$ at 1.2 pore volume injected vs. the pressure $(100 \%$ nitrogen at 250F).

3.8. The components of each injected gas mixture (carbon dioxide and lean gas)

3.9. Simulator result of the minimum miscibility pressure of $30 \%$ carbon dioxide and $70 \%$ lean gas at $160 \mathrm{~F}$.

3.10. The oil recovery factor of $90 \%$ at 1.2 pore volume injected vs. the pressure ( $70 \%$ lean gas and $30 \%$ carbon dioxide at $160 \mathrm{~F})$

3.11. Simulator result of the minimum miscibility pressure of $50 \%$ carbon dioxide and $50 \%$ lean gas at 200F.

3.12. The oil recovery factor of $90 \%$ at 1.2 pore volume injected vs. the pressure ( $50 \%$ lean gas and $50 \%$ carbon dioxide at $200 \mathrm{~F}$ ).

3.13. Simulator result of the minimum miscibility pressure of $80 \%$ carbon dioxide and $20 \%$ lean gas at $250 \mathrm{~F}$.

3.14. The oil recovery factor of $90 \%$ at 1.2 pore volume injected vs. the pressure ( $20 \%$ lean gas and $80 \%$ carbon dioxide at $250 \mathrm{~F}$ ).

3.15. Carbon dioxide $\%$ as a function of the minimum miscibility pressure (lean gas-carbon dioxide)

3.16. The components of each injected gas mixture (carbon dioxide and nitrogen)......

3.17. Simulator result of the minimum miscibility pressure of $25 \%$ carbon dioxide and $75 \%$ nitrogen at $250 \mathrm{~F}$

3.18. The oil recovery factor of $90 \%$ at 1.2 pore volume injected vs. the pressure ( $75 \%$ carbon dioxide and $25 \%$ nitrogen at $250 \mathrm{~F}$ )

3.19. Simulator result of the minimum miscibility pressure of $50 \%$ carbon dioxide and $50 \%$ nitrogen at $250 \mathrm{~F}$

3.20. The oil recovery factor of $90 \%$ at 1.2 pore volume injected vs. the pressure ( $50 \%$ carbon dioxide and $50 \%$ nitrogen at $250 \mathrm{~F}$ )

3.21. Simulator result of the minimum miscibility pressure of $25 \%$ carbon dioxide and $75 \%$ nitrogen at $250 \mathrm{~F}$

3.22. The oil recovery factor of $90 \%$ at 1.2 pore volume injected vs. the pressure ( $25 \%$ carbon dioxide and $75 \%$ nitrogen at $250 \mathrm{~F}$ ) 
3.23. Carbon dioxide $\%$ as a function of the minimum miscibility pressure (nitrgen-carbon dioxide)

3.24. Simulator result of the minimum miscibility pressure of $100 \%$ carbon dioxide at $200 \mathrm{~F} \ldots . . .46$

3.25. The oil recovery factor of $90 \%$ at 1.2 pore volume injected vs. the pressure $(100 \% \mathrm{CO} 2$ at 200F)

3.26. Simulator result of the minimum miscibility pressure of $100 \%$ carbon dioxide at $160 \mathrm{~F}$.

3.27. The oil recovery factor of $90 \%$ at 1.2 pore volume injected vs. the pressure $(100 \%$ CO2 at 160F)

3.28. Simulator result of the minimum miscibility pressure of $80 \%$ carbon dioxide and $20 \%$ lean gas at 200F.

3.29. The oil recovery factor of $90 \%$ at 1.2 pore volume injected vs. the pressure ( $80 \%$ carbon dioxide and $20 \%$ at $200 \mathrm{~F}$ ).

3.30. Simulator result of the minimum miscibility pressure of $80 \%$ carbon dioxide and $20 \%$ lean gas at $160 \mathrm{~F}$.

3.31. The oil recovery factor of $90 \%$ at 1.2 pore volume injected vs. the pressure ( $80 \%$ carbon dioxide and $20 \%$ at $160 \mathrm{~F}$ ).

3.32. Simulator result of the minimum miscibility pressure of $50 \%$ carbon dioxide and $50 \%$ lean gas at 200F.

3.33. The oil recovery factor of $90 \%$ at 1.2 pore volume injected vs. the pressure ( $50 \%$ carbon dioxide and $50 \%$ at $200 \mathrm{~F}$ )

3.34. Simulator result of the minimum miscibility pressure of $50 \%$ carbon dioxide and $50 \%$ lean gas at $160 \mathrm{~F}$.

3.35. The oil recovery factor of $90 \%$ at 1.2 pore volume injected vs. the pressure ( $50 \%$ carbon dioxide and $50 \%$ at $160 \mathrm{~F})$.

3.36. Simulator result of the minimum miscibility pressure of $30 \%$ carbon dioxide and $70 \%$ nitrogen at $200 \mathrm{~F}$

3.37. The oil recovery factor of $90 \%$ at 1.2 pore volume injected vs. the pressure ( $30 \%$ carbon dioxide and $70 \%$ at $200 \mathrm{~F}$ ).

3.38. Simulator result of the minimum miscibility pressure of $30 \%$ carbon dioxide and $70 \%$ nitrogen at 160F). 
3.39. The oil recovery factor of $90 \%$ at 1.2 pore volume injected vs. the pressure $(30 \%$ carbon dioxide and $70 \%$ lean gas at $200 \mathrm{~F}$ ).

3.40. Simulator result of the minimum miscibility pressure of $100 \%$ lean gas at $200 \mathrm{~F}$. 54

3.41. The oil recovery factor of $90 \%$ at 1.2 pore volume injected vs. the pressure ( $100 \%$ lean gas at 200F)

3.42. Simulator result of the minimum miscibility pressure of $100 \%$ lean gas at $160 \mathrm{~F}$. 55

3.43. The oil recovery factor of $90 \%$ at 1.2 pore volume injected vs. the pressure ( $100 \%$ lean gas at 160F)

3.44. Simulator result of the minimum miscibility pressure of $25 \%$ nitrogen and $75 \%$ carbon dioxide at $200 \mathrm{~F}$

3.45. The oil recovery factor of $90 \%$ at 1.2 pore volume injected vs. the pressure $(75 \%$ carbon dioxide and $25 \%$ nitrogen at $200 \mathrm{~F}$ )

3.46. Simulator result of the minimum miscibility pressure of $25 \%$ nitrogen and $75 \%$ carbon dioxide at $160 \mathrm{~F}$

3.47. The oil recovery factor of $90 \%$ at 1.2 pore volume injected vs. the pressure ( $75 \%$ carbon dioxide and $25 \%$ nitrogen at $160 \mathrm{~F}$ )

3.48. Simulator result of the minimum miscibility pressure of $50 \%$ nitrogen and $50 \%$ carbon dioxide at $200 \mathrm{~F}$

3.49. The oil recovery factor of $90 \%$ at 1.2 pore volume injected vs. the pressure ( $75 \%$ carbon dioxide and $25 \%$ nitrogen at $200 \mathrm{~F}$ )

3.50. Simulator result of the minimum miscibility pressure of $50 \%$ nitrogen and $50 \%$ carbon dioxide at $160 \mathrm{~F}$.

3.51. The oil recovery factor of $90 \%$ at 1.2 pore volume injected vs. the pressure ( $50 \%$ carbon dioxide and $50 \%$ nitrogen at $160 \mathrm{~F}$ )

3.52. Simulator result of the minimum miscibility pressure of $75 \%$ nitrogen and $25 \%$ carbon dioxide at $200 \mathrm{~F}$

3.53. The oil recovery factor of $90 \%$ at 1.2 pore volume injected vs. the pressure ( $25 \%$ carbon dioxide and $75 \%$ nitrogen at $200 \mathrm{~F}$ )

3.54. Simulator result of the minimum miscibility pressure of $75 \%$ nitrogen and $25 \%$ carbon dioxide at $160 \mathrm{~F}$ 
3.55. The oil recovery factor of $90 \%$ at 1.2 pore volume injected vs. the pressure ( $25 \%$ carbon dioxide and $75 \%$ nitrogen at $160 \mathrm{~F}$ )

3.56. Simulator result of the minimum miscibility pressure of $100 \%$ nitrogen at $200 \mathrm{~F}$

3.57. The oil recovery factor of $90 \%$ at 1.2 pore volume injected vs. the pressure ( $100 \%$ nitrogen at 200F)

3.58. Simulator result of the minimum miscibility pressure of $100 \%$ nitrogen at $250 \mathrm{~F}$...... 63

3.59. The oil recovery factor of $90 \%$ at 1.2 pore volume injected vs. the pressure ( $100 \%$ nitrogen at 160F)

3.60. Carbon dioxide $\%$ as a function of the minimum miscibility pressure (lean gas-carbon dioxide) with different temperatures.

3.61. Carbon dioxide $\%$ as a function of the minimum miscibility pressure (nitrogen-carbon dioxide) with different temperatures.

4.1. Carbon dioxide $\%$ as a function of the minimum miscibility pressure (lean gas-carbon dioxide)

4.2. Carbon dioxide $\%$ as a function of the minimum miscibility pressure (nitrogen-carbon dioxide)

4.3. Summary of the five gas injected composition with their minimum miscibility pressure

4.4. the amount oil recovered at 1.2 injected pore volume for all of the five injected gas mixture.

4.5. The amount of gas injected for all of the five gas mixtures that is needed to produce a fixed amount of oil (30 SCC). 


\section{NOMENCLATURE}

\begin{tabular}{|c|c|}
\hline MMP & Minimum Miscibility Pressure \\
\hline SCC & Standard Cubic Centimeter \\
\hline EOR & Enhanced Oil Recovery \\
\hline $\mathbf{R F}$ & Recovery Factor \\
\hline $\mathbf{N}_{2}$ & Nitrogen \\
\hline $\mathrm{CO}_{2}$ & Carbon Dioxide \\
\hline $\mathbf{T}$ & Temperature \\
\hline $\mathbf{M}_{\mathrm{c7}+}$ & The Molecular Weight of Heptane Plus \\
\hline $\mathbf{P}_{\mathrm{C2}-\mathrm{C6}}$ & Mole Fraction of Methane through Pentane \\
\hline 1-D & One Dimensional \\
\hline API & American Petroleum Institute \\
\hline PV & Pore Volume \\
\hline STB & Stock Tank Barrel \\
\hline $\mathbf{M}_{\mathrm{C5}+}$ & Pentane Plus Molecular Weight \\
\hline $\mathbf{X}_{\mathrm{vol}}$ & Mole fraction of volatile $\left(C_{1}, N_{2}\right)$ oil components \\
\hline Xint & Mole fraction of intermediate $\left(\mathrm{CO}_{2}, \mathrm{H}_{2} \mathrm{~S}, \mathrm{C}_{2}-\mathrm{C}_{6}\right)$ oil components \\
\hline
\end{tabular}




\section{CHAPTER I}

\section{INTRODUCTION}

\subsection{Background}

Gas injection has been used since the 1920's to improve oil recovery. Most of the developments came after performing research to understand the chemistry and physics of the multiphase flow in the early 1950s. The first successful field test of carbon dioxide injection was conducted in Mead Strawn, Texas in the 1960's; however, the first fullscale carbon dioxide flood was in SACROC, North Cross. In New Mexico and Colorado, the natural carbon dioxide sources were developed in the 1980's (Rao, 2001.) Figure (1.1) gives an idea about the expenses of enhanced oil recovery fluids. Figure (1.2) shows the oil produced in stock tank barrel ( $y$-axis) of the different enhanced oil recovery types. It shows how the miscible flooding is being used throughout the years (Kossack, 2013.) 


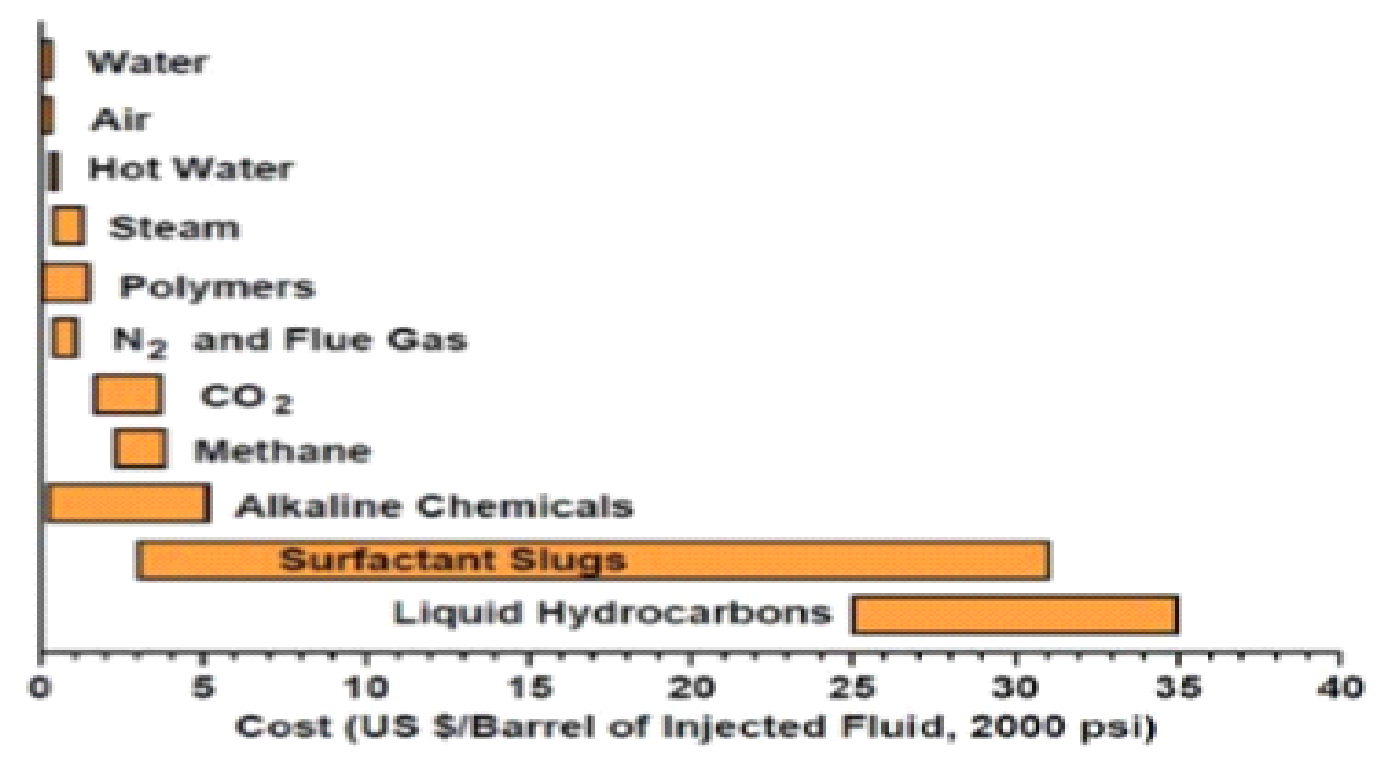

Figure 1.1 The oil produced in stock tank barrel of the different enhanced oil recovery types (Kossack, 2013.)

Three main methods were developed for enhanced oil recovery (EOR): chemical, thermal and miscible. The main purpose of the thermal enhanced oil recovery is to lower the viscosity of the heavy crude oil in order to increase its mobility. Miscible and chemical enhanced oil recovery are mainly used to lower the interfacial tension between the crude oil and the injected gas mixture for the medium and light gravity oils; hence, the oil tapped within the rock pores is minimized. A near complete efficiency of microscopic displacement is achieved due to the absence of the interfacial tension (Rao, 2001.) Figure (1.2) shows the number of projects performed for each of the three main enhanced oil recovery methods throughout the years. Figure (1.3) shows the oil produced in stock tank barrel ( $y$-axis) of the different enhanced oil recovery types. It shows how the miscible flooding is being used throughout the years (Kossack, 2013.) 


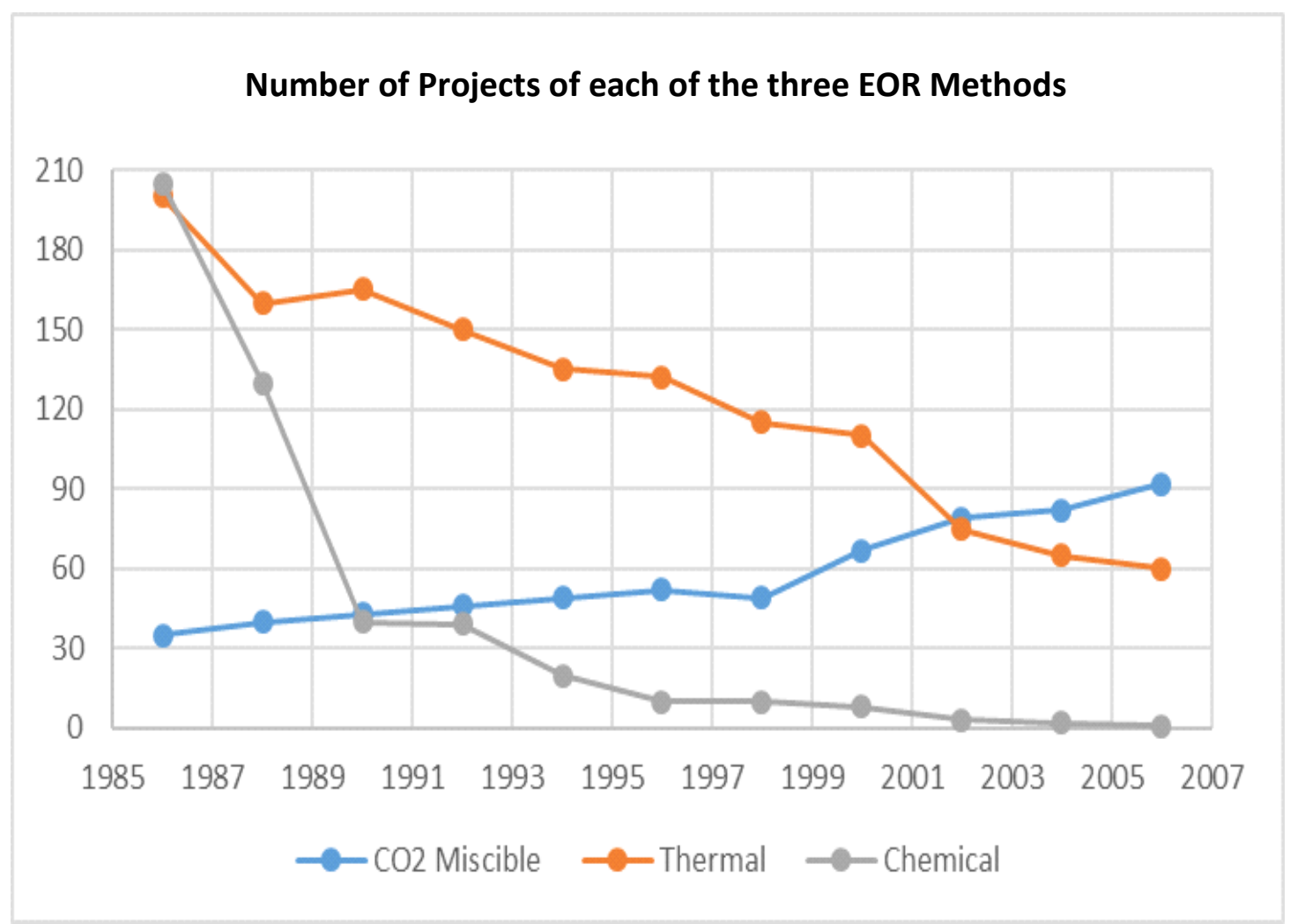

Figure 1.2 The number of projects performed for each of the three main enhanced oil recovery methods throughout the years (Kossack, 2013.) 


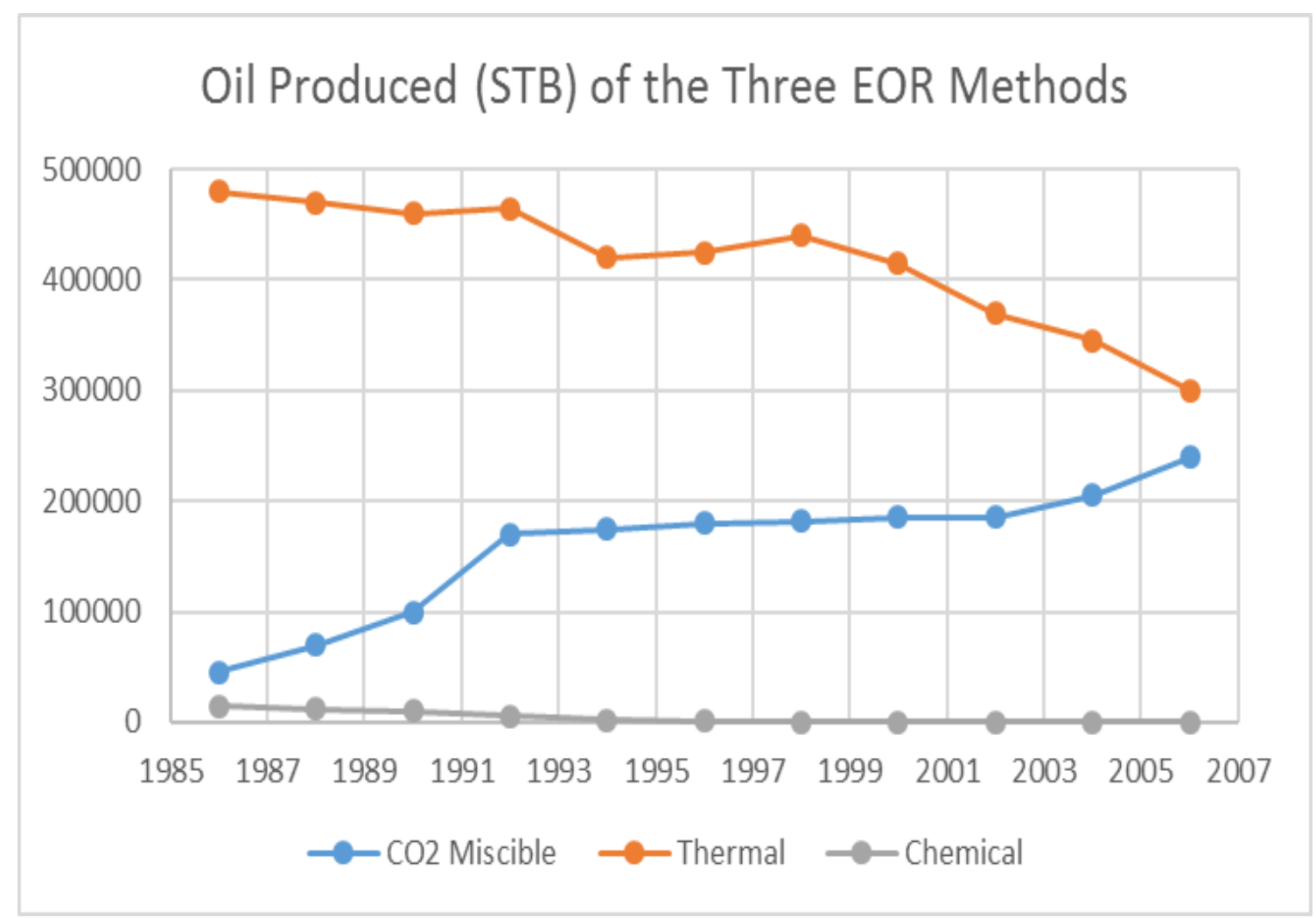

Figure 1.3 The oil produced in stock tank barrel (y-axis) of the different enhanced oil recovery types (Kossack, 2013.)

Optimizing of production and injection strategies is one of the main challenges for the modern reservoir management (Daoyong, 2003.) Moreover, some challenges are faced in miscible carbon dioxide flooding. The early breakthrough causes problems when carbon dioxide is used in a gas injection project. The corrosion that takes place in the pipes as a result of carbon dioxide damages the pipe lines. It is important to separate the oil produced at the surface from the injected carbon dioxide. All of these are challenges and disadvantages in regards to using carbon dioxide as an injection gas. Table (1) shows the recent projects of carbon dioxide in the field (kossack, 2013.) 
Table 1.1 The recent projects of carbon dioxide in the field (Kossack, 2013.)

\begin{tabular}{|c|c|c|}
\hline Project Name & Start Date & Location \\
\hline Brindisi & 2010 & Italy \\
\hline Husnes & 2011 & Norway \\
\hline Plant Barry & 2011 & USA \\
\hline Port Arthur & 2012 & USA \\
\hline WA Parish & 2013 & USA \\
\hline TCEP & 2014 & USA \\
\hline Trailblazer & 2014 & USA \\
\hline Kemper Country & 2014 & USA \\
\hline HECA & 2014 & USA \\
\hline Bow City & 2014 & Canada \\
\hline Longannet & 2014 & UK \\
\hline Leucadia & 2014 & USA \\
\hline Williston & 2014 & USA \\
\hline Maasvlkte & 2015 & Netherlands \\
\hline Boundary Dam & 2015 & Canada \\
\hline NZEC & 2015 & China \\
\hline Swan Hills & 2015 & Canada \\
\hline Magnum & 2015 & Netherlands \\
\hline Masdar CCS Project & Delayed & UAE \\
\hline
\end{tabular}


Is miscible flooding a secondary or tertiary recovery? When there is no mobile water in the reservoir, the miscible flooding can be considered as a secondary recovery. It can also be a secondary if water is injected as well. In the secondary recovery, the efficiency of the macroscopic displacement is controlled by viscous fingering, mobility ratio, the heterogeneity of the reservoir and gravity segregation. However, if oil and water are both mobile produced from the production wells, the recovery can be considered as tertiary (Rao, 2001.) Figure (1.4) illustrates where the miscible flooding fits.

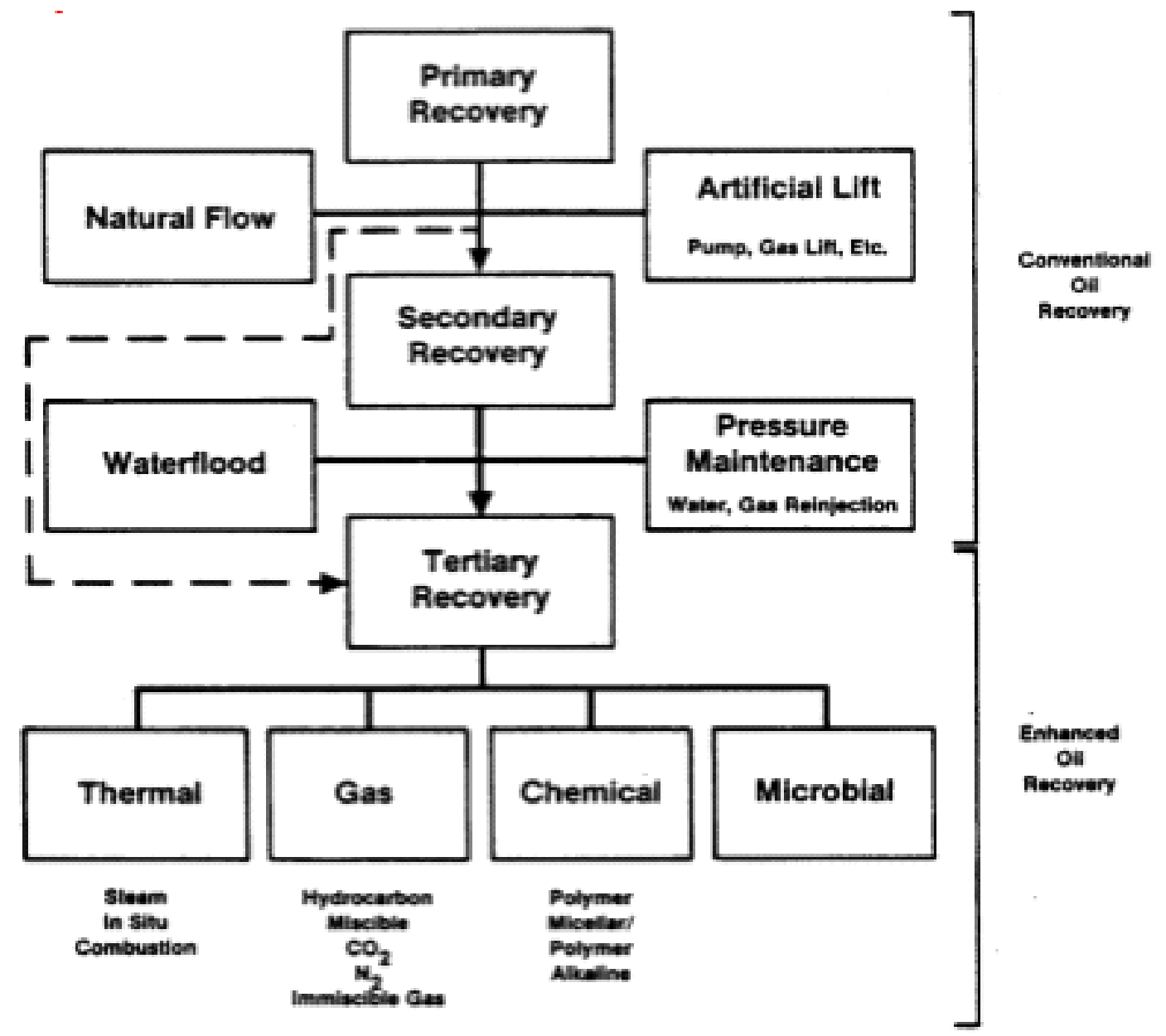

Figure 1.4 Primary, secondary and tertiary recoveries' diagram (Kossack, 2013.) 
Miscible carbon dioxide is defended by a multiple contact process, which the interaction between injected carbon dioxide and the reservoir oil is involved. Light oil fraction is vaporized by carbon dioxide in to the injected gas; hence, the miscibility is achieved. Due to the low viscosity, minimized interfacial tension and improved mobility, the reservoir oil is remobilized to reduce the residual oil saturation after water flooding. However, immiscible carbon dioxide flooding takes place when the oil has high percentage of heavy components or reservoir pressure is not high enough. In general, miscible carbon dioxide is more efficient than immiscible carbon dioxide flooding (Rao, 2001.) Figure (1.6) illustrates the miscible carbon dioxide stages in the reservoir.

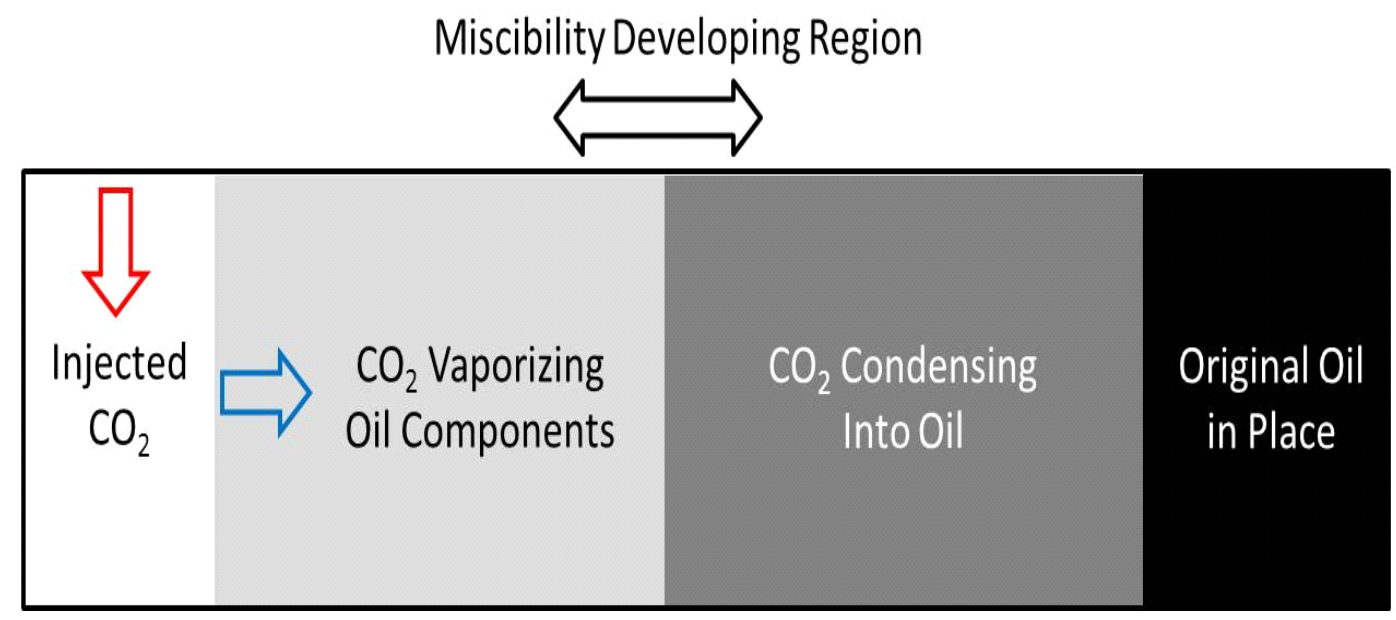

Figure 1.5. The miscible carbon dioxide stages in the reservoir (Kossack, 2013.)

Depending on the wettability of the reservoirs, gas flooding can be immiscible, near miscible or miscible. In water wet reservoirs, miscible solvent is needed to decrease the interfacial tension. However, minimizing the interfacial tension when miscibility is achieved is not important for the intermediate-wet reservoirs due to the 
90-degree contact angle. In oil-wet reservoirs, reducing the interfacial tension is not as important as overcoming the adhesion forces between oil and rock. As a result, surfactants or chemicals are used for oil separation from the other three phases and wettability alternation rather than reducing the interfacial tension (Rao, 2001.)

\subsection{Statement of the Problem}

Carbon dioxide is one of the gases that is used for gas injection projects besides nitrogen and lean hydrocarbon gases. Its low minimum miscibility pressure is an advantage over the other injection gases, which is almost around 1500 psi depending on the reservoir oil composition and the reservoir temperature. Hence, the injection pressure required to inject carbon dioxide at the surface is economical. However, the availability of the carbon dioxide or even the cost of capturing it and storing it is high.

Nitrogen as an injection gas can solve the problem of the carbon dioxide availability. Nitrogen can be easily found and retrieved, which makes it favorable to be used over carbon dioxide. Unlike carbon dioxide, nitrogen has a very high minimum miscibility pressure that can be as high as 9000 psi. This requirement results from nitrogen not being as soluble as carbon dioxide. Hence, the subsurface facilities needed to pump the injected gas to the reservoir is higher than when carbon dioxide is used in injection gas mixture. 
The produced lean gases, mainly methane, can be an alternative solution for gas injection projects instead of other gases. Due to the market demand, storing lean hydrocarbon gases might not be economical; therefore, it can be reinjected rather than storing it. It does not have a high minimum miscibility pressure as nitrogen, but it is not as low as the carbon dioxide minimum miscibility pressure. Based on that lean gases are a better option than nitrogen in the absence of carbon dioxide in terms of the minimum miscibility pressure.

In some of the gas injection projects, the total amount of gas needed is not available. One of the solutions that can be used is mixing the available gas with another available one to create a gas mixture consisting of more than one gas. For example, $50 \%$ of carbon dioxide is mixed with $50 \%$ of lean hydrocarbon gas or $50 \%$ nitrogen. This technique can solve many problems in regards to the lack of carbon dioxide. The percentages of gas mixture's components have to be studied to come up with optimum percentages for a given oil sample.

\subsection{Objectives of the Project}

A simulation model of slim tube experiment using Schlumberger Eclipse simulator is used in this project to measure the minimum miscibility pressure of an injected gas mixture. In this gas mixture, carbon dioxide was mixed with lean gas in different percentages in the first part of the project; then, it was mixed with different percentages of nitrogen in the second part of the research. The first 30 runs were 
conducted using $100 \%$ carbon dioxide, $100 \%$ lean hydrocarbon gas and $100 \%$ nitrogen. Based on the first 30 runs, the simulation model was validated using the minimum miscibility pressure correlations in the literature to check the accuracy of the results.

A gas mixture (carbon dioxide and nitrogen) was simulated using the developed compositional model to test the effect of the variation of the gas mixture component's percentages on the minimum miscibility pressure. The carbon dioxide percentage in the mixture varied from $90 \%$ to $10 \%$ with an increment of $10 \%$. The rest of the injected gas mixture was lean hydrocarbon gas (mainly methane). The main purpose of changing the volumes of the gas injected mixtures' components was to find the optimum percentage of each component in the mixture in terms of minimum miscibility pressure. The same work on carbon dioxide and lean hydrocarbon gas mixture was repeated with nitrogen instead of the lean hydrocarbon gas.

In the next part of the research, the temperature was changed using three different temperature values to simulate the results of the minimum miscibility pressure as a function of temperature. As it is presented in the literature, the minimum miscibility pressure increases as the temperature increases. This part of the research is not only to find the value of the minimum miscibility pressure at different temperatures but to validate the result of the compositional model to the results from the minimum miscibility pressure correlations presented in the literature.

From the twenty-one different gas injection compositions, five compositions were chosen to perform a final compression. The oil recovery factor was measured by the 
simulator at 1.2 pore volume injected in all of the five injected gas mixtures. The volume of the total gas injected were measured at a fixed total produced oil volume. The ratio of the total oil produced to the total gas injected, where the total oil produced volume was fixed, is used to show the best injected gas composition from the twenty-one compositions for a given oil composition and reservoir temperature. 


\section{CHAPTER II}

\section{LITERATURE REVIEW}

\subsection{Minimum Miscibility Pressure and Its Measurement Methods}

In any gas injection project, minimum miscibility pressure (MMP) is one of the most important parameters that has to be determined. It is defined as the lowest pressure needed for the injected gas to be miscible with the reservoir oil in a given reservoir temperature. It also known as the intersection between two lines in the plot of the oil recovery factor as a function of the pressure. Generally, recovery factor is measured at 1.2 pore volume of gas injected, which is considered to be the cutoff point where almost $90 \%$ of the oil is produced (Matthew, 2012.) This makes the measurement of the minimum miscibility pressure an essential key in any gas injection project. Figure (2.2) and figure (2.3) show an idea of the intersection between two lines in the plot of the oil recovery factor as a function of the pressure, where the MMP can be obtained (Adel, 2016.)

Many experimental and computational methods are used for minimum miscibility pressure measurement. The most common methods that are used in the lab are the slim tube experiment, vanishing interfacial tension and the rising the bubble. The vanishing interfacial tension method and the rising the bubble method are not as accurate as the slim tube experiment. These two methods do not entirely emphasize the 
multi-contact mechanisms. The slim tube experiment is a tube filled with sand pack coil that is fully saturated with crude oil. It is a 1-D displacement by injecting gas and taking into account the thermodynamic phenomena that takes a place in carbon dioxide-oil system inside the slim tube. A low injection rate and a long coil tube are used in the slim tube experiment in order to ensure the front is thermodynamically stable and to avoid the effect of fingering and composition variation. Figure (2.1) illustrates the apparatus that are used in the lab to measure the minimum miscibility pressure using the slim tube (Adel, 2016.)

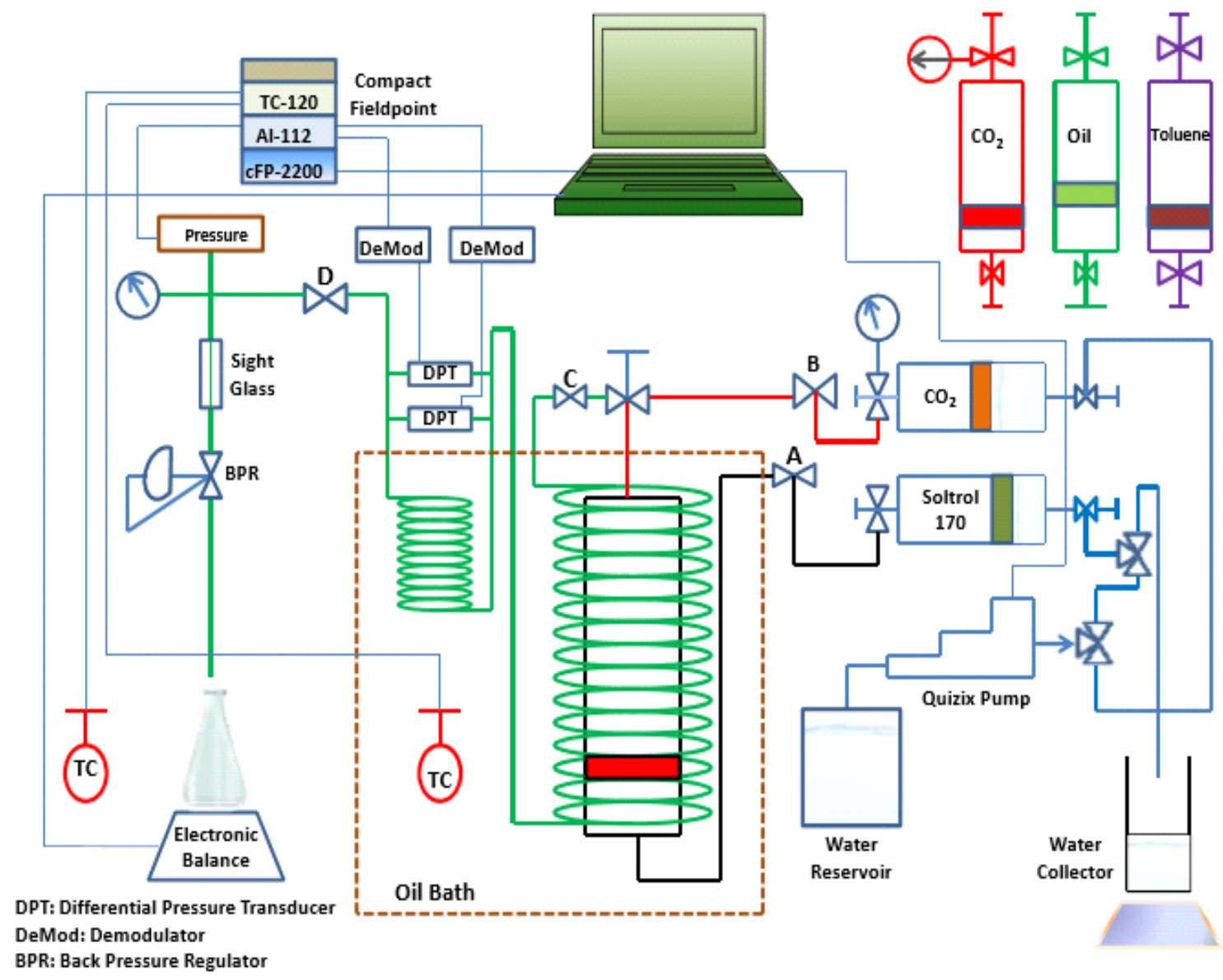

Figure 2.1 The apparatus that are used in the lab to measure the minimum miscibility pressure using the slim tube (Matthew, 2012.) 


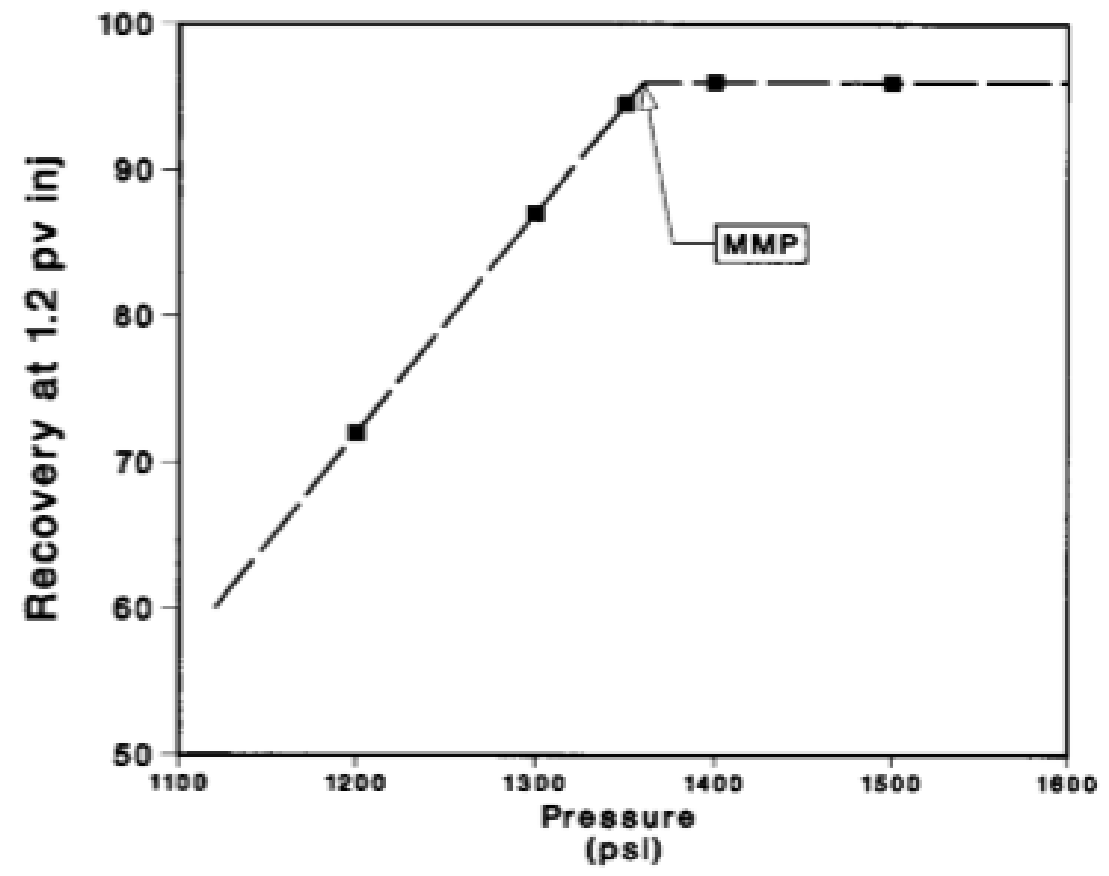

Figure 2.2: Example of the intersection between two lines in the plot of the oil recovery factor as a function of the pressure.

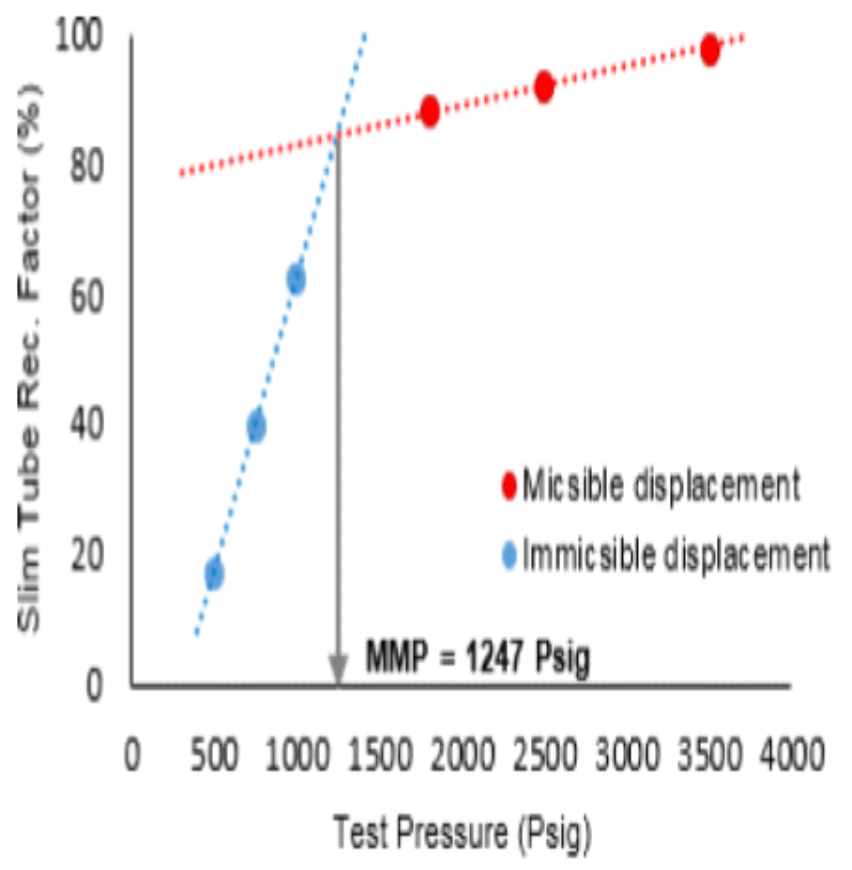

Figure 2.3: Another example of the intersection between two lines in the plot of the oil recovery factor as a function of the pressure (Adel, 2016.) 
Based on Flock's and Nouar's (1984) experiment, they recommend 60 to $80 \mathrm{ft}$ slim tube length in order to achieve a stable displacement. As a result, the experiment will be at least five weeks to measure the MMP for only one oil sample when four pressure values are used to determine the minimum miscible pressure. However, four values of pressure are not enough to get an accurate result of the MMP. Tovar et al. (2015) conducted a MMP slim tube experiment on North Burbank Unit dead crude oil with a short slim tube (20 psi) to reduce the time taken to finish the experiment. The result of the MMP was 1563 psig when the slim tube was 20ft long, whereas the result of the $40 \mathrm{ft}$ slim tube long (commercial laboratory) was 1687psig (Adel, 2016.)

The reason the results were not identical was due to the assumption that oil recovery was $100 \%$ at 2400 psig. The results were affected by other factors as well. The lengths of the two slim tubes were different and the samples were collected at different times even though they were from the same reservoir. Imad (2016) conducted some slim tube experiments with five light oil samples using a $20 \mathrm{ft}$ slim tube. He was able to prove that results obtained by a $20 \mathrm{ft}$ long slim tube were accurate and could be retrieved within a short experiment time. This validation made the slim tube experiment economically acceptable. In other words, the length of the slim tube and the number of the pressure points should be highly considered for more accuracy. This does not mean that the result is not acceptable if the light oil is used (Adel, 2016.)

The pressure composition diagram is one of the methods used to measure the minimum miscibility pressure where the phase behavior measurement is conducted for miscibility evaluation in a visual cell with a high pressure at a given reservoir pressure. 
The injected gas mixture expresses the composition as mole fraction on the diagram. In order to generate the phase boundaries, the dew point and the bubble point pressures are determined by adding different amounts of the injection gas to the reservoir crude oil. Two of the phases coexist within the two boundary (dew and bubble points pressure), while a single phase exists outside the two boundaries. The diagram helps to determine the needed miscibility conditions for any injected gas composition at a given temperature. However, this method has some major disadvantages. It is not economical, needs large amounts of fluids and is time-consuming. (Ayirala, 2006.)

The vanishing interfacial tension technique is another method used to measure the minimum miscibility pressure. When the value of the interfacial tension between two phases is zero, this means the miscibility condition is met due to the absence of the interfacial tension. Based on this definition, this technique has been developed. The interfacial tension between the gas and the oil is measured at different pressures at a given reservoir temperature. A plot of the interfacial tension is used where the extrapolated value to a zero interfacial tension represents the minimum miscible pressure value. This method has several advantages. It is economical and can be performed within a short period of time, such as one to two days. However, the lack of calibration and the absence of the compositional path specification are the disadvantages of using this method. Moreover, one of the weak points of this method is that the displacement of the conventional multiple contact is not taken into account since this method is used as a single contact technique. (Ayirala, 2006.) 


\subsection{Carbon Dioxide Injection}

Carbon dioxide has been one of the most efficient ways of enhanced oil recovery (EOR) techniques for decades. Its use has continuously grown and devolved from research during the past years. This growth and research has made carbon dioxide injection the most popular used EOR method in the US by $41 \%$, as the Oil and Gas Journal reported in 2012. Oil viscosity reduction, oil swelling due to the hydrocarbon high solubility and override effect decreasing are the reasons carbon dioxide is preferred to be used over the other EOR techniques. From the environmental point of view, carbon dioxide capturing and injecting reduces its concentration; hence, global warming is reduced. Carbon dioxide increases the ultimate recovery when it is injected to achieve miscibility, similar to other gases (nitrogen and hydrocarbon gases). However, hydrogen and hydrocarbon gases require a higher pressure to achieve miscibility, unlike carbon dioxide, which makes it more favorable than the other gases. (Yuan, 2004.)

Besides all of the method of measuring carbon dioxide minimum miscible pressure (slim tube experiment, compositional simulation, mixing-cell method and the analytical methods), correlations are used to approximate the minimum miscibility pressure. Minimum miscible pressure correlations are easy, quick and few input parameters are needed despite its accuracy. Therefore, they give a quick look and idea about the potential of carbon dioxide flooding for a given reservoir. Using the slim tube data regressions to come up with those correlations, however, is a disadvantage due to 
the uncertainty of the slim tube results. Some minimum miscible pressure correlations use only API of the reservoir fluids, which makes it less accurate than the other correlations that use the reservoir temperature and the total C2-C6 content. Almost all of the correlations were developed under the assumption that the methane content has a negligible effect on the value of MMP. (Yuan, 2004.)

The literature states that the oil composition affects the value of the carbon dioxide. The small hydrocarbon molecules are extracted more efficiently with a carbon dioxide- rich phase than the large molecules. It means that the molecular size distribution of the hydrocarbon components in the crude oil is important for the miscibility development. Moreover, it is shown in the literature that the variation in the molecular structure of the hydrocarbon in the oil sample has an effect too. An experimental result presented by Silva and Orr shows that branched alkanes are extracted by carbon dioxide better than the normal alkanes. In their research, they proved that the oil that has multiple rings in the heavy components of the oil sample are poorly extracted by carbon dioxide. (Hagedorn, 1994.)

Most of the correlations presented in the literature predict the carbon dioxide in a liner behavior as a function of the temperature. As most of the correlations in the literature, it is expected that with the increase of the temperature, the MMP value increases. However, another correlation was developed by Dindoruk that showed that it is not expected that the MMP increases at extreme temperatures. The following correlation gives accurate results that was devolved by Dindoruk (Yuan, 2004): 
MMP (Pure CO2)

$$
\begin{aligned}
& =a 1+a 2(M C 7+)+\left(a 4+a 5(M C 7+)+a 6\left(\frac{P c 2-6}{M C 7+^{2}}\right)\right) T \\
& +\left(a 7+a 8(M C 7+)+a 9(M C 7+)^{2}+a 10(P c 2-6)\right) T^{2}
\end{aligned}
$$

\begin{tabular}{lllll}
\hline $\mathbf{A 1}=$ & $\mathrm{A} 2=$ & $\mathrm{A3}=$ & $\mathrm{A4}=$ & $\mathrm{A5}=$ \\
$\mathbf{- 1 . 4 6 3 4 E + 0 3}$ & $\mathbf{0 . 6 6 1 2 E + 0 1}$ & $-4.4979 E+01$ & $\mathbf{0 . 2 1 3 9 E + 0 1}$ & $\mathbf{1 . 1 6 6 7 E + 0 3}$ \\
\hline $\mathbf{A 6}=$ & $\mathrm{A} 7=-1.2258 \mathrm{E}-$ & $\mathrm{A} 8=1.2883 \mathrm{E}-$ & $\mathrm{A} 9=-4.0152 \mathrm{E}-$ & $\mathrm{A} 10=-$ \\
$\mathbf{8 . 1 6 6 1 e + 0 3}$ & 01 & 03 & 06 & $9.2577 \mathrm{E}-04$ \\
\hline
\end{tabular}

\subsection{Nitrogen Injection}

Due to the unavailability of the carbon dioxide in some places, such as the areas outside of North America, nitrogen can be used as another option. However, the problem with using nitrogen is that the minimum miscible pressure can reach as high as 9000 psi, Alaskan oil. (Yuan, 2004.)

In some of the Norwegian offshore fields, the hydrocarbon gases that are produced are reinjected for mainly three reasons. Enhanced oil recovery, pressure maintenance or the market demand fluctuations are the reasons why the produced gas is reinjected. However, nitrogen is also suggested in some situations where the reservoir temperature is high and when the reservoir oil is light volatile oil. Due to the high miscibility of 
nitrogen, a high injection pressure is needed. This is necessary due to the MMP of the nitrogen being higher than carbon dioxide and lean hydrocarbon gas. (Sebastian, 1992.)

The vaporizing mechanism is the way that nitrogen, methane, and carbon dioxide develop miscibility with oil. The correlation presented in literature shows that the correlation used for measuring the nitrogen minimum miscible pressure can be used also for methane, which means that both of them should have the same values. However, some experiments show that using nitrogen as an injection pressure leads to a MMP of 6800 psi while the result of using methane instead is 5500 psi (a difference of 1300 psi.) Carbon dioxide and methane are more soluble in oil; hence, more pressure is needed to achieve miscibility when nitrogen is used. The critical pressure at any temperature represents the minimum miscible at that selected temperature (only for binary systems.) At all temperatures the critical pressure (MMP) of nitrogen is higher than the MMP of methane and carbon dioxide. Figure (2.4) shows how all of the MMP values when nitrogen is used are higher than the methane ones. (Sebastian, 1992.) 


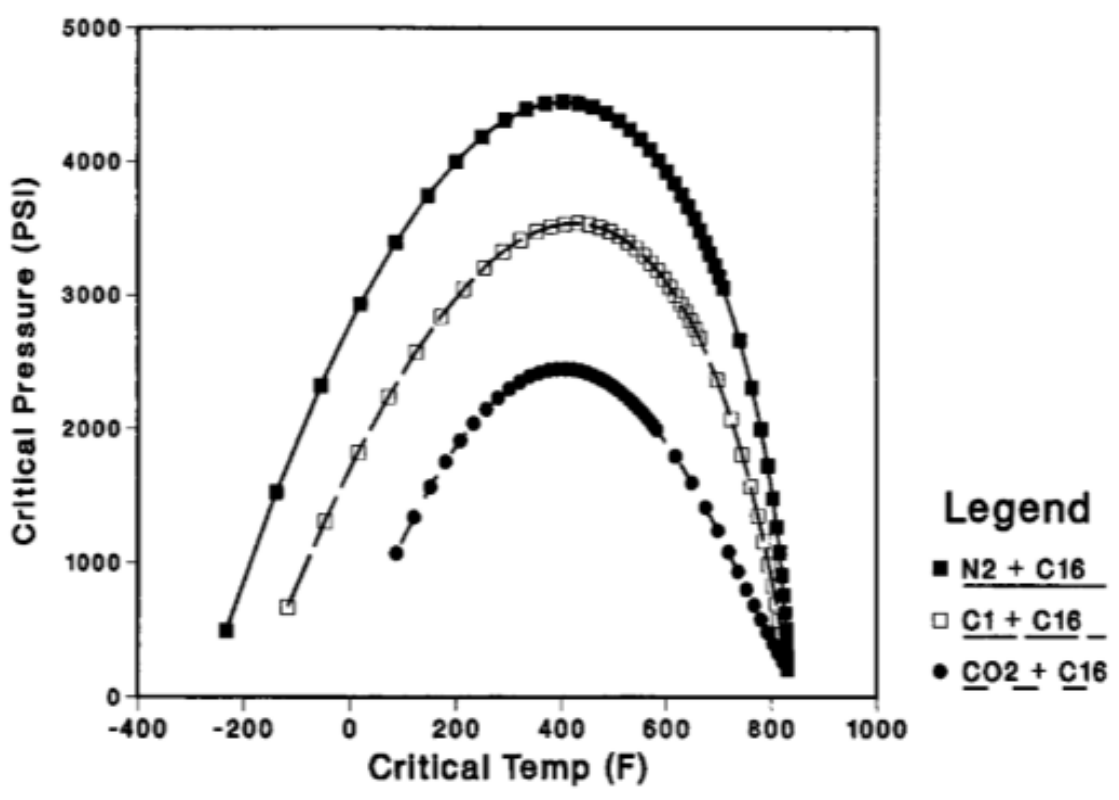

Figure 2.4: All of the MMP values when nitrogen is used are higher than the methane ones.

Dindoruk et al. conducted some experiments to measure the minimum miscible pressure using a mixture of nitrogen and methane. The results proved that the MMP value is a high function of the methane content in the injection gas mixture, especially when a high percentage of nitrogen is used in the injected gas mixture. In contrast, if the nitrogen concentration in the injected gas mixture is low, the effect of methane concentration is not that high. Therefore, the methane content input is not used in some of the carbon dioxide MMP correlations. (Yuan, 2004.)

The largest scale high pressure gas injection pressure (Devonian reservoir) has approximately $20 \%$ fine crystalline and sucrosic limestone, and $65 \%$ tripolitic chert. After the discovery of this field by 3 years and a half in 1952, a gas injection project was started using lean hydrocarbon gas to raise the reservoir pressure to the miscibility pressure. In part of the field, $88 \%$ of nitrogen with $12 \%$ carbon dioxide were injected 
and nitrogen-contaminated lean hydrocarbon gas was reinjected in the rest of the reservoir. Due to the reason that the carbon dioxide is highly soluble in interstitial water, nitrogen mainly displacing oil. This type of gas injection raised the ultimate recovery to $65 \%$. Another example is Algeria's Hassi Messaoud field, which is undergoing lean hydrocarbon gas miscible drive. Water was injected in this field in some parts, whereas water alternating gas was used in the rest of the field. In the areas where only water was injected, the recovery was expected to be $33 \%$; on the other hand, in the miscible gas injection areas, the ultimate recovery was expected to be $50 \%$. In other words, gas injection can raise the ultimate recovery more than water injection alone. The use of nitrogen with lean gas is more efficient in high temperature reservoirs. (Firoozabadi, 1986.)

Few correlations were developed based on the few data that was available about nitrogen miscible flooding, such as Firoozabadi, Aziz, Glaso and Hudgins et al. correlations (Sebastion, 1992.) Figure (2.5), figure (2.6), figure (2.7), and figure (2.8) show the results of these four correlations compared to the experimental data: 


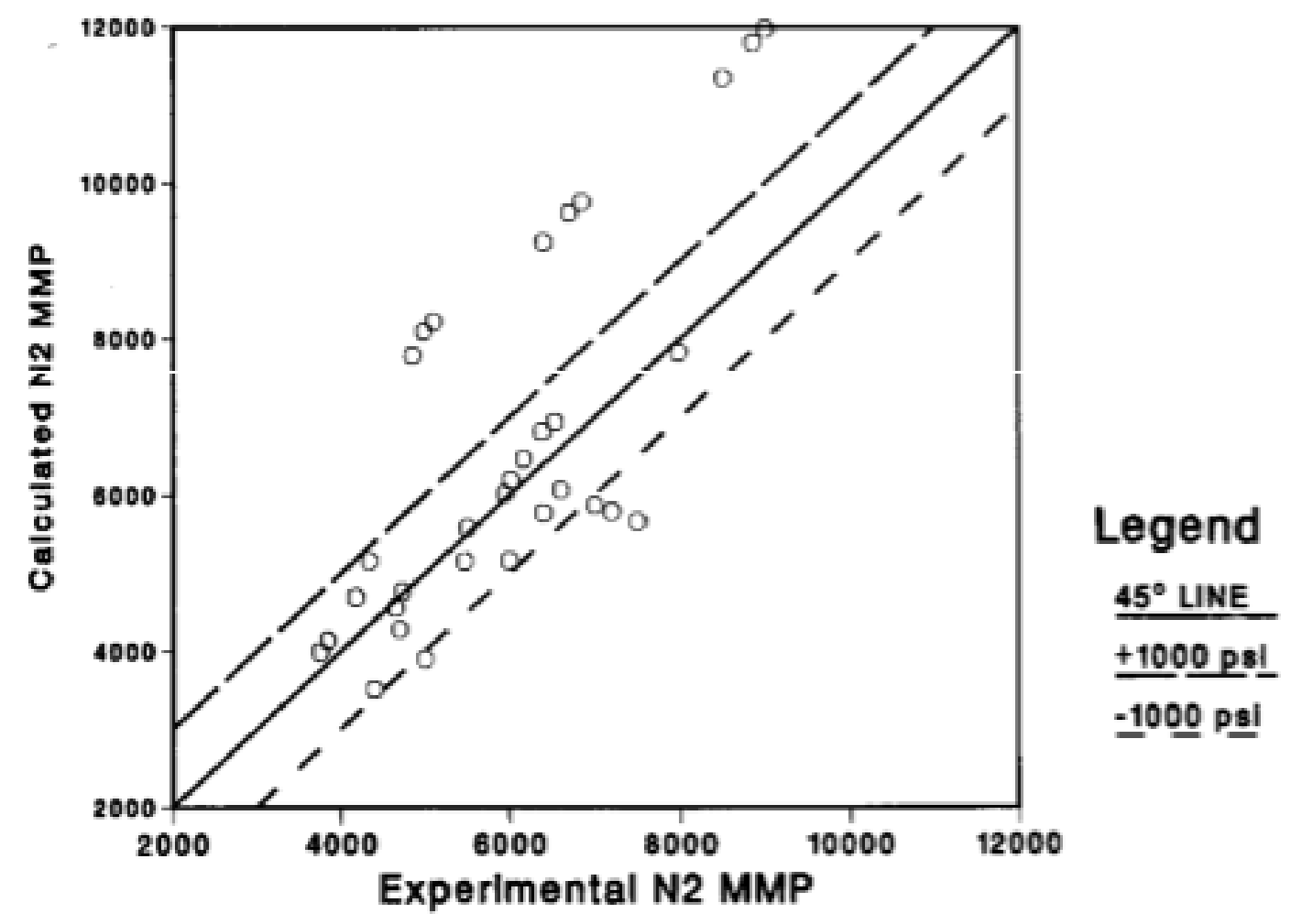

Figure 2.5 Comparison of Hannsen correlation with experimental data (Sebastain, 1992.)

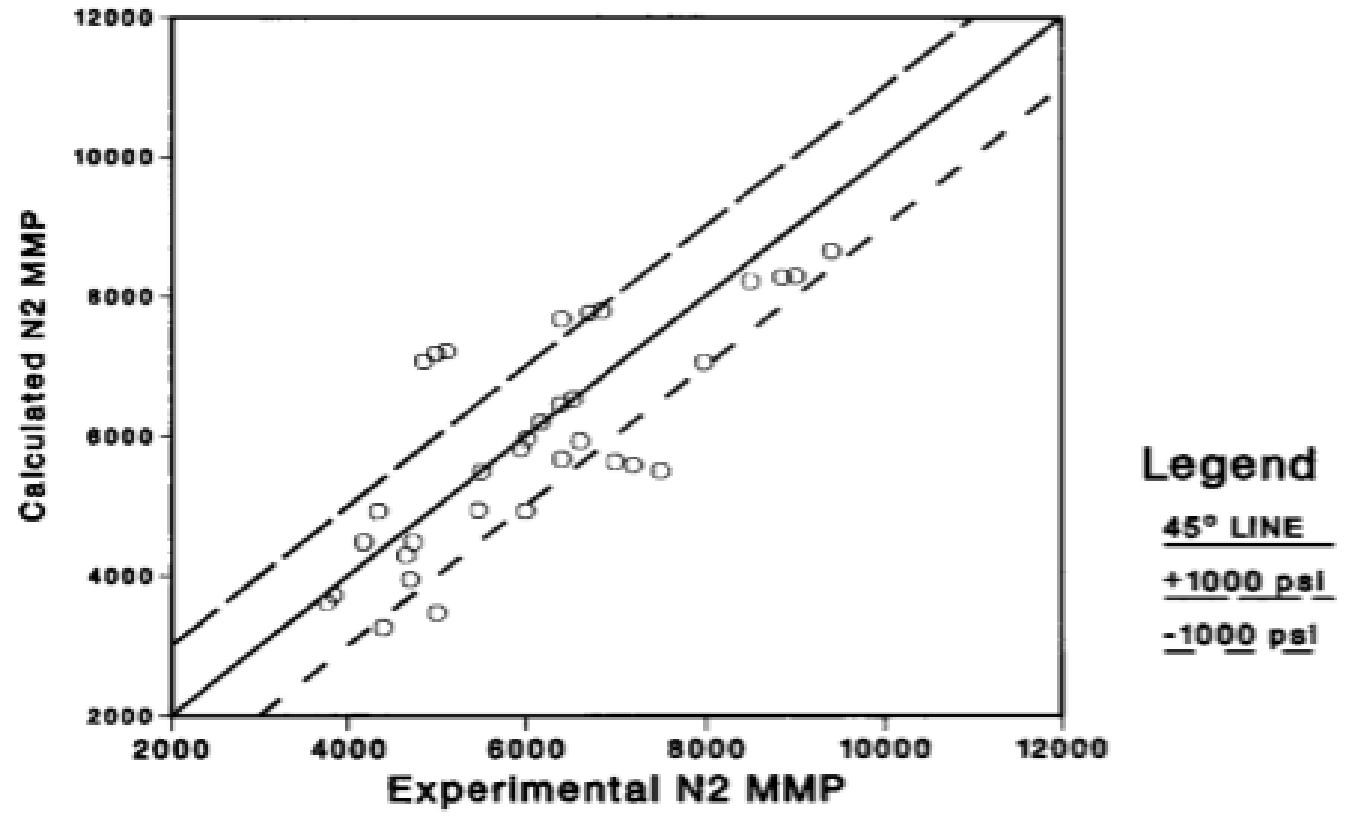

Figure 2.6 Comparison of Flroozabadl correlation with experimental data (Sebastain, 1992.) 


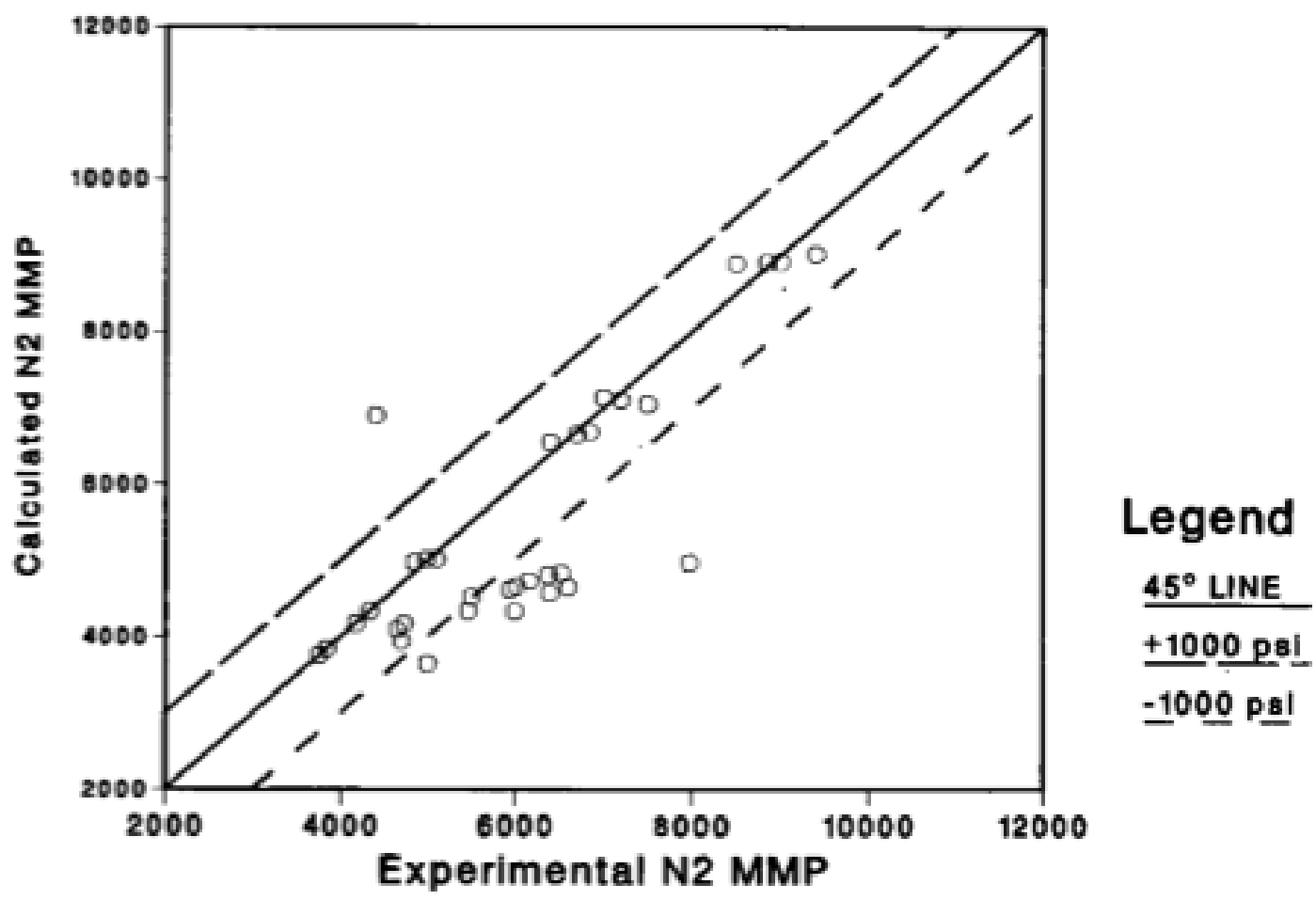

Figure 2.7 Comparison of NIPER correlation with experimental data (Sebastain, 1992.)

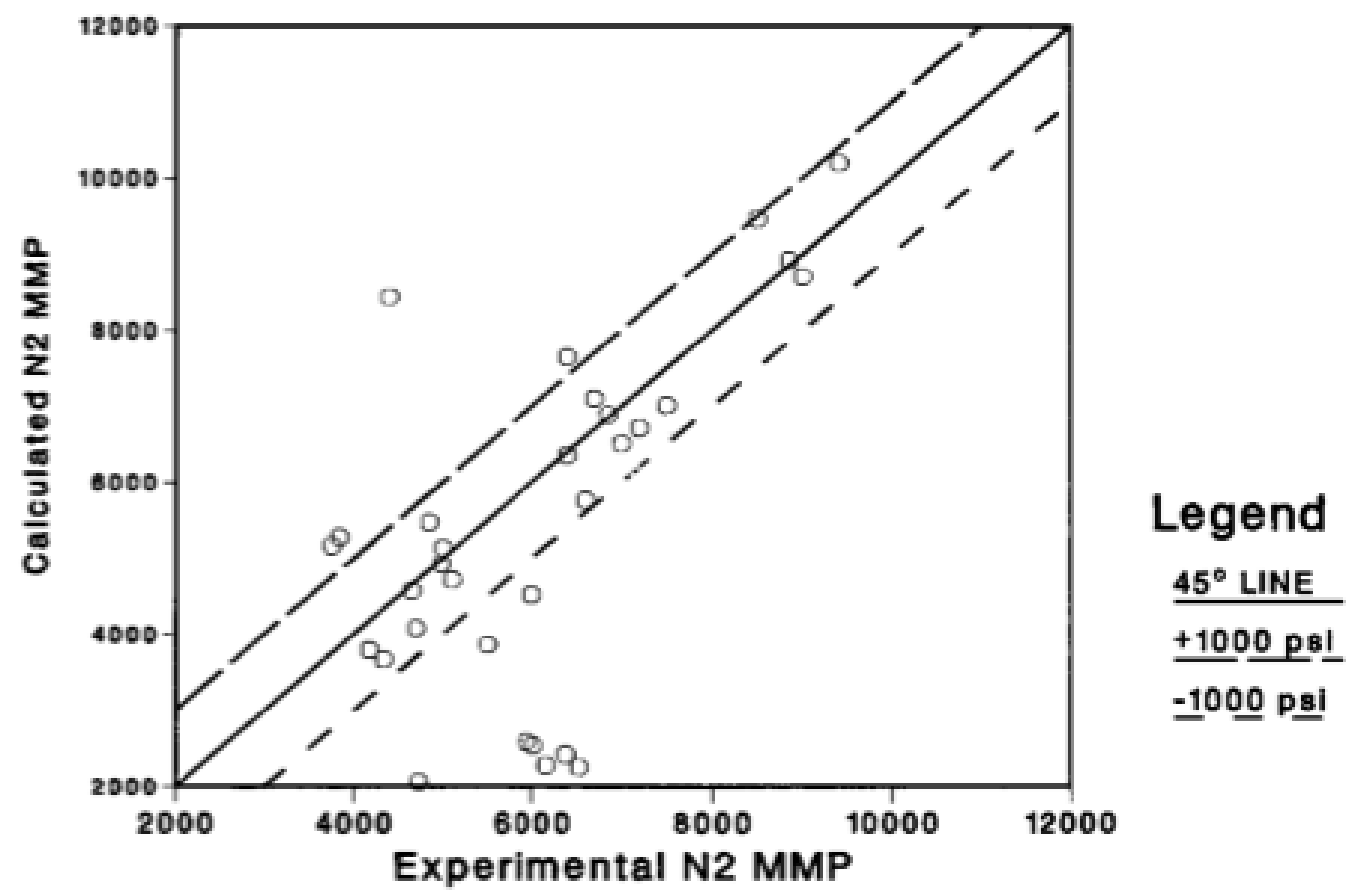

Figure 2.8 Comparison of Glaso correlation with experimental data (Sebastain, 1992.) 
All the points in the four graphs above that are falling on the solid line are the accurate points that matches the experimental results. However, all of the other points that are falling on the two dashed lines between the solid line are representing the result of the correlation where those points are higher or lower by 1000 psi than the experimental results. This shows that the results obtained from correlations to measure the minimum miscible pressure when nitrogen is used to be injected can lead to inaccurate results. Also, from the four graphs, it is clear that some of the points are way off from the right answer; therefore, it is recommended to use multiple correlations. (Sebastion, 1992.)

Nitrogen is similar to other injection gases (carbon dioxide and lean hydrocarbon gasses) by having its minimum miscible pressure as a function of temperature. In general, the higher the temperature is, the higher the minimum miscible pressure is. Moreover, the higher $\mathrm{C} 7+$ molecular weight, the higher the nitrogen minimum miscible pressure is. In oil samples of high methane or intermediate components, the nitrogen MMP decreases. The amount of decrease is a function of the oil composition. Based on this information, the following correlation was developed (Sebastion, 1992.) 


\section{CHAPTER III}

\section{MODEL SPECIFICATION, VALIDATION AND RESULTS}

\subsection{Compositional Model Specifications.}

Schlumberger Eclipse 300 simulator was used to create a compositional model for the slim tube experiments of almost 33 feet long and 0.0011 square feet cross sectional are to measure the minimum miscibility pressure of an injected gas mixture. One fixed oil composition that has manly heavy hydrocarbon components $(2.47 \%$ carbon dioxide, $25.16 \%$ methane, $24.07 \%$ ethane, $7.33 \%$ propane, 40.97 heptane plus with a molecular weight of 224.) Peng-Robinson equation of state is used in this simulation. The slim tube is packed and fully saturated with oil only, no water, and gas was injected from one end and oil is produced from the other end. The slim tube model is a 1-D displacement of 200 grid block in the x-direction ( 0.164 feet wide) and one grid block in both of the z- and y-directions. The porosity of the system is $10 \%$ with $2000 \mathrm{mD}$ permeability of all of the directions ( $x-, y^{-}$, and $z$-directions.) The mid-point of all of the cells is set to be at 3.28 feet depth. Standard conditions were specified as 59 degrees Fahrenheit for the temperature and 14.65 psi for the pressure. The reference pressure of the rock is used as 2000 psi with a rock compressibility of $0.00000061 /$ psi. The gas saturation table that was used in the project is presented in figure (3.1). The temperature in the separator at the surface is about 59 degrees Fahrenheit and a pressure of $14.65 \mathrm{psi}$. The model was designed to inject one pore volume in 10 hours, where the runs are simulating 12 to 40 hours of production to ensure obtaining 1.2 pore 
volume at an oil recovery factor of around $90 \%$. The length of the initial time step was specified as 0.001 hour, while the minimum and maximum time steps are 0.0001 and 0.02 hour, respectively.

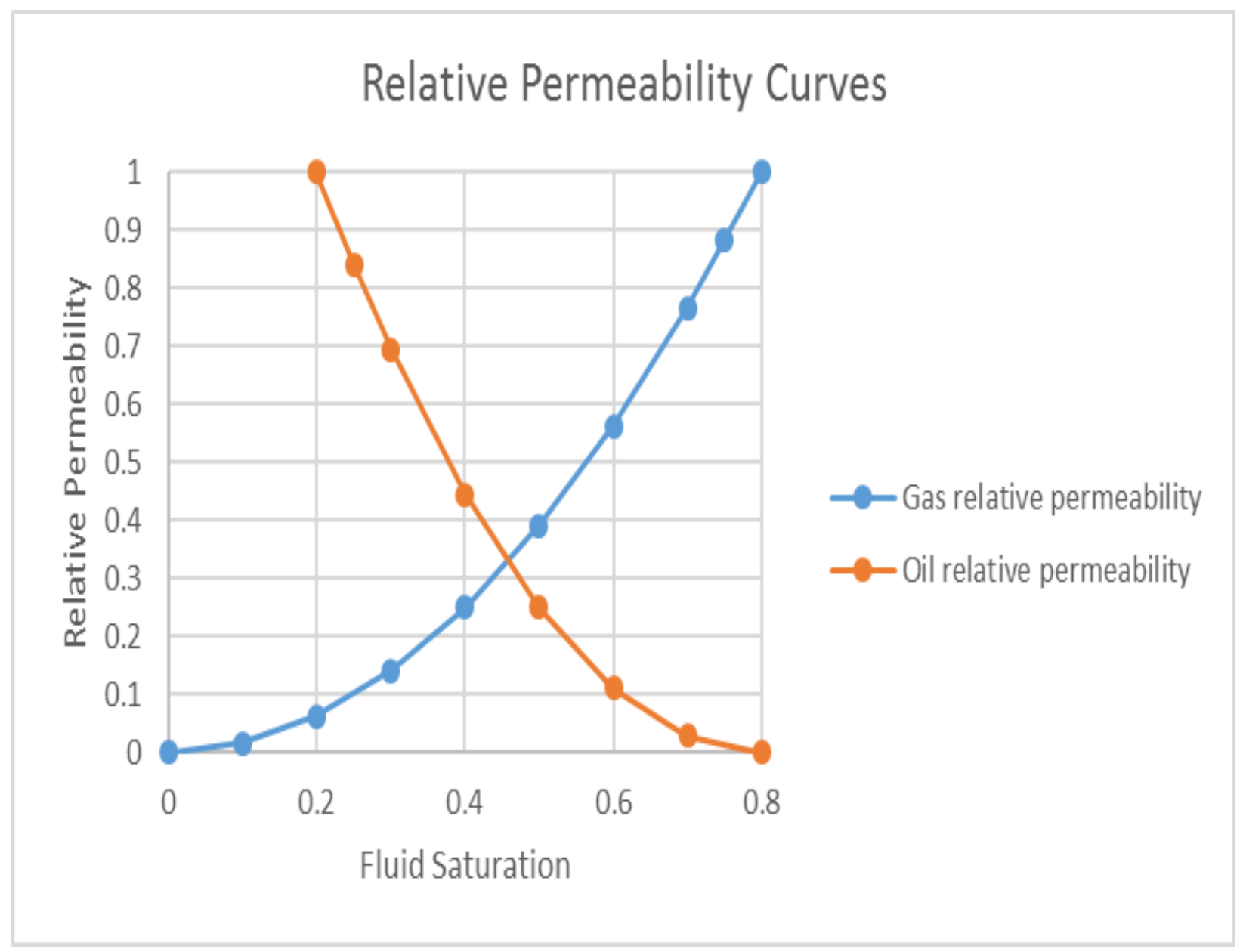

Figure 3.1 Relative Permeability Curves

\subsection{Compositional Model Validation}

Carbon dioxide, lean hydrocarbon gases, and nitrogen are the main three injected gases that are used in this project. Nine different gas compositions were used to 
measure the minimum miscibility pressure for a given oil composition and reservoir temperature (250 F.) After creating the model, it was validated using the correlations presented in the literature. An injection gas mixture of $100 \%$ carbon dioxide was injected at $250 \mathrm{~F}$ to measure the minimum miscibility pressure. The 300 eclipse result of 100\% carbon dioxide is 2875 psi. Three different correlations were used (Alston, Cronquist, and Glaso) that gave the following results: 1580 psi, 1780 psi, and 2580 psi, respectively. The variation of the results of the three correlations makes it difficult to ensure that the model gives accurate results. The three correlations are as follows:

- Alston (1985);

$$
M M P(C O 2)=0.000878\left(T^{1.06}\right)(M C 5+)^{1.78}\left[\frac{X v o l}{X i n t}\right]^{0.136}
$$

- Cronquist (1978);

$$
M M P=16 T^{0.744+0.0011 M W C 5+0.0015 X v o l}
$$

- Glaso (1980);

$$
M M P=810-(3.404 M C 7+)+\left(1.7 \times 10^{-9}(M C 7+)^{3.730}\left(e^{786.8 M C 7+^{-1.058}}\right)\right) T
$$

Moreover, an injected gas mixture of $100 \%$ lean hydrocarbon gas was injected for validation propose. The 300 eclipse result of $100 \%$ lean hydrocarbon gas was 4250 psi. Glaso's correlation was used to approximate the minimum miscibility pressure of an injected gas mixture of $100 \%$ lean hydrocarbon gas, and the result is 3455 psi. Nitrogen is also used as a gas injection to validate the result of the developed compositional model. An injected gas mixture of $100 \%$ of nitrogen was injected to measure the 
minimum miscibility pressure, which gave a result of 4370 psi. Two correlation were used to validate the result of the modal: Hudgins and Glaso, and the results are $4320 \mathrm{psi}$ and 4350 psi, respectively. The correlations of the nitrogen show that the result form the compositional model is accurate enough to start the next part of the research. The correlations for lean gas and nitrogen's minimum miscibility pressure approximation are as follows:

- Glaso (1980) for lean hydrocarbon gas:

$$
\begin{aligned}
& \operatorname{MMP}(x=34) \\
& =6329-25.41 y-(46.475-0.185 y) z \\
& +\left(1.127 \times 10^{-12} \times y^{5.28} \times e^{319.8 z y^{-1.703}}\right) T \\
& \operatorname{MMP}(x=44) \\
& =5503-19.238 y-(80.913-0.273 y) z \\
& +\left(1.7 \times 10^{-9} \times y^{3.73} \times e^{21.706 z y^{-1.109}}\right) T \\
& \operatorname{MMP}(x=54) \\
& =7437-25.703 y-(73.515-0.214 y) z \\
& +\left(4.920 \times 10^{-14} \times y^{5.520} \times e^{(21.706 z y)^{-1.109}}\right) T \\
& \text { Where, } \quad y=\left(\frac{2.622}{\gamma C 7+^{-0.846}}\right)^{6.558}
\end{aligned}
$$

Following the trend of the approximated results of the minimum miscibility pressure that Glaso developed of lean hydrocarbon gas, the result of a higher molecular weight of $\mathrm{C}_{2}-\mathrm{C}_{6}$ can be calculated.

- $\quad$ Glaso (1980) for nitrogen: 


$$
\begin{aligned}
M M P=6364 & -(12.09 M c 7+) \\
& +\left(1.127 \times 10^{-12}(M C 7+)^{5.258} e^{23025 M C 7+^{-1.703}}-20.80\right) T
\end{aligned}
$$

- Hudgins for nitrogen:

$$
\begin{gathered}
M M P=5568 e^{-R 1}+3641 e^{-R 2} \\
R 2=\frac{792.06[C 2-C 6]}{M c 7+}\left(T^{0.25}\right) \\
R 2=2.158 \times \frac{10^{6}\left[C 1^{5.632}\right]}{M c 7+}\left(T^{0.25}\right)
\end{gathered}
$$

Figure (3.2) through figure (3.7) show how the simulated results were analyzed to measure the minimum miscibility pressure. The recovery factor of $90 \%$ at 1.2 pore volume injected is recorded and plotted against the pressure. 


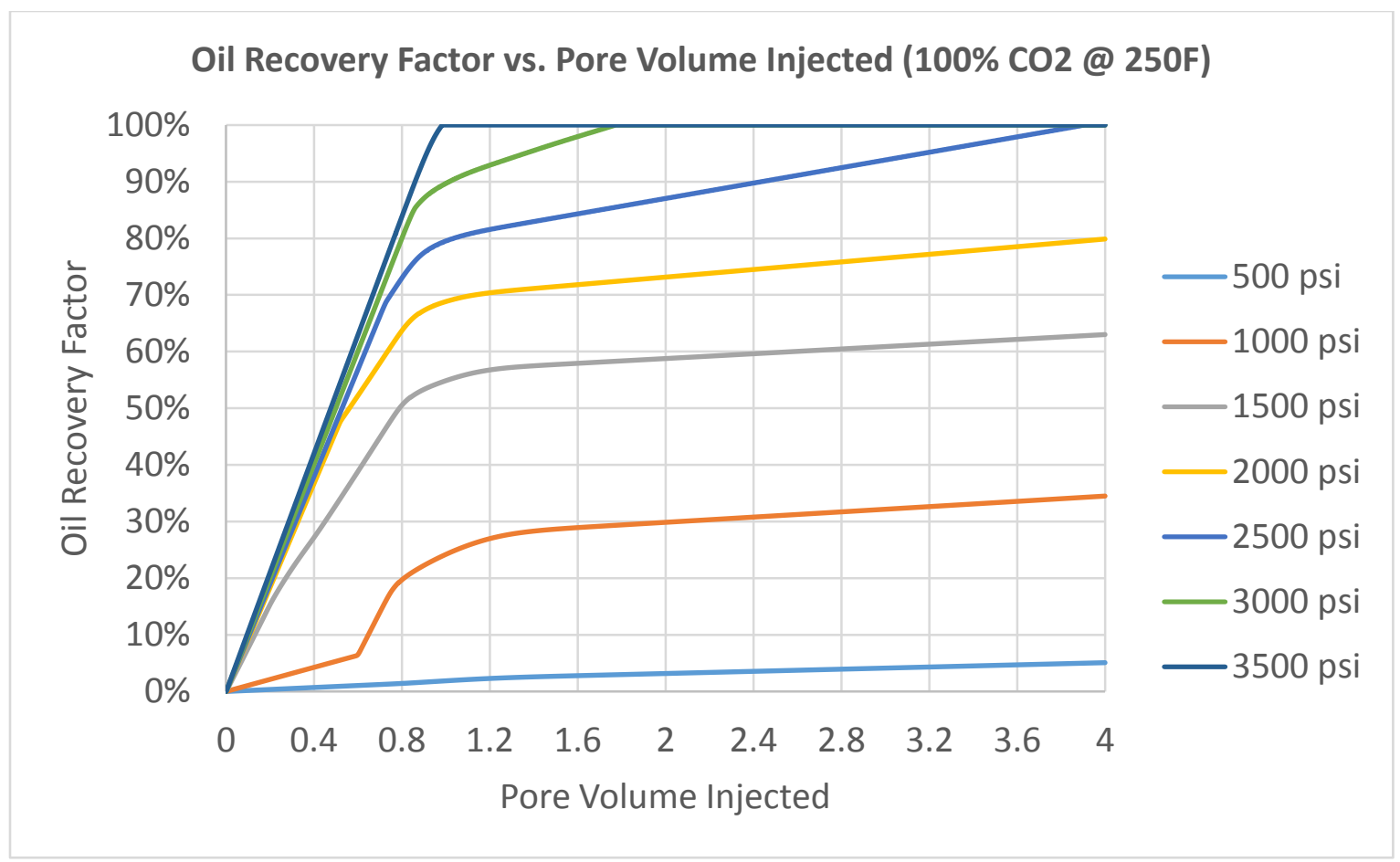

Figure 3.2 Simulator result of the minimum miscibility pressure of $100 \%$ carbon dioxide at $250 F$.

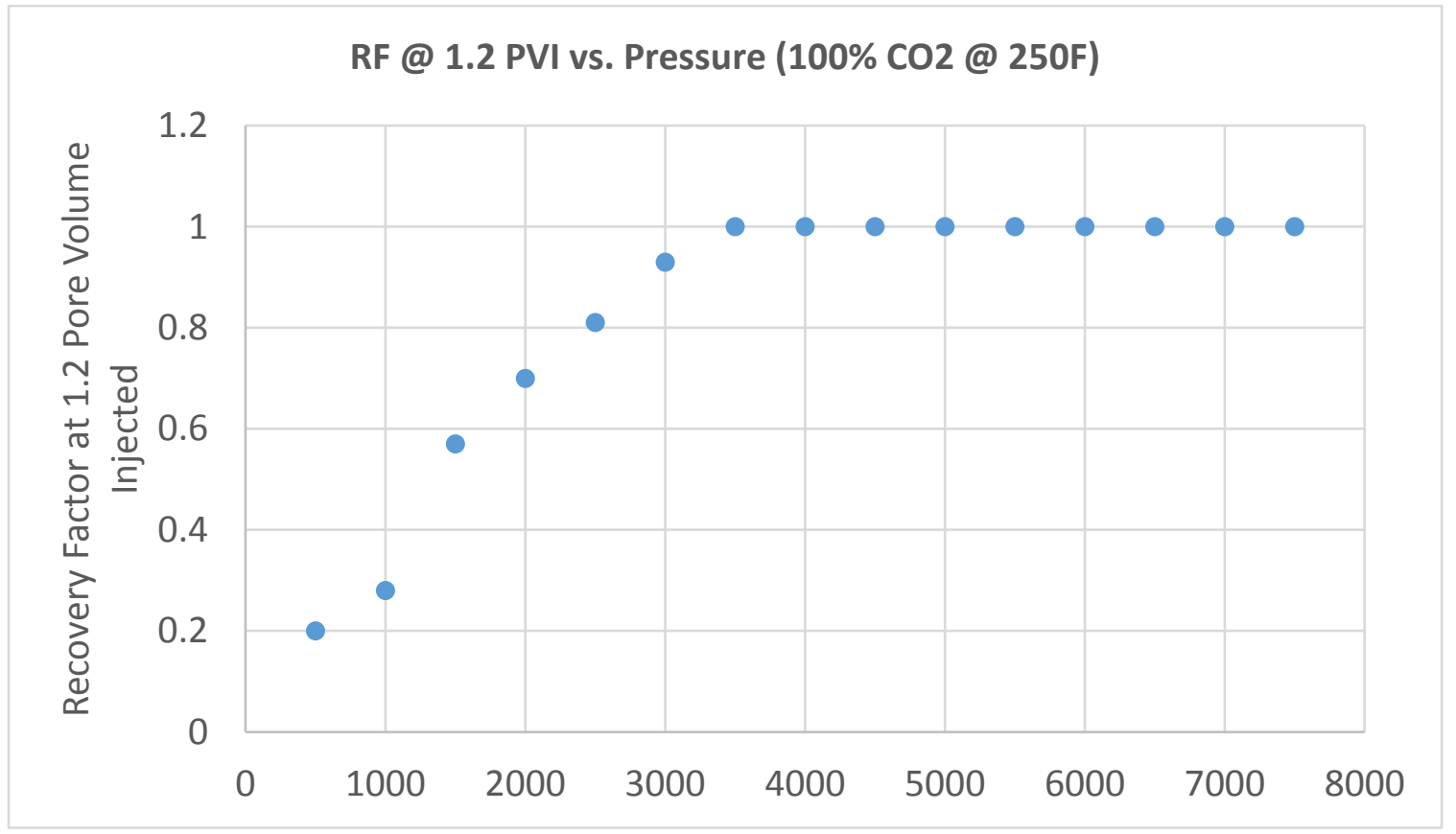

Figure 3.3 The oil recovery factor of $90 \%$ at 1.2 pore volume injected vs. the pressure (100\% carbon dioxide at 250F) 


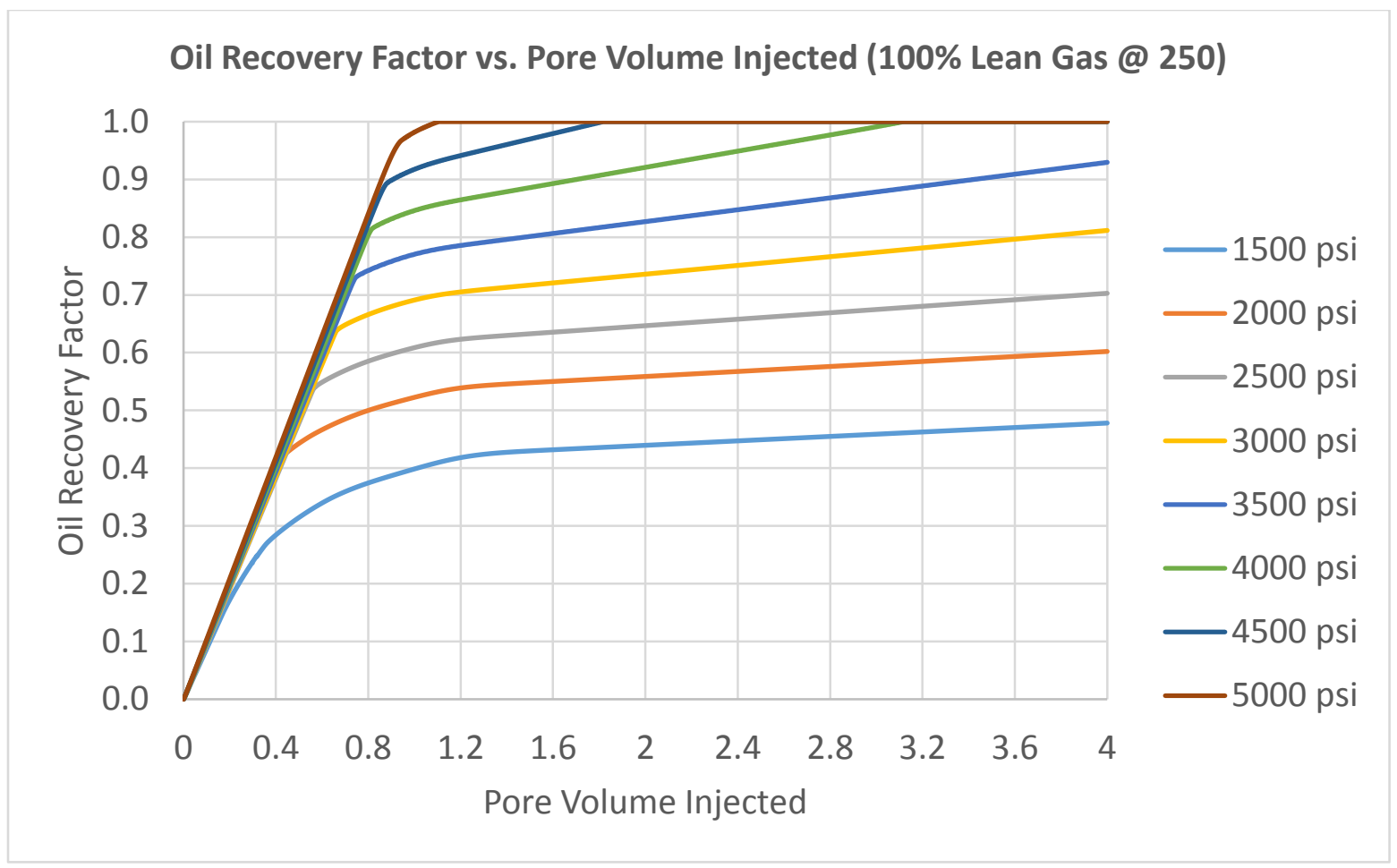

Figure 3.4 Simulator result of the minimum miscibility pressure of $100 \%$ lean gas at $250 \mathrm{~F}$.

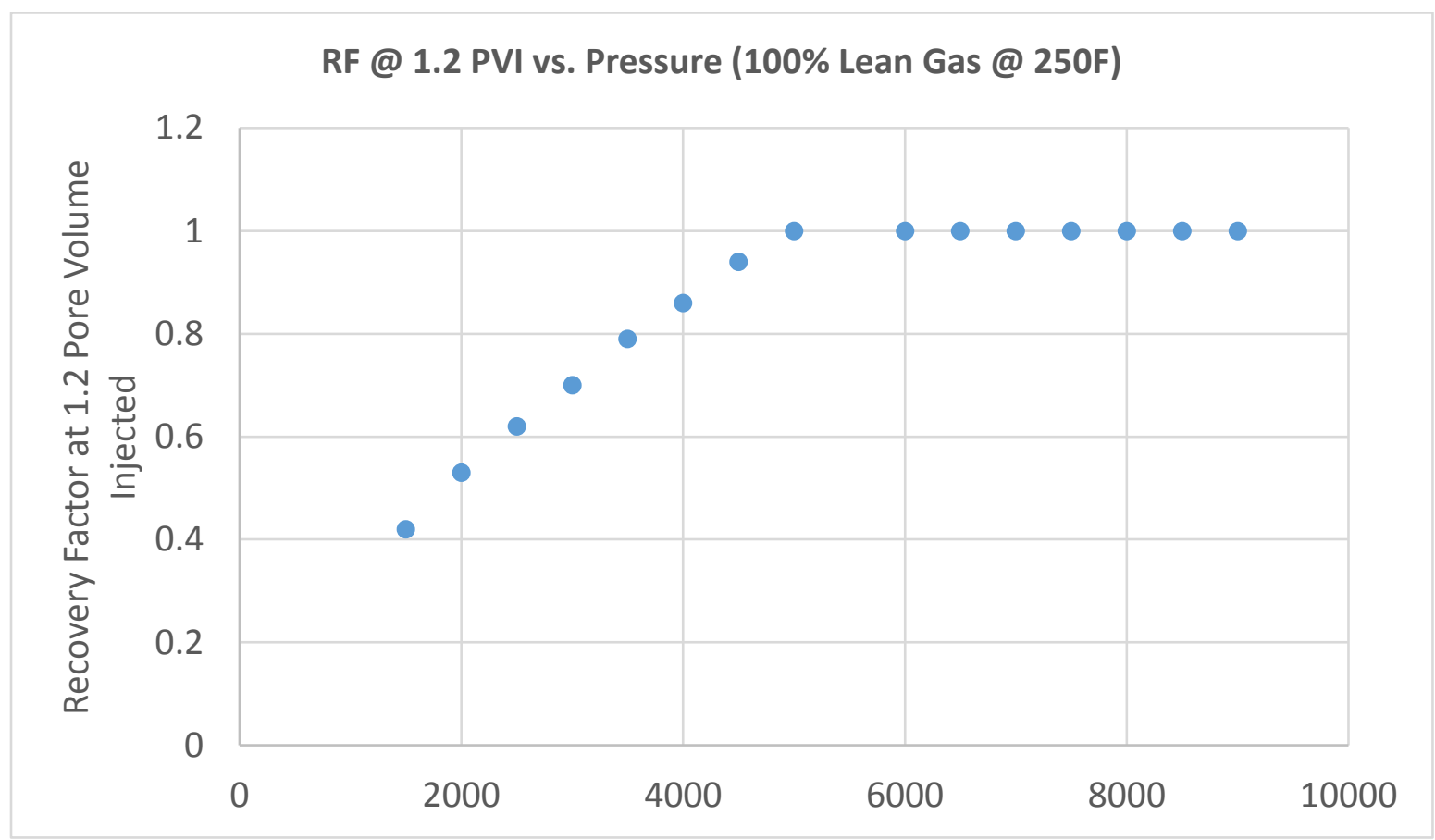

Figure 3.5 The oil recovery factor of $90 \%$ at 1.2 pore volume injected vs. the pressure (100\% lean gas at 250F) 


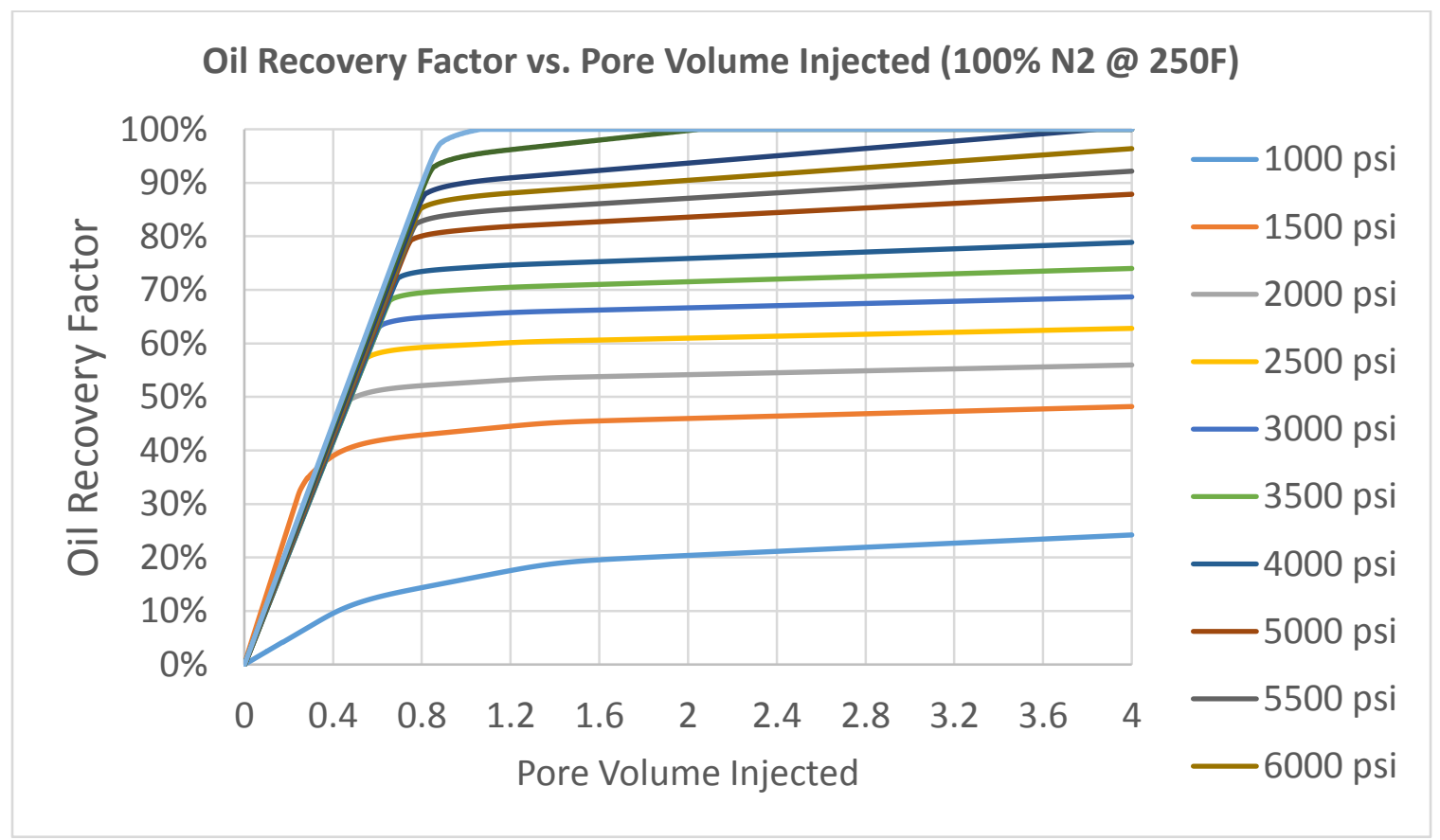

Figure 3.6 Simulator result of the minimum miscibility pressure of $100 \%$ nitrogen at $250 \mathrm{~F}$

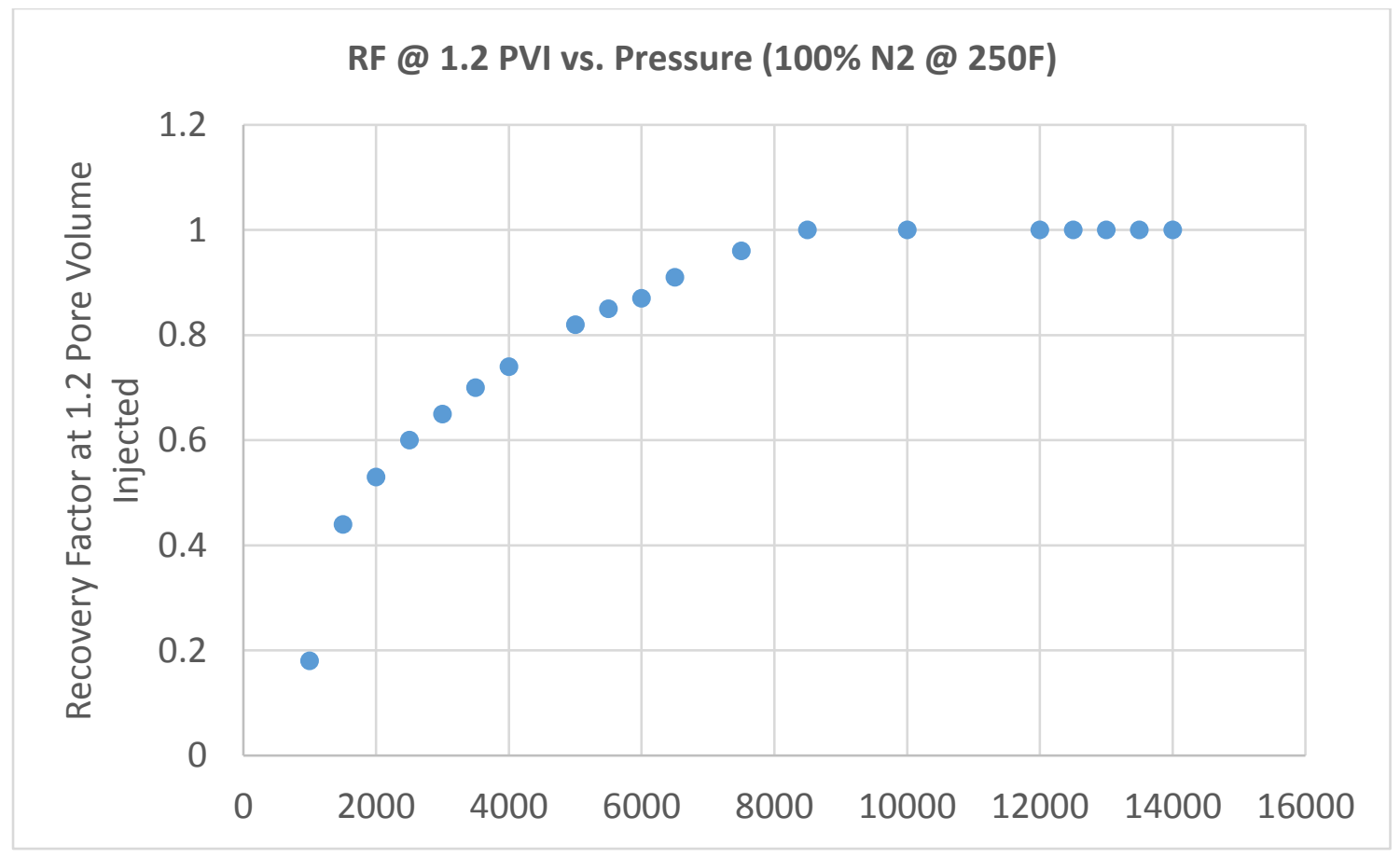

Figure 3.7 The oil recovery factor of $90 \%$ at 1.2 pore volume injected vs. the pressure (100\% nitrogen at 250F) 


\subsection{Carbon Dioxide and Lean Hydrocarbon Gas Mixture Results}

In this part of the research, the percentages of carbon dioxide and lean hydrocarbon gas (methane) in the injected gas were varied to create 5 different injected gas mixtures at a reservoir temperature of $250 \mathrm{~F}$. The main target of the section is to measure the minimum miscibility pressure in all the 5 gas mixtures. Figure (3.8) summarizes the components of all of the mixtures. The injection pressure was varied to get different oil recovery factors at 1.2 pore volume injected.

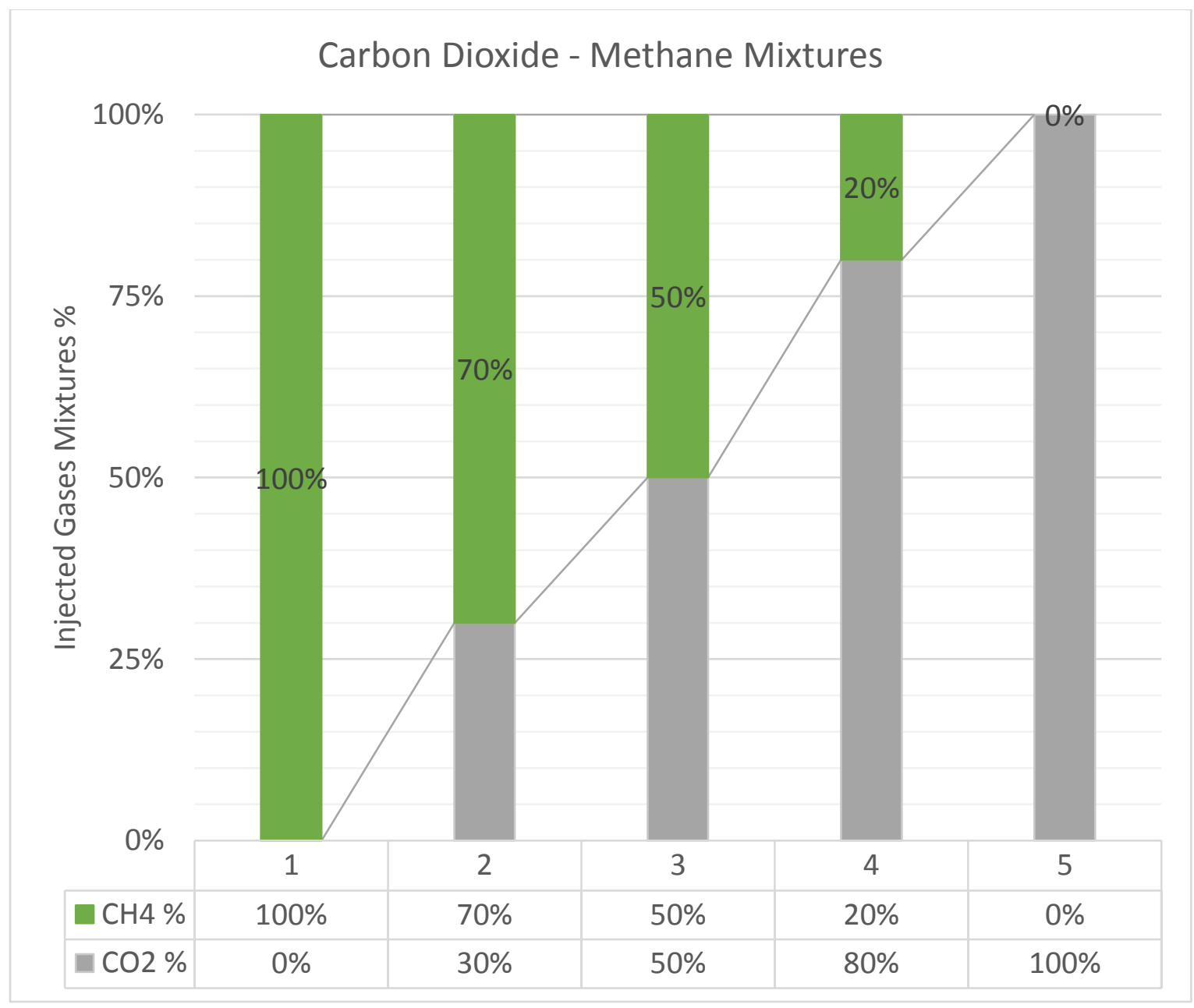

Figure 3.8 The components of each injected gas mixture (carbon dioxide and lean gas) 
figure (3.9) to figure (3.14) are used to illustrate how the minimum miscibility pressure is measured for the three carbon dioxide and lean hydrocarbon gas mixtures presented in the in figure (3.15.) Table (3.16) shows how the minimum miscibility pressure changes corresponding to the injected gas compositions. The minimum miscibility pressure results of the injected gas mixture (carbon dioxide and lean hydrocarbon gas) are plotted to show how the minimum miscibility pressure values change as a function of the composition of the injected gas mixture, as its shown in figure (3.17).

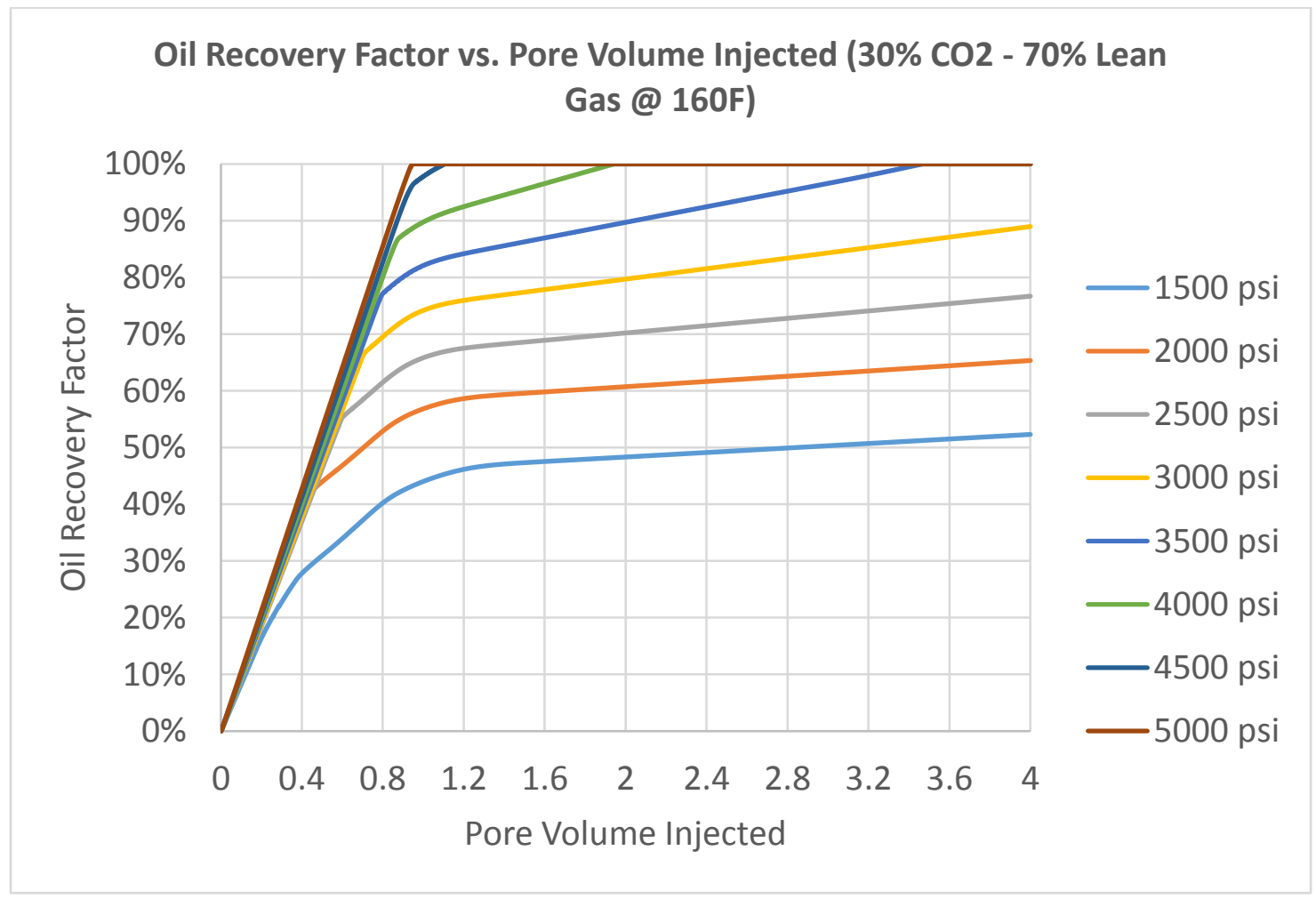

Figure 3.9 Simulator result of the minimum miscibility pressure of $30 \%$ carbon dioxide and $70 \%$ lean gas at $160 F$. 


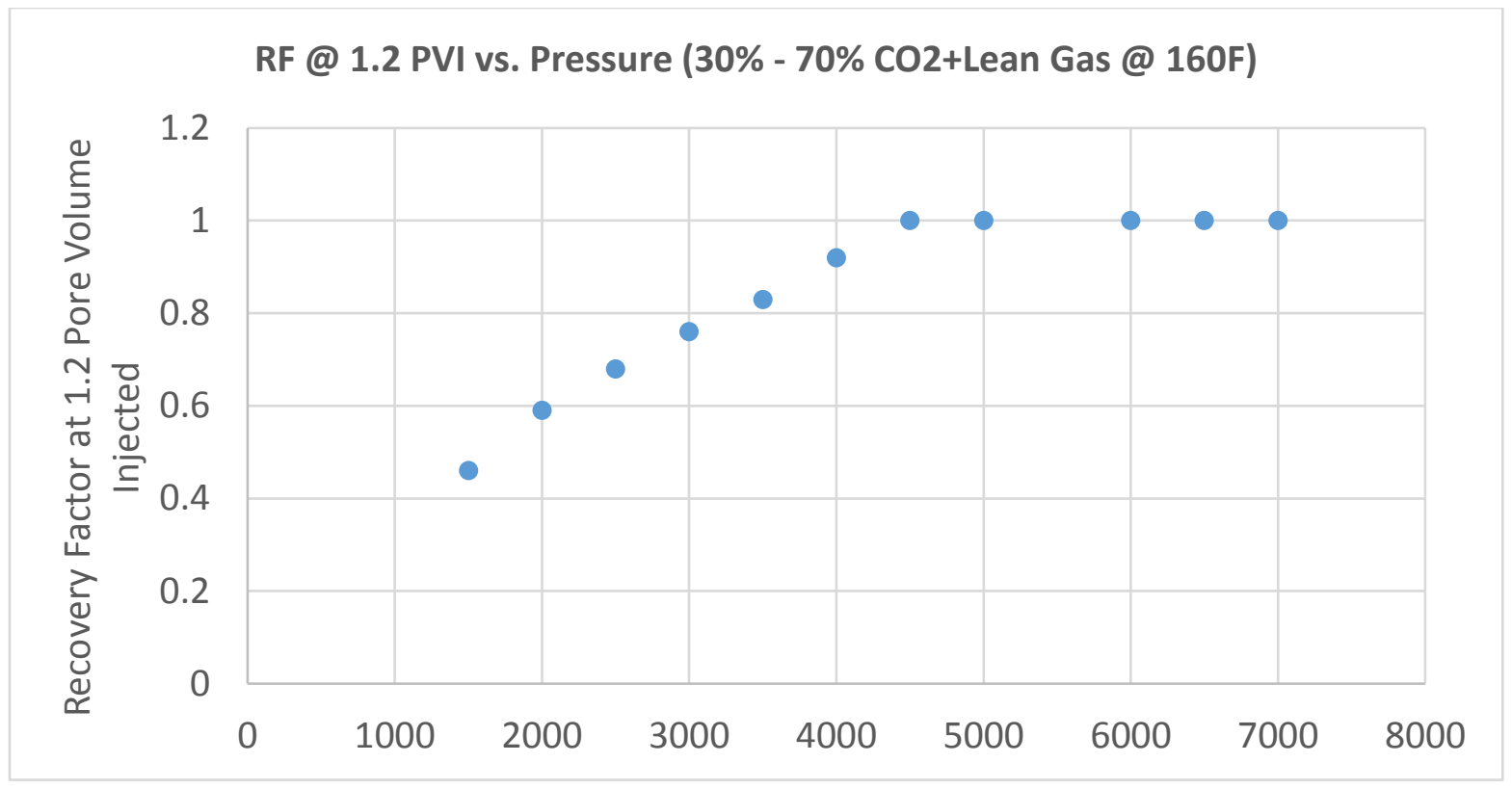

Figure 3.10 The oil recovery factor of $90 \%$ at 1.2 pore volume injected vs. the pressure (70\% lean gas and 30\% carbon dioxide at 160F)

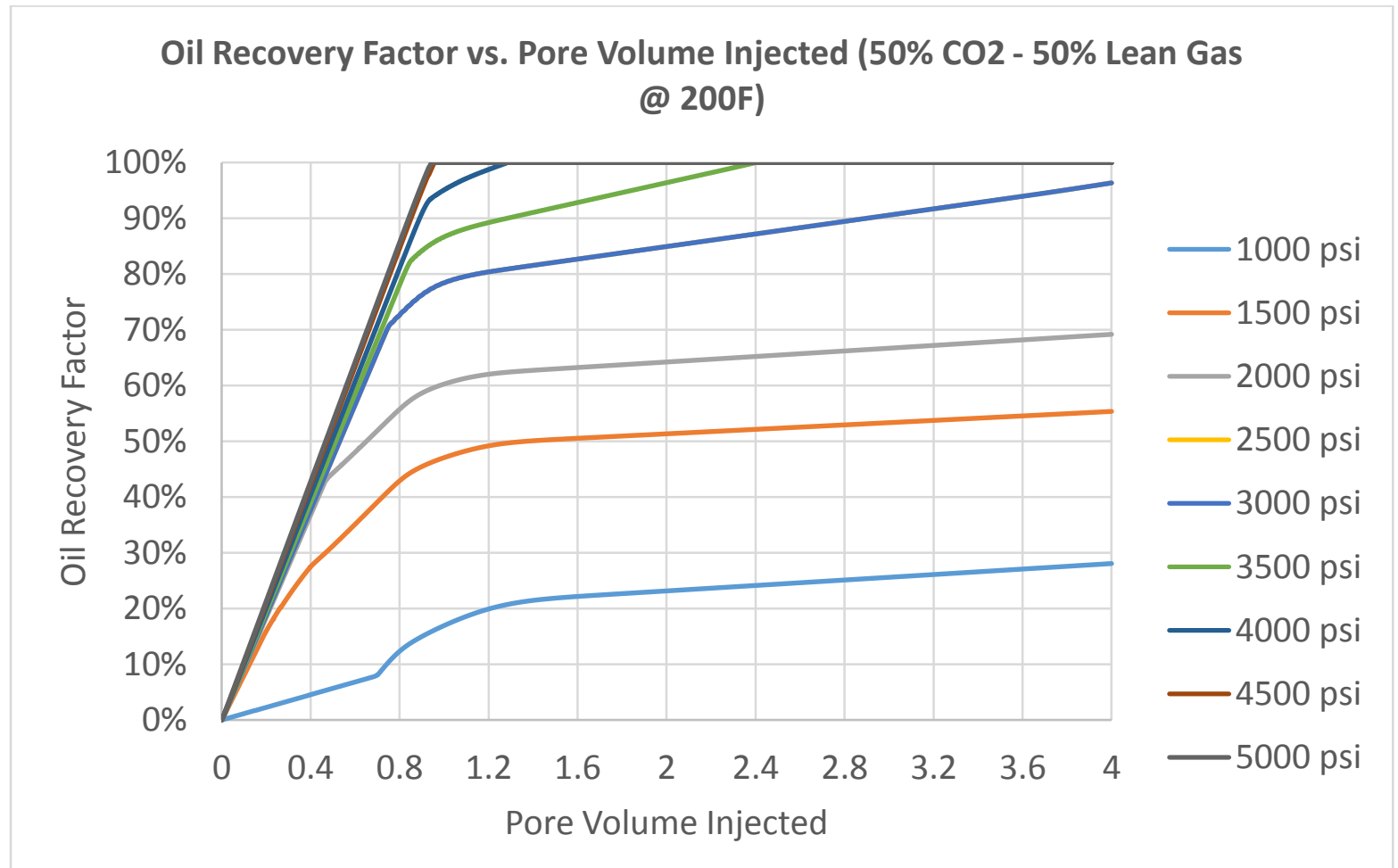

Figure 3.11 Simulator result of the minimum miscibility pressure of $50 \%$ carbon dioxide and $50 \%$ lean gas at $200 F$. 


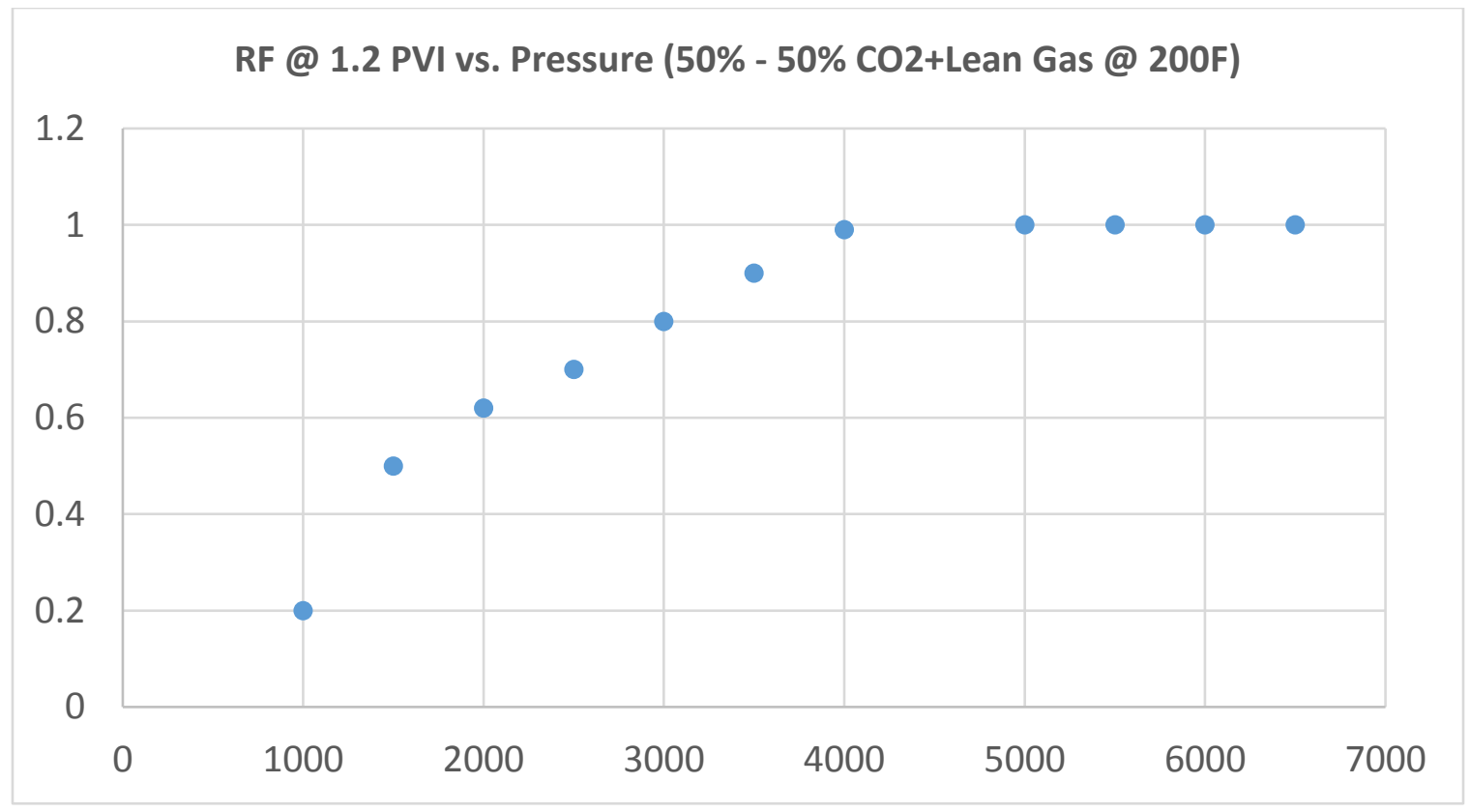

Figure 3.12 The oil recovery factor of $90 \%$ at 1.2 pore volume injected vs. the pressure (50\% lean gas and 50\% carbon dioxide at 200F)

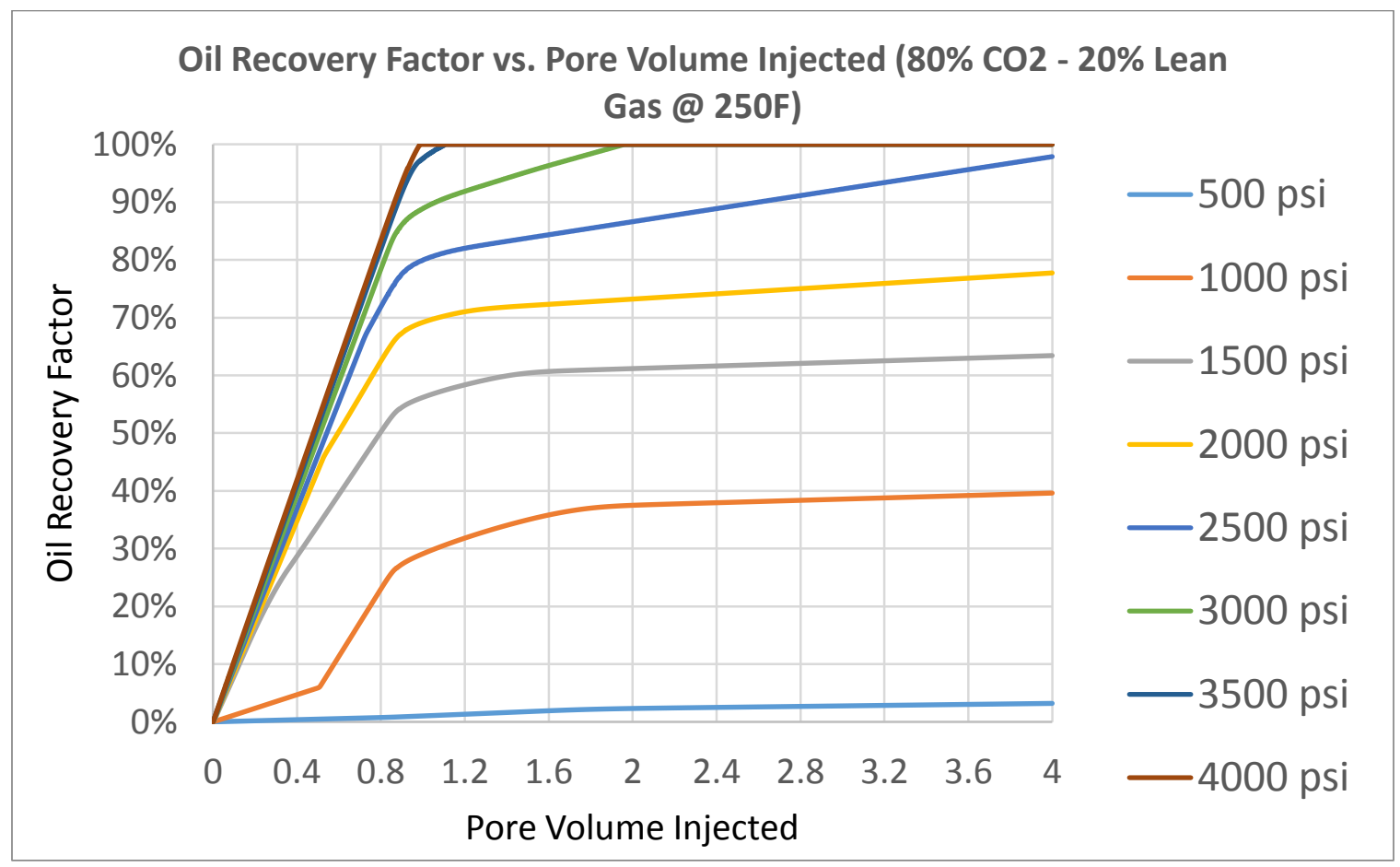

Figure 3.13 Simulator result of the minimum miscibility pressure of $80 \%$ carbon dioxide and $20 \%$ lean gas at $250 F$. 


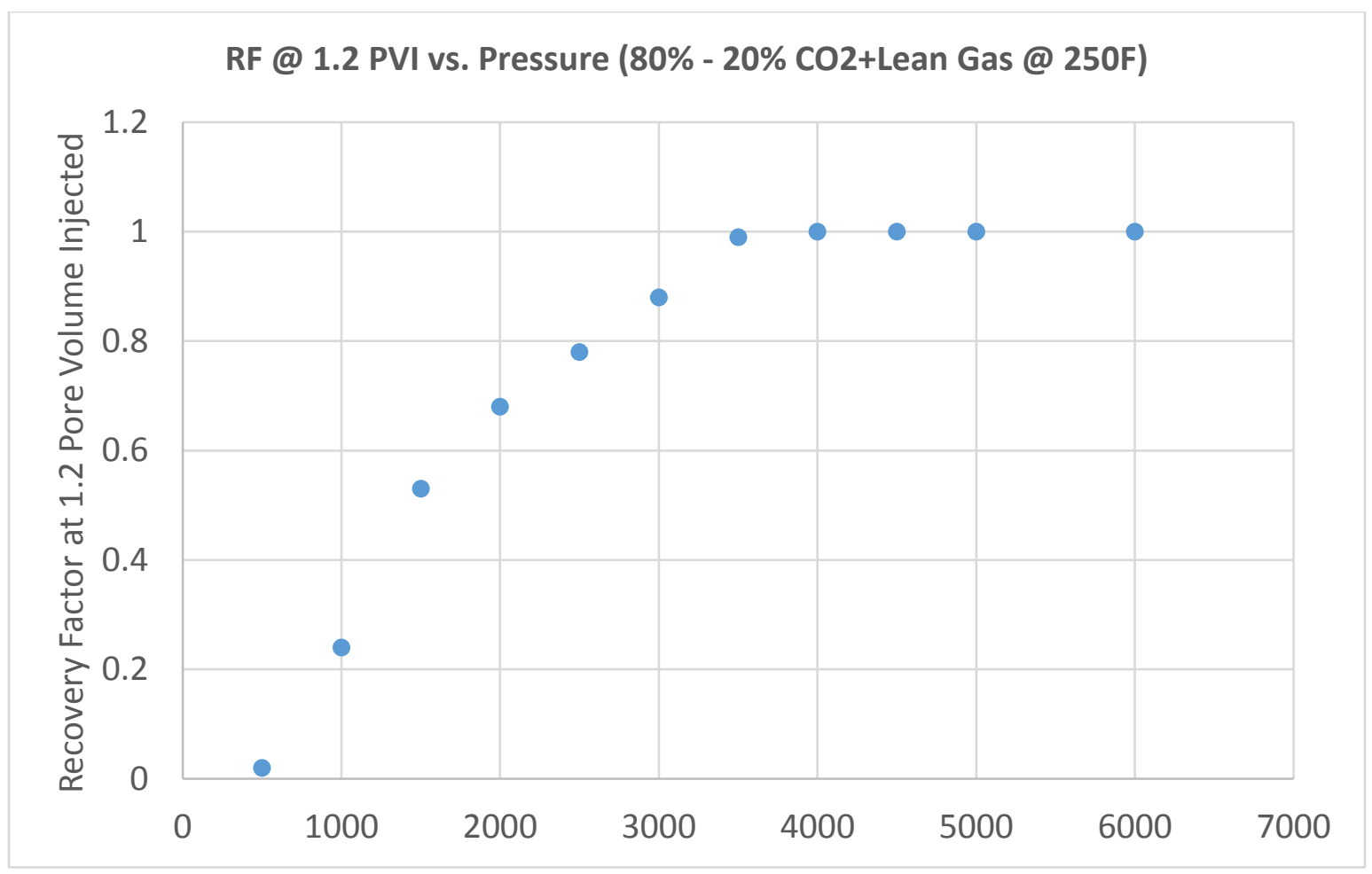

Figure 3.14 The oil recovery factor of $90 \%$ at 1.2 pore volume injected vs. the pressure (20\% lean gas and $80 \%$ carbon dioxide at 250F)

Table 3.1 Lean gas and carbon dioxide gas mixture's minimum miscibility pressure at $250 F$.

\begin{tabular}{|c|c|c|c|c|}
\hline \multicolumn{4}{|c|}{ Gas Injection Composition } & MMP @ 250 F \\
\hline CO2 & C1 & C2 & Total & Model \\
\hline $0 \%$ & $98 \%$ & $2 \%$ & $100 \%$ & 4250 \\
\hline $30 \%$ & $68 \%$ & $2 \%$ & $100 \%$ & 3889 \\
\hline $50 \%$ & $48 \%$ & $2 \%$ & $100 \%$ & 3500 \\
\hline $80 \%$ & $18 \%$ & $2 \%$ & $100 \%$ & 3091 \\
\hline $100 \%$ & $0 \%$ & $0 \%$ & $100 \%$ & 2875 \\
\hline
\end{tabular}




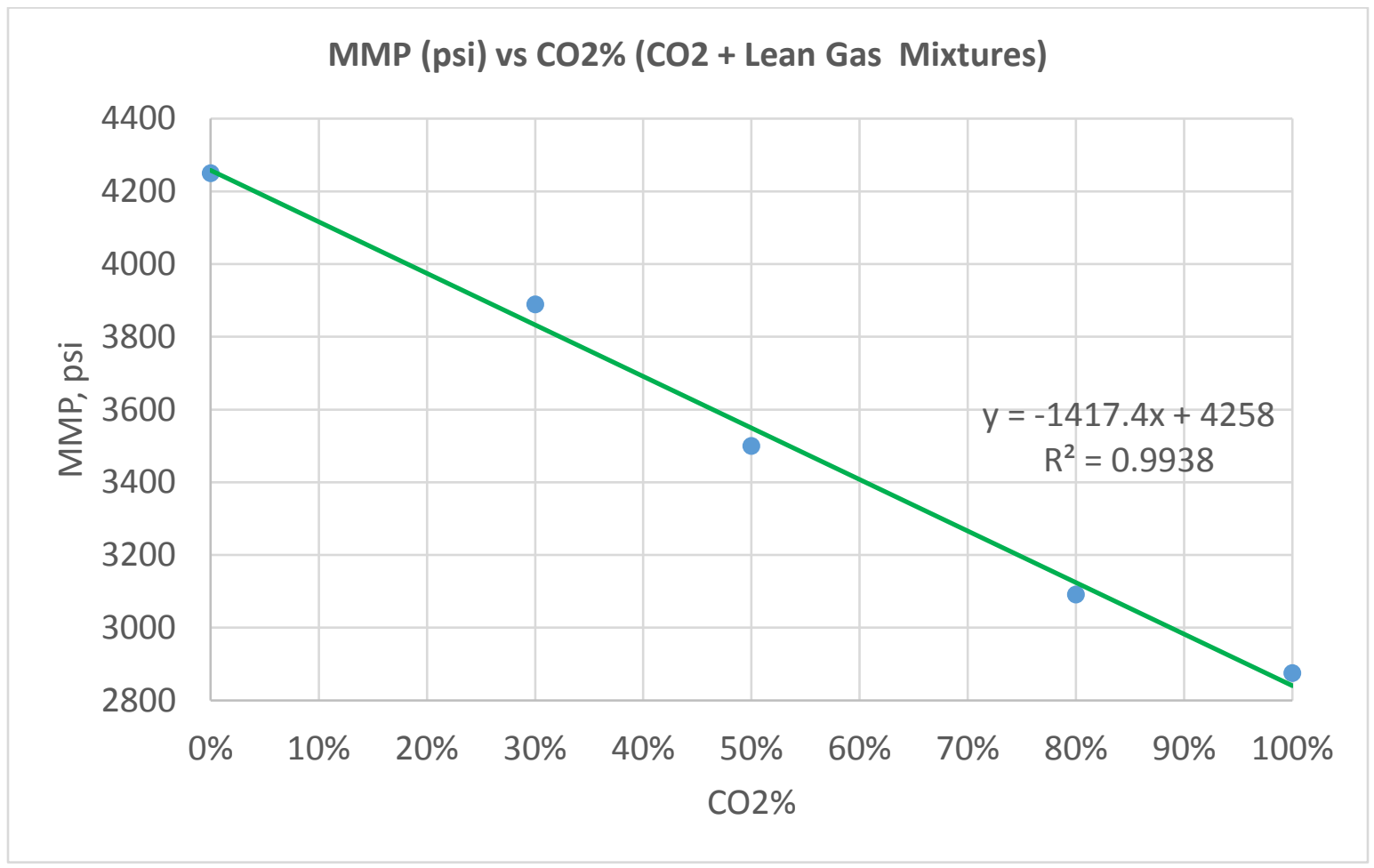

Figure 3.15 Carbon dioxide \% as a function of the minimum miscibility pressure (lean gas-carbon dioxide)

\subsection{Carbon Dioxide and Nitrogen Gas Mixture Results}

In this second part of the project, the percentages of carbon dioxide and nitrogen in the injected gas were varied to create 5 different injected gas mixtures at a reservoir temperature of $250 \mathrm{~F}$. The main target of this section is to measure the minimum miscibility pressure in all of the 5 gas mixtures. Figure (3.16) shows the components of each mixture. The injection pressure was varied to get different oil recovery factors at 1.2 pore volume injected. 


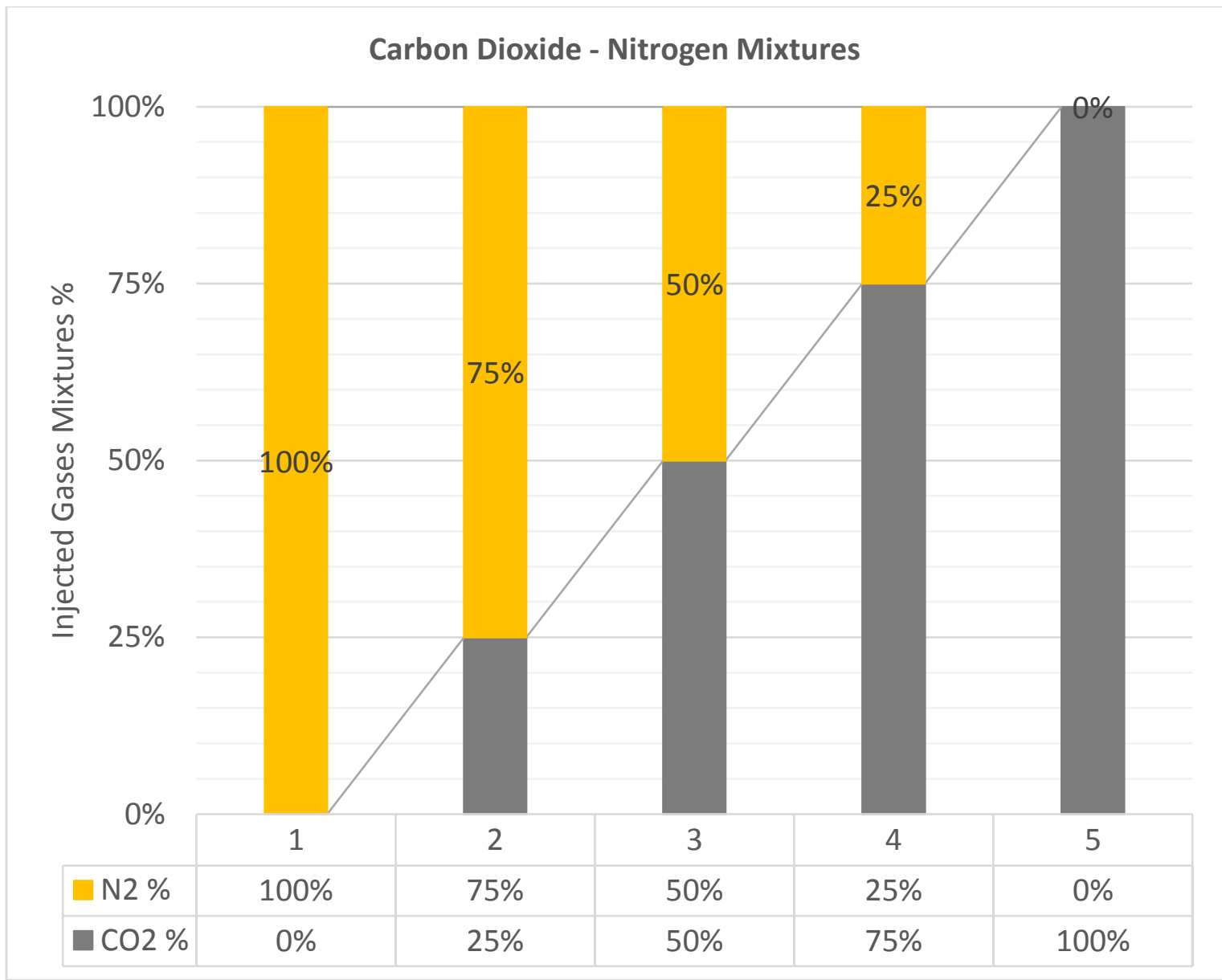

Figure 3.16 The components of each injected gas mixture (carbon dioxide and nitrogen)

Figure (3.17) to figure (3.22) are used to show how the minimum miscibility pressure is measured for the three carbon dioxide and nitrogen mixtures presented in figure (3.23). Table (3) summarizes that the minimum miscibility pressure corresponding to the injected gas composition. The minimum miscibility pressure results of the injected gas mixture (carbon dioxide and nitrogen) are plotted to show how the minimum miscibility pressure values change as a function of the composition of the injected gas mixture, as it shown figure (2.24). 


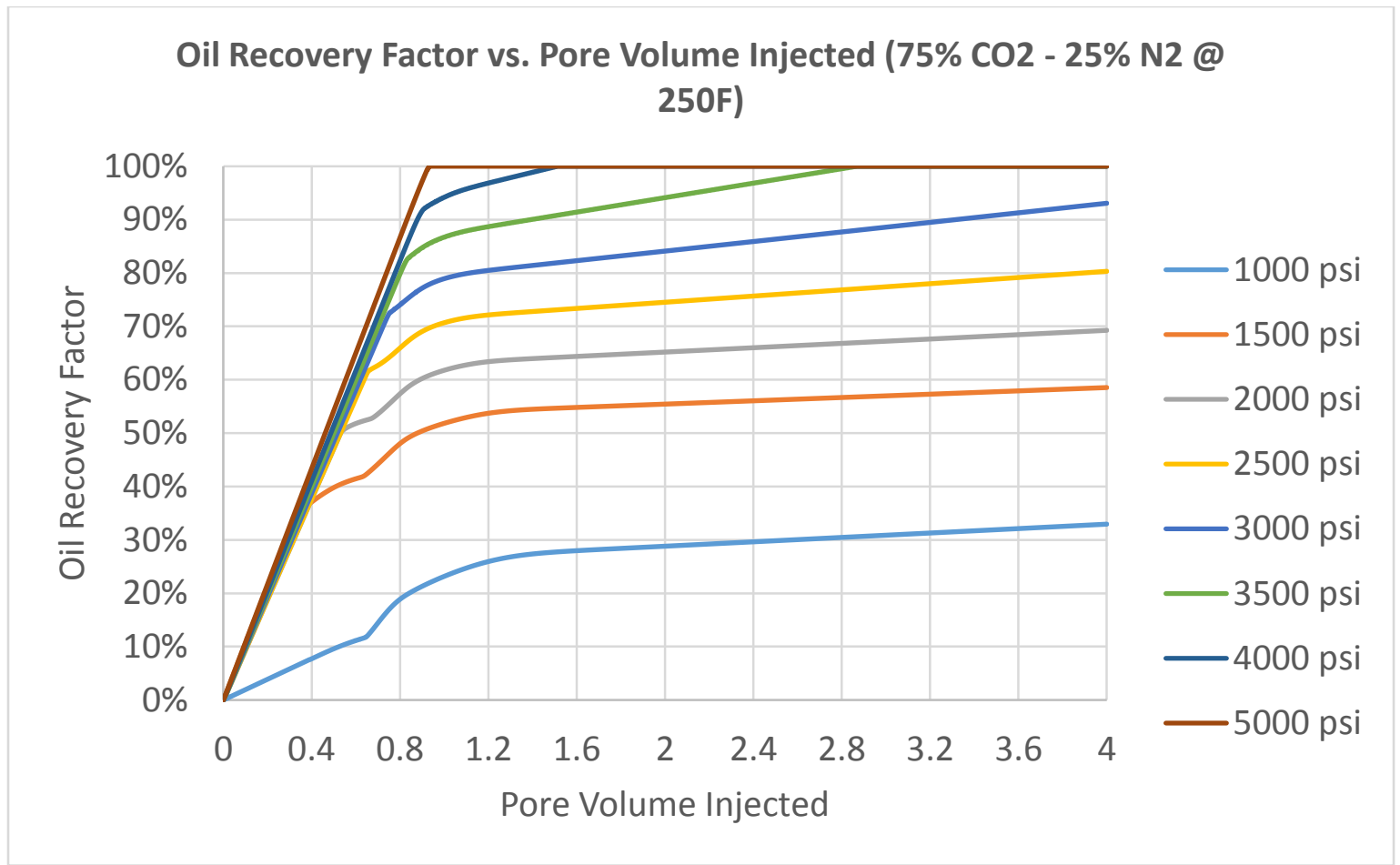

Figure 3.17 Simulator result of the minimum miscibility pressure of $25 \%$ carbon dioxide and $75 \%$ nitrogen at $250 \mathrm{~F}$.

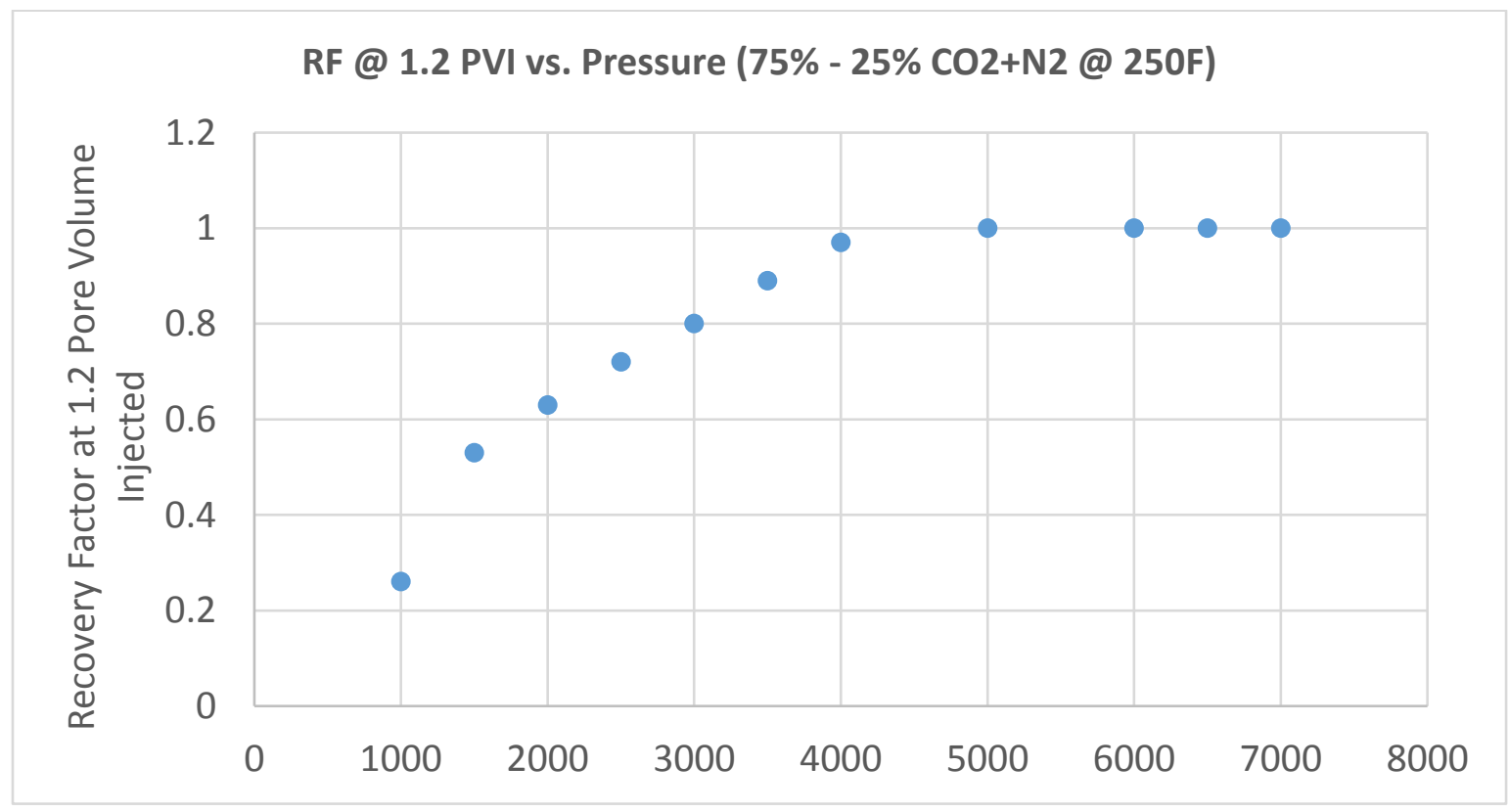

Figure 3.18 The oil recovery factor of $90 \%$ at 1.2 pore volume injected vs. the pressure (75\% carbon dioxide and $25 \%$ nitrogen at 250F) 


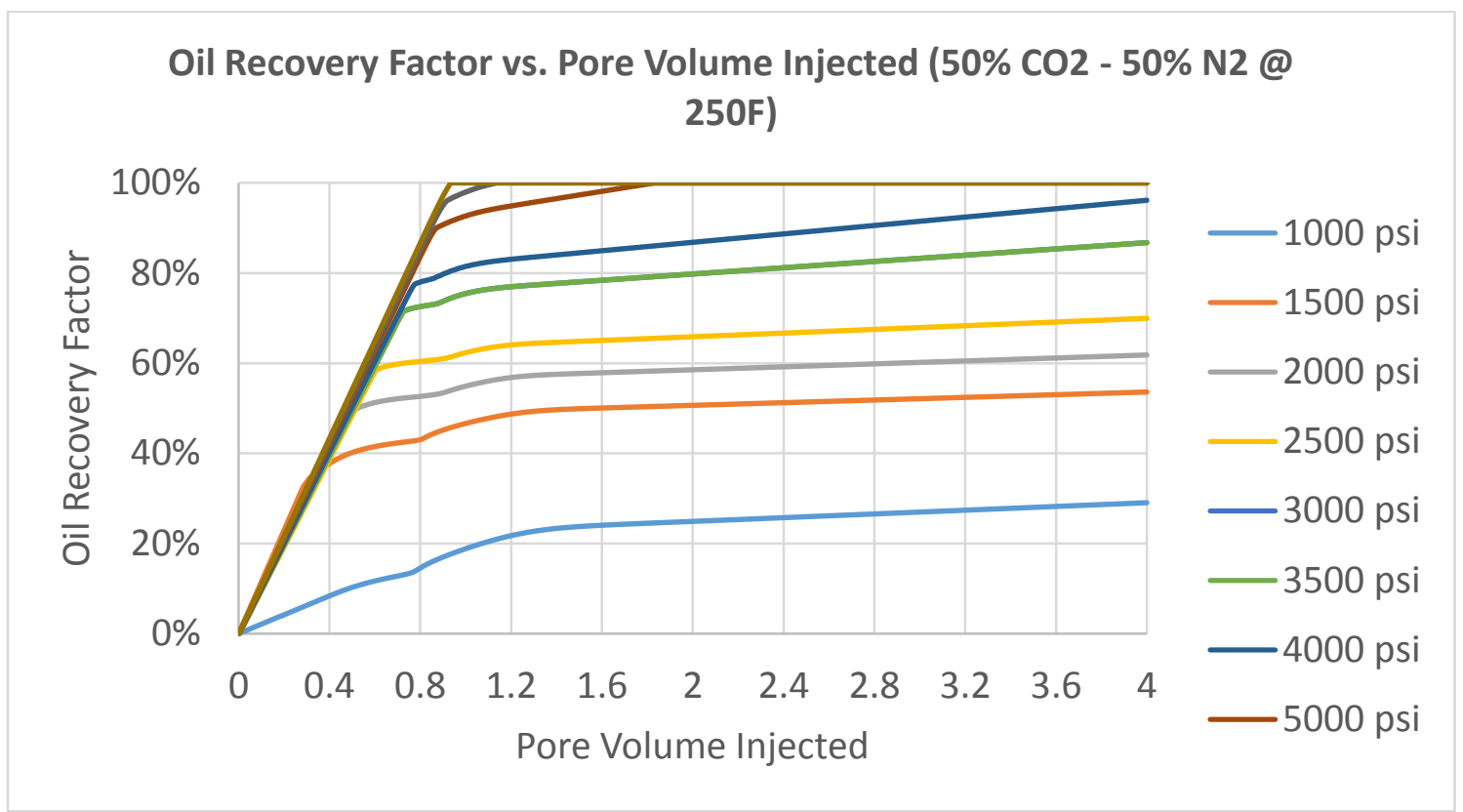

Figure 3.19 Simulator result of the minimum miscibility pressure of 50\% carbon dioxide and $50 \%$ nitrogen at $250 F$.

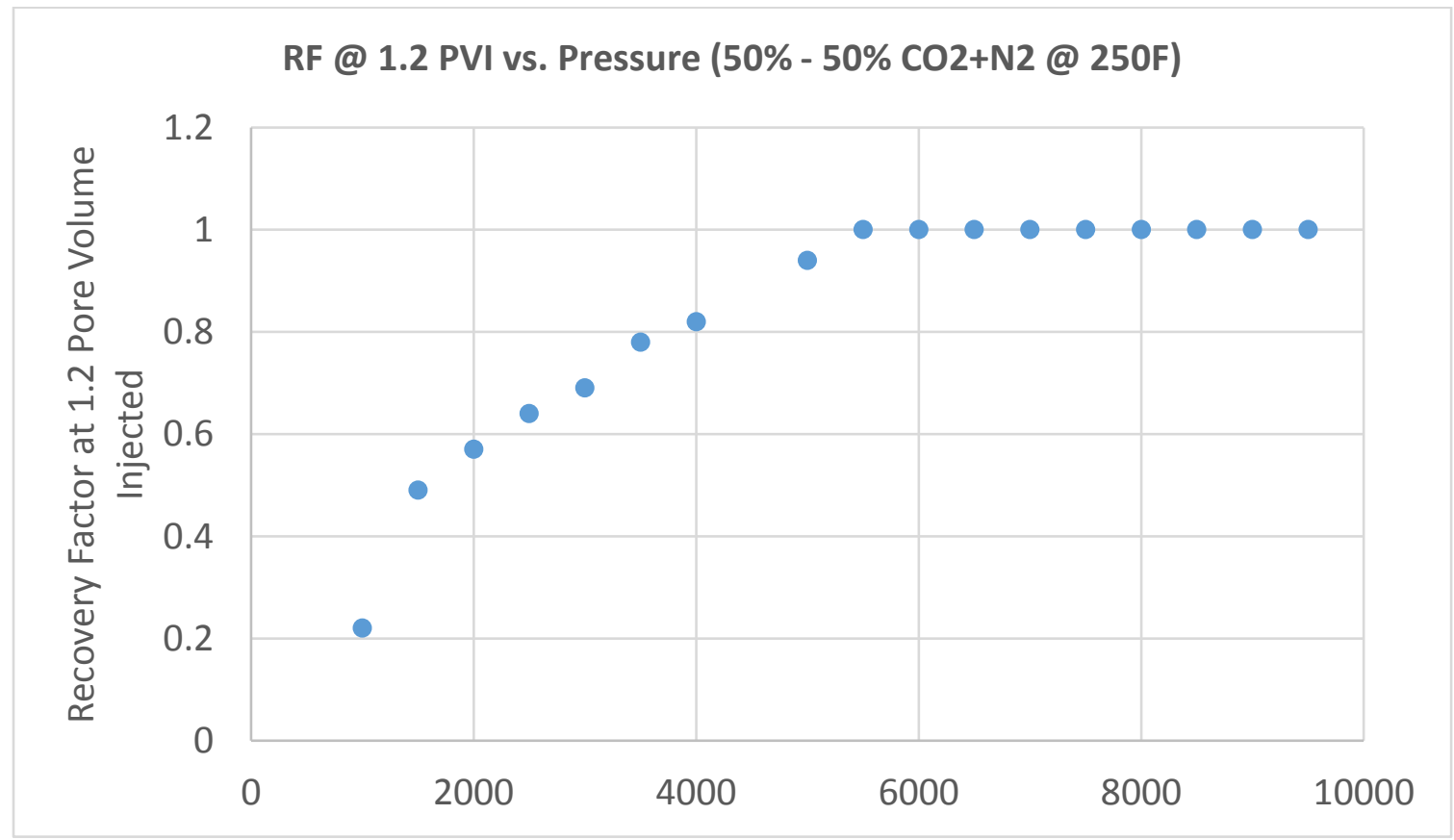

Figure 3.20 The oil recovery factor of $90 \%$ at 1.2 pore volume injected vs. the pressure (50\% carbon dioxide and 50\% nitrogen at 250F) 


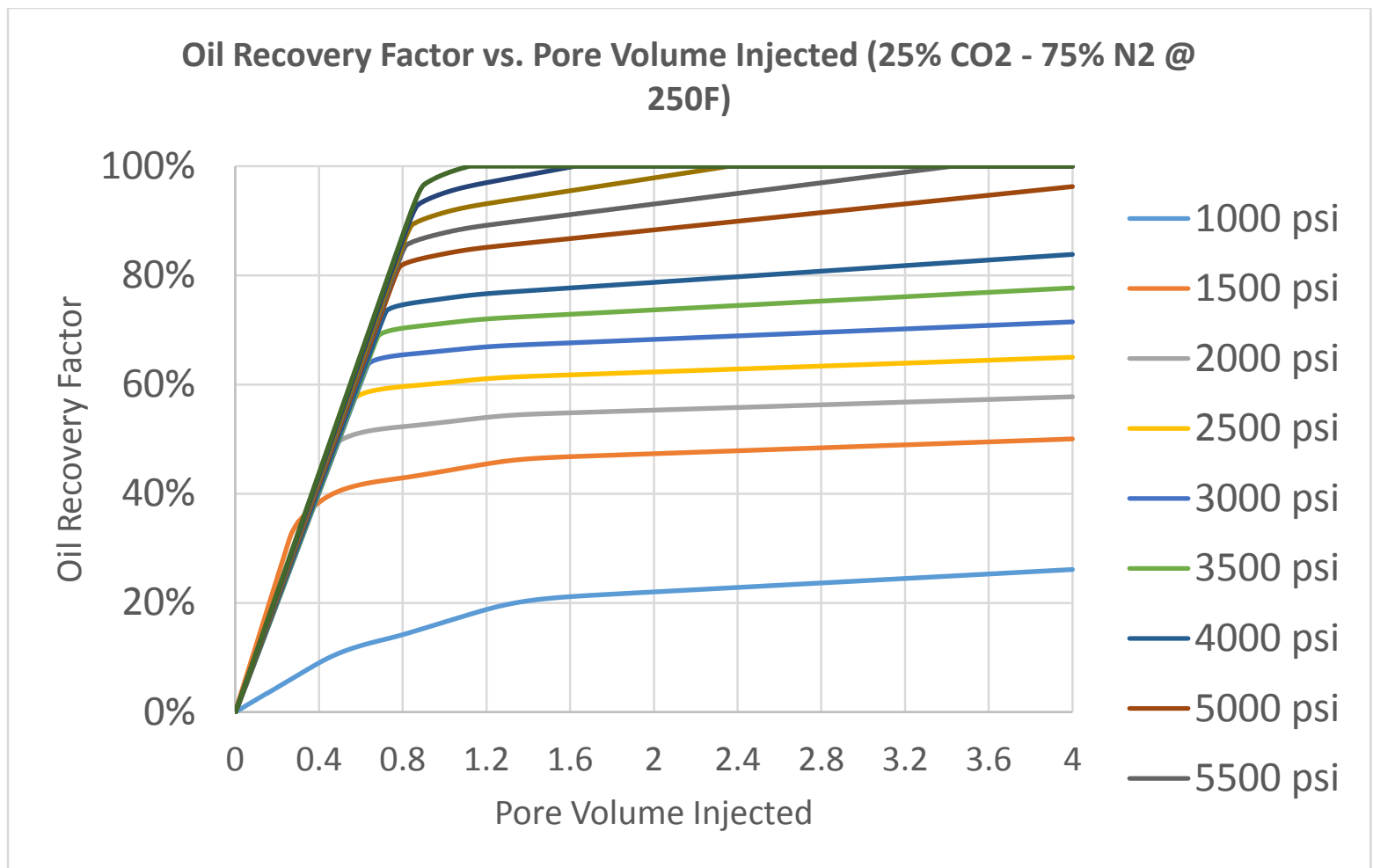

Figure 3.21 Simulator result of the minimum miscibility pressure of $25 \%$ carbon dioxide and $75 \%$ nitrogen at $250 \mathrm{~F}$.

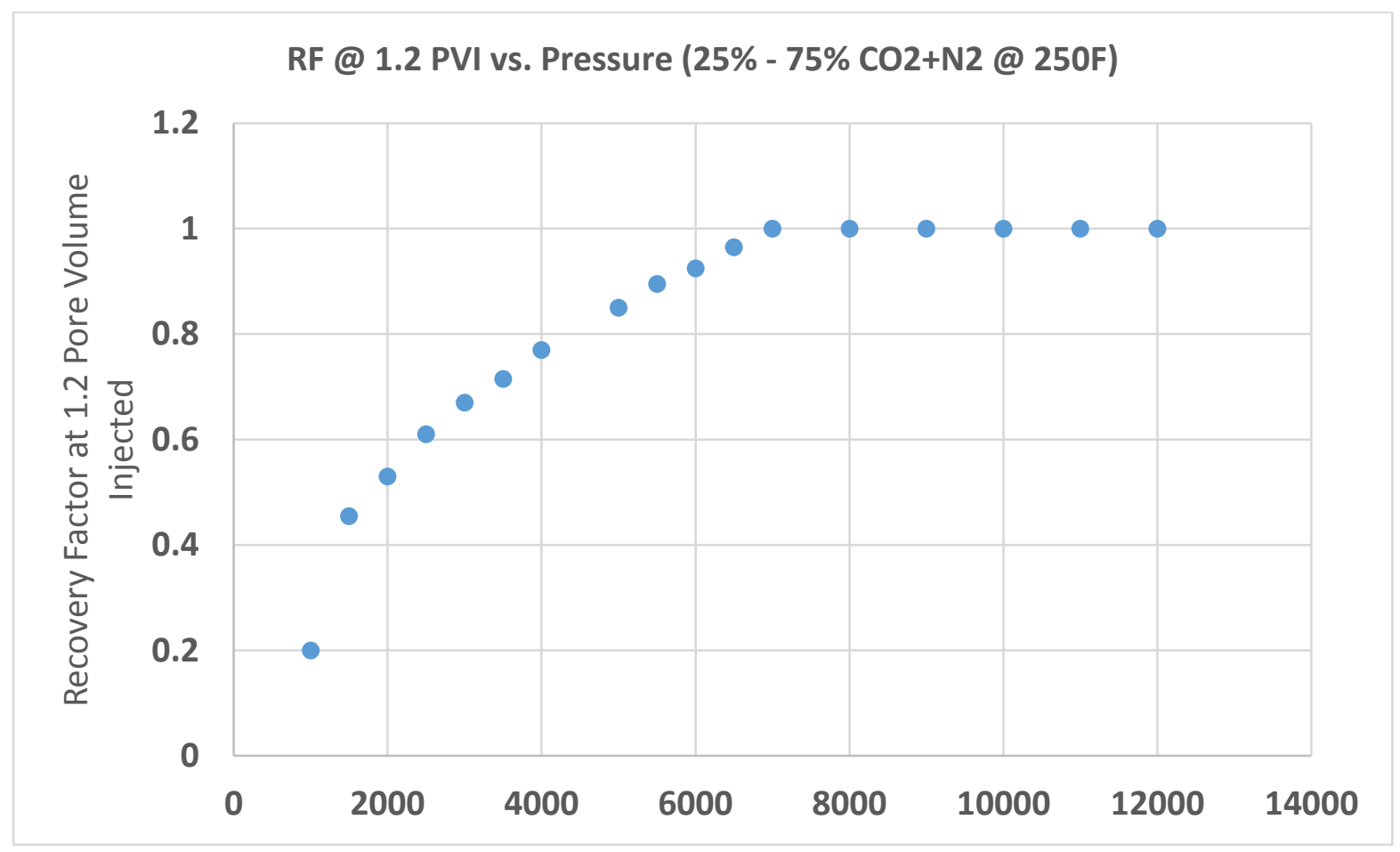

Figure 3.22 The oil recovery factor of $90 \%$ at 1.2 pore volume injected vs. the pressure (25\% carbon dioxide and $75 \%$ nitrogen at 250F) 
Table 3.2 Nitrogen and carbon dioxide gas mixture's minimum miscibility pressure at $250 F$.

\begin{tabular}{|c|c|c|c|}
\hline \multicolumn{2}{|c|}{ Gas Injection Composition } & MMP @ 160 F \\
\hline CO2 & N2 & Total & Model \\
\hline $0 \%$ & $100 \%$ & $100 \%$ & 6375 \\
\hline $25 \%$ & $75 \%$ & $100 \%$ & 5583 \\
\hline $50 \%$ & $50 \%$ & $100 \%$ & 4667 \\
\hline $75 \%$ & $25 \%$ & $100 \%$ & 3563 \\
\hline $100 \%$ & $0 \%$ & $100 \%$ & 2875 \\
\hline
\end{tabular}




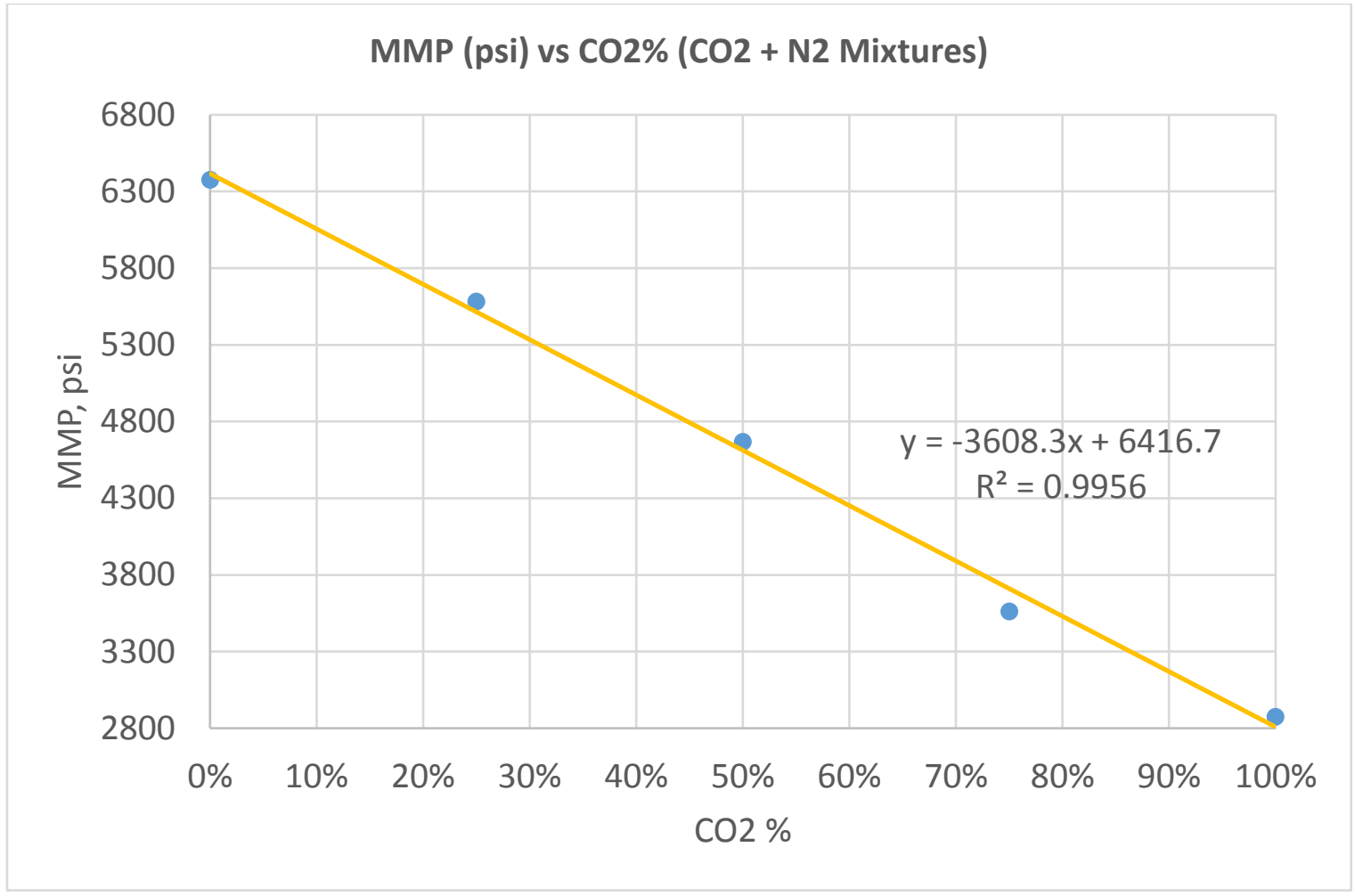

Figure 3.23 Carbon dioxide \% as a function of the minimum miscibility pressure (nitrgencarbon dioxide)

\subsection{Reservoir Temperature Effect on the Minimum Miscible Pressure}

Based on most of the experiments presented in the literature, the oil composition and the reservoir temperate have the most effect on the value of the minimum miscibility pressure. In this section of this research, the same work that was done on the injected gas mixture of carbon dioxide - lean hydrocarbon gas and carbon dioxide and nitrogen was repeated using 3 different temperatures: 160 F, 200 F, and 250 F, as its shown in figures (3.24) to figure (3.59). Figure (3.60), figure (3.61), table (4) and table (5) show of the minimum miscibility pressure as a function of the pressure and 
they show how the results of the minimum miscibility pressure change as the temperature changes.

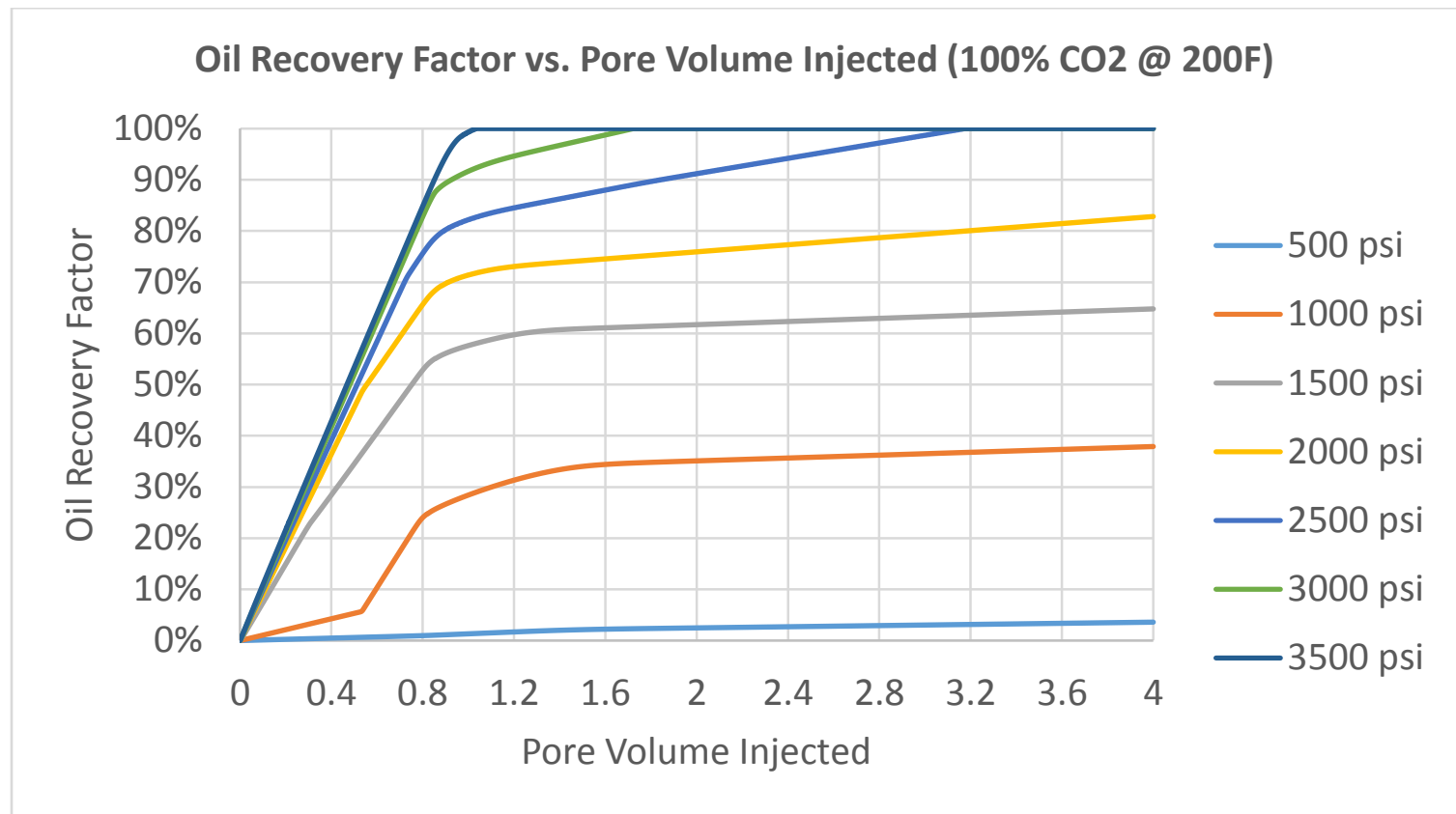

Figure 3.24 Simulator result of the minimum miscibility pressure of $100 \%$ carbon dioxide at $200 F$.

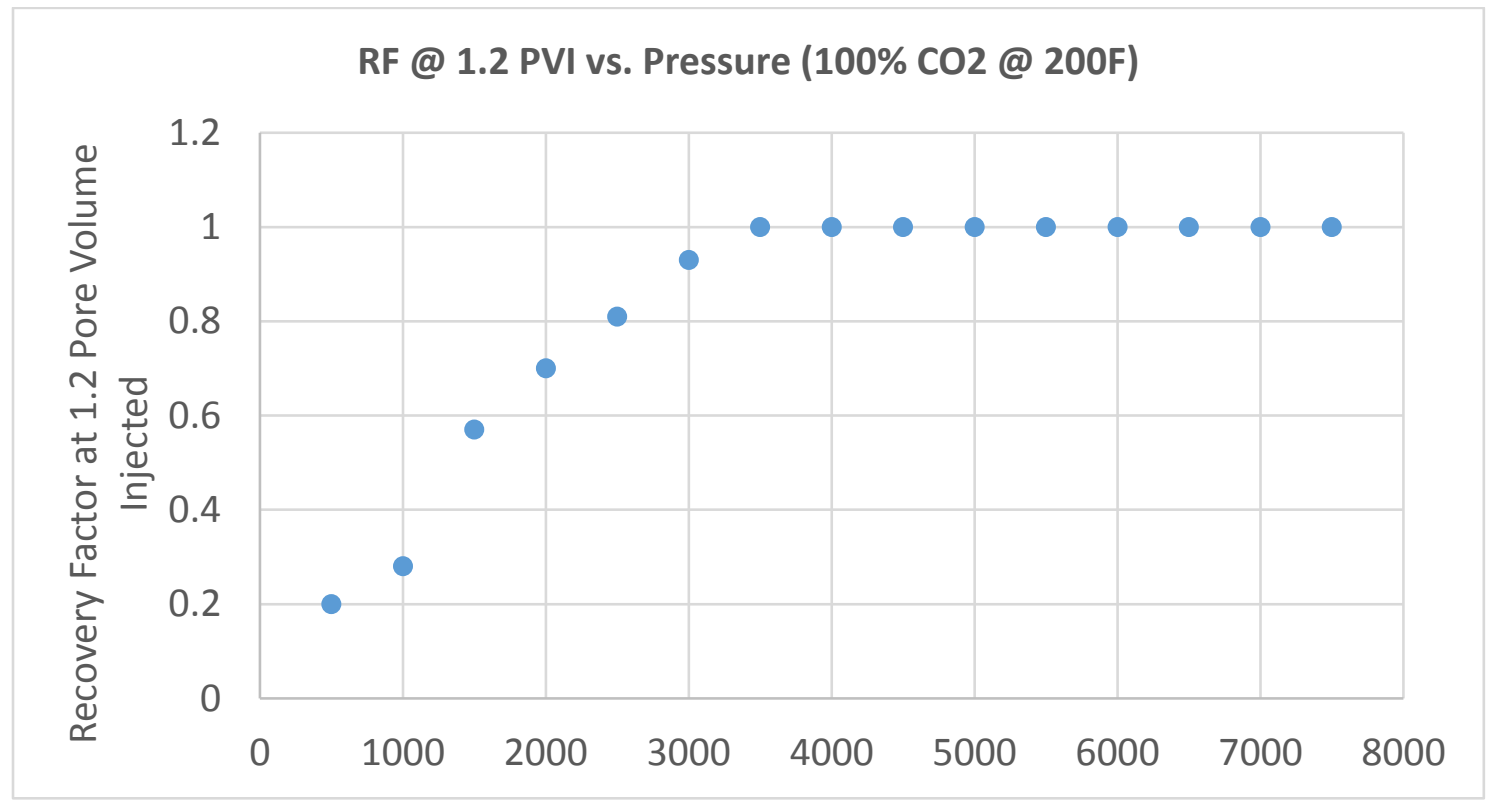

Figure 3.25 The oil recovery factor of $90 \%$ at 1.2 pore volume injected vs. the pressure (100\% CO2 at 200F) 


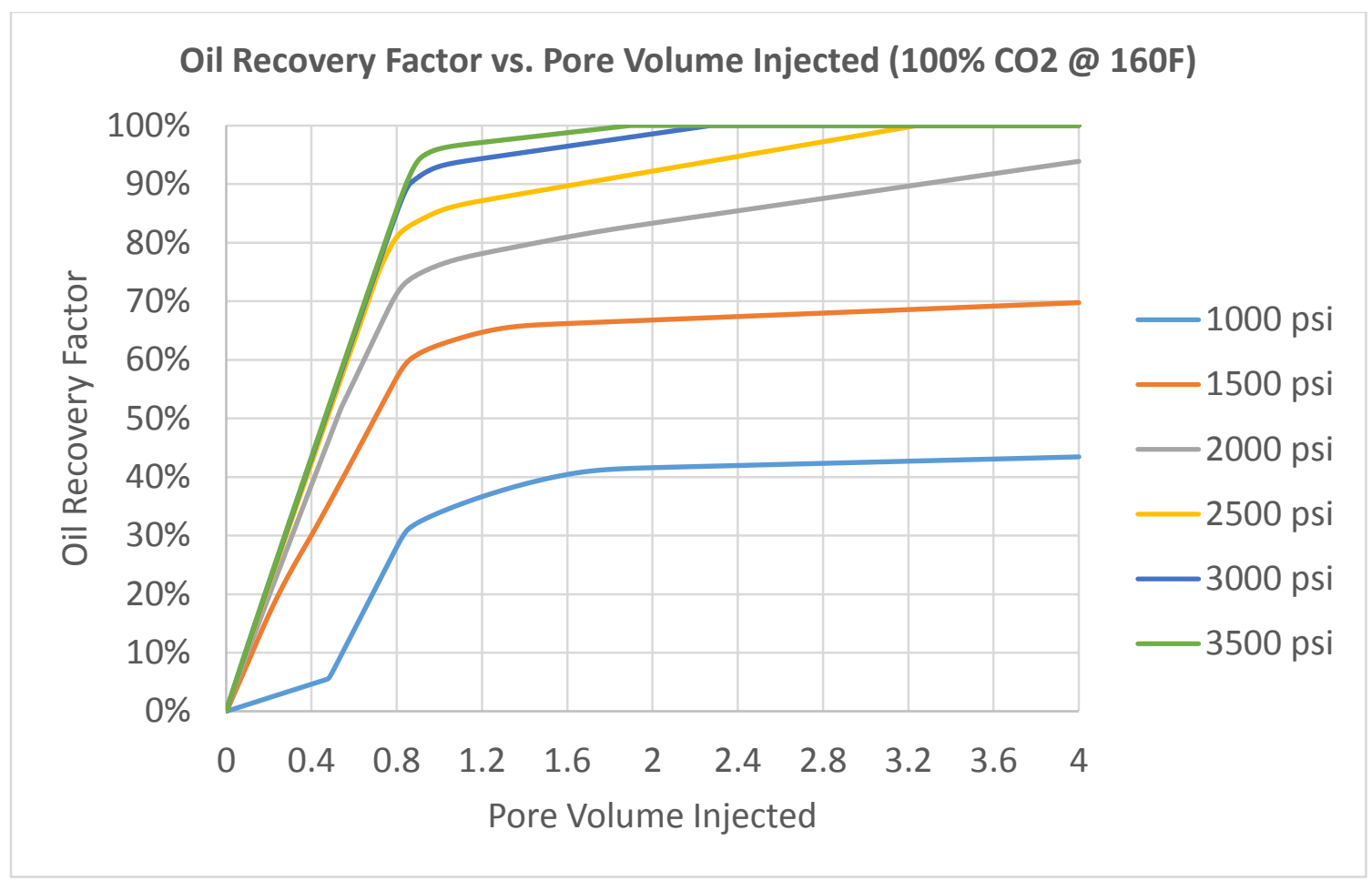

Figure 3.26 Simulator result of the minimum miscibility pressure of $100 \%$ carbon dioxide at $160 F$.

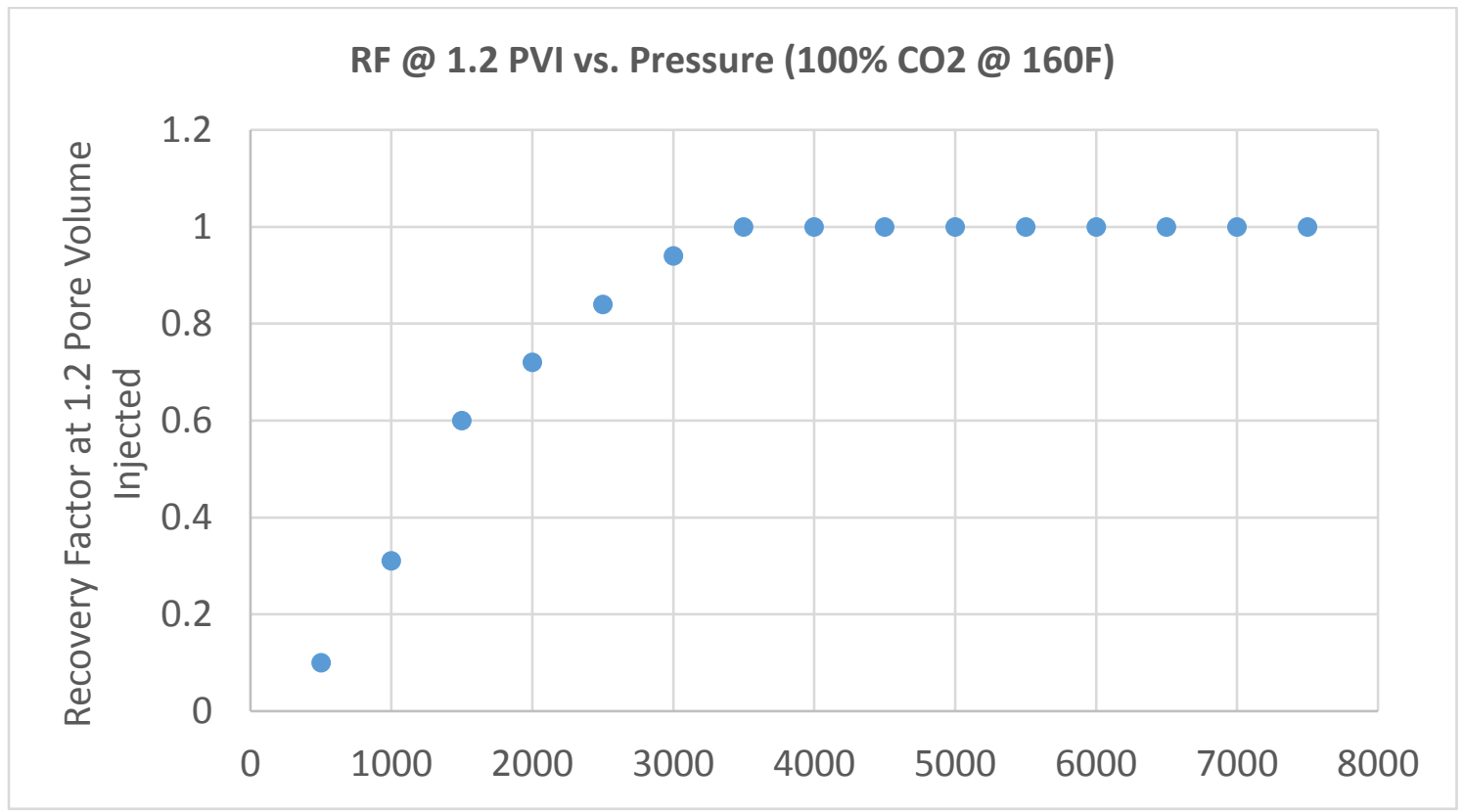

Figure 3.27 The oil recovery factor of $90 \%$ at 1.2 pore volume injected vs. the pressure (100\% CO2 at 160F) 


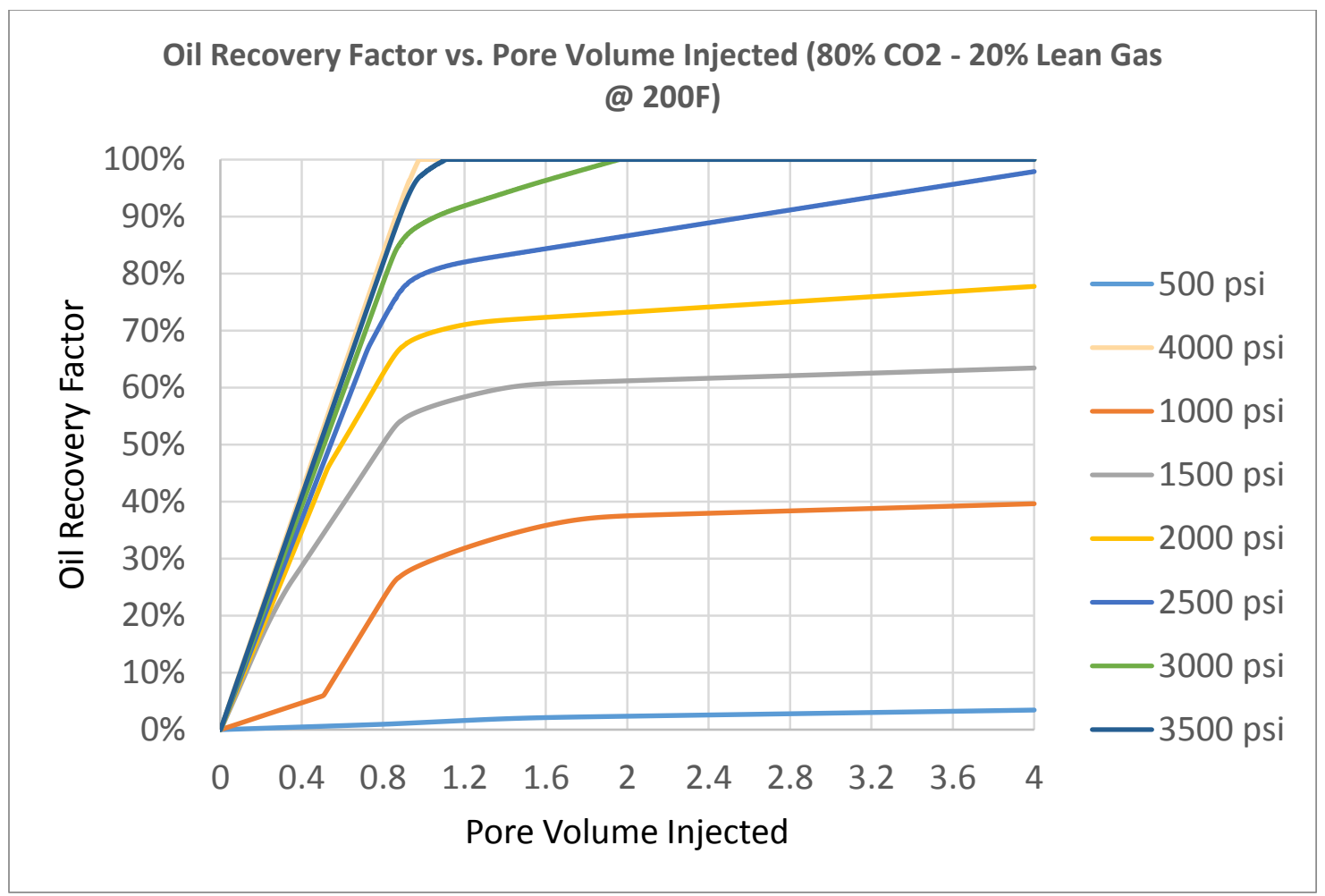

Figure 3.28 Simulator result of the minimum miscibility pressure of $80 \%$ carbon dioxide and $20 \%$ lean gas at $200 \mathrm{~F}$.

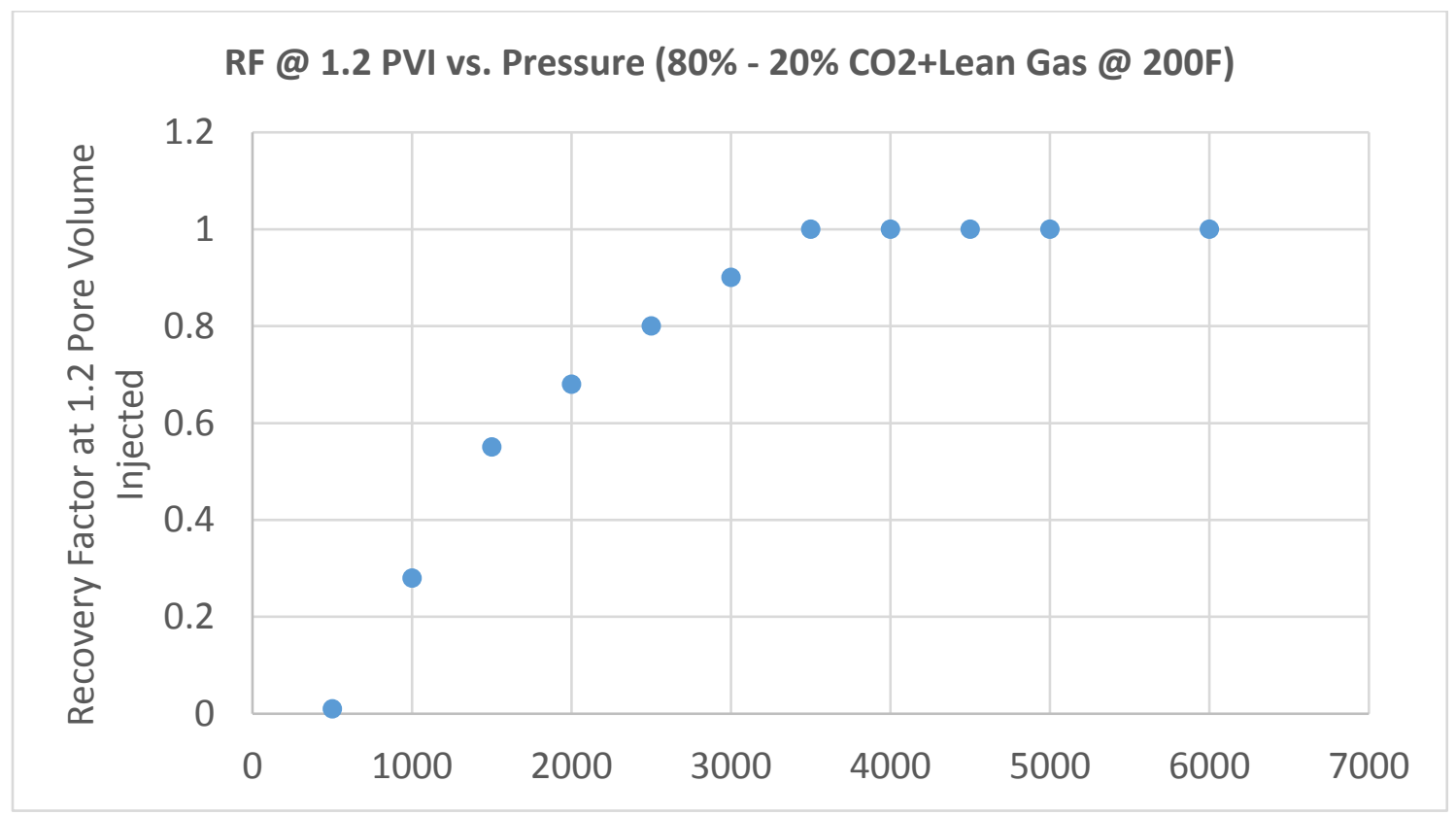

Figure 3.29 The oil recovery factor of $90 \%$ at 1.2 pore volume injected vs. the pressure (80\% carbon dioxide and $20 \%$ at 200F) 


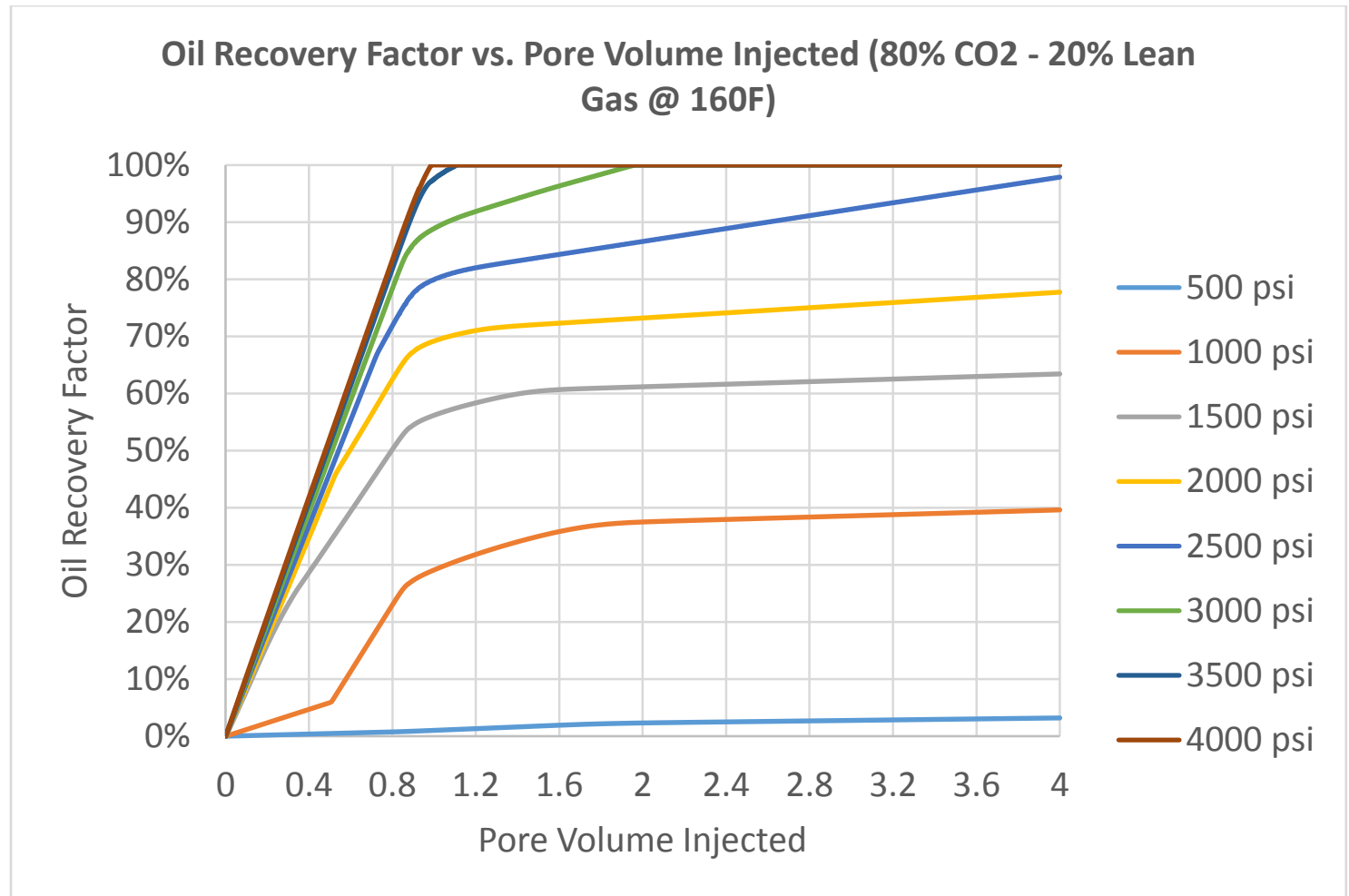

Figure 3.30 Simulator result of the minimum miscibility pressure of $80 \%$ carbon dioxide and $20 \%$ lean gas at $160 \mathrm{~F}$.

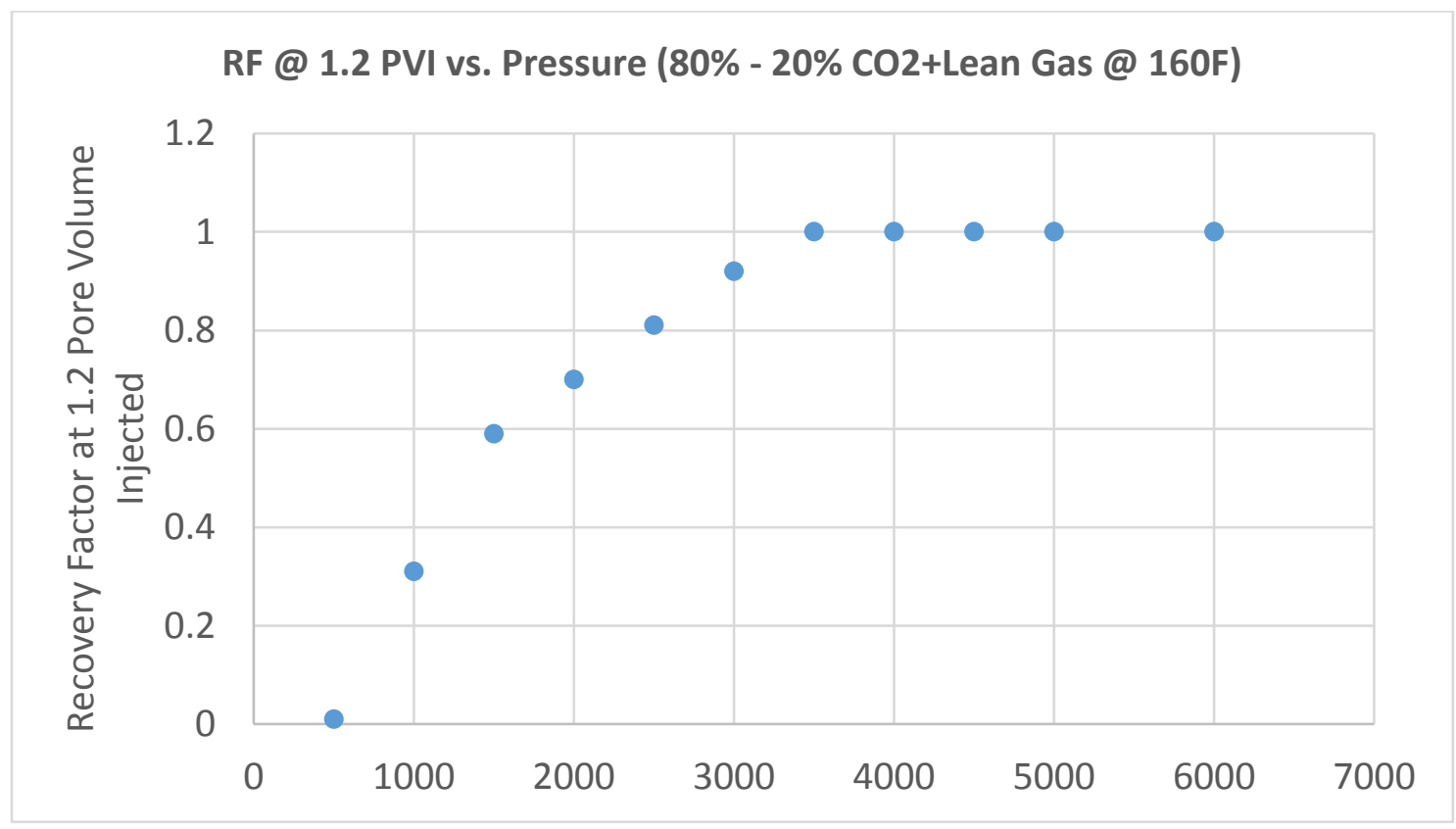

Figure 3.31 The oil recovery factor of $90 \%$ at 1.2 pore volume injected vs. the pressure (80\% carbon dioxide and $20 \%$ at 160 F) 


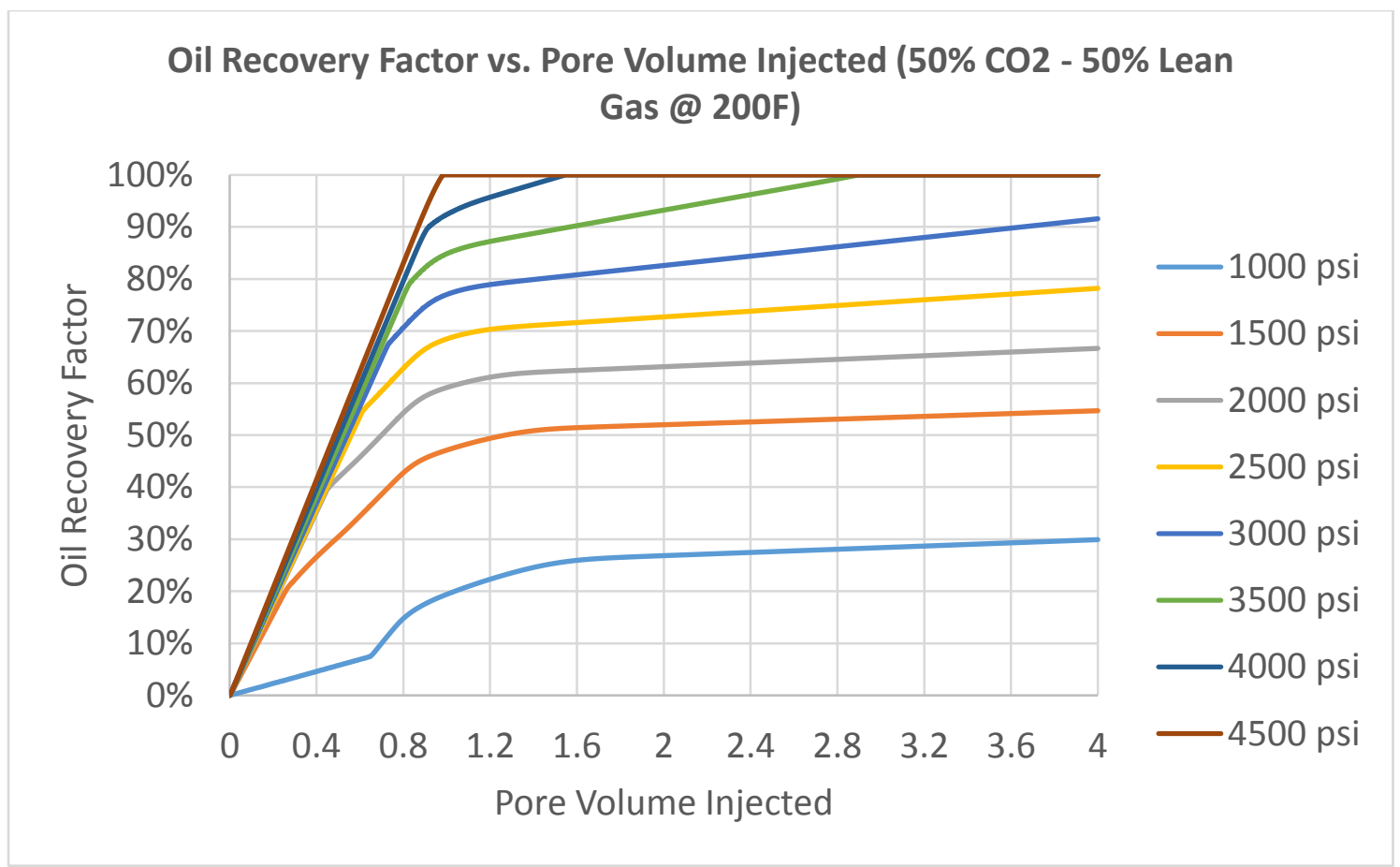

Figure 3.32 Simulator result of the minimum miscibility pressure of $50 \%$ carbon dioxide and $50 \%$ lean gas at 200F.

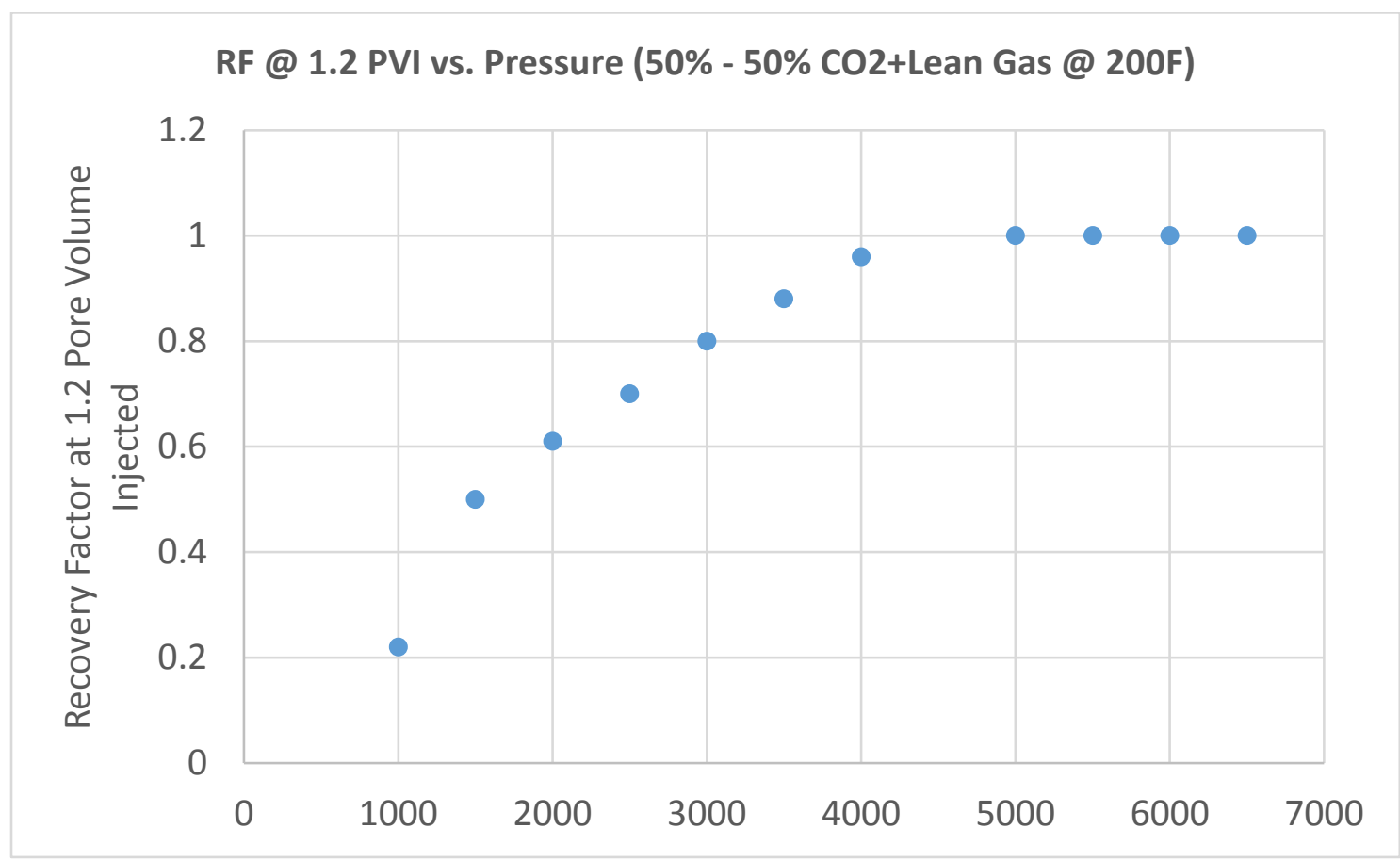

Figure 3.33 The oil recovery factor of $90 \%$ at 1.2 pore volume injected vs. the pressure (50\% carbon dioxide and 50\% at 200F) 


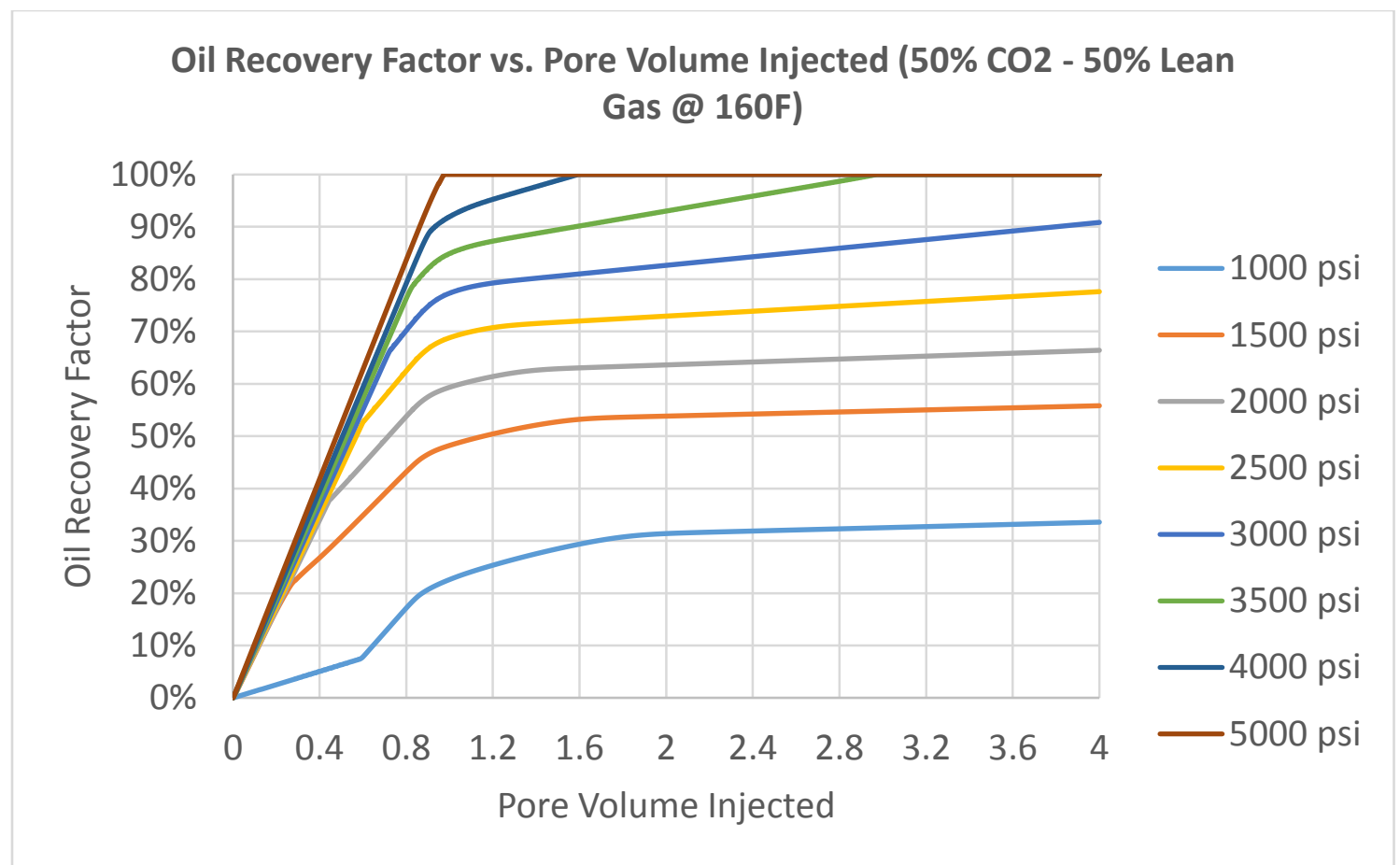

Figure 3.34 Simulator result of the minimum miscibility pressure of 50\% carbon dioxide and $50 \%$ lean gas at $160 \mathrm{~F}$.

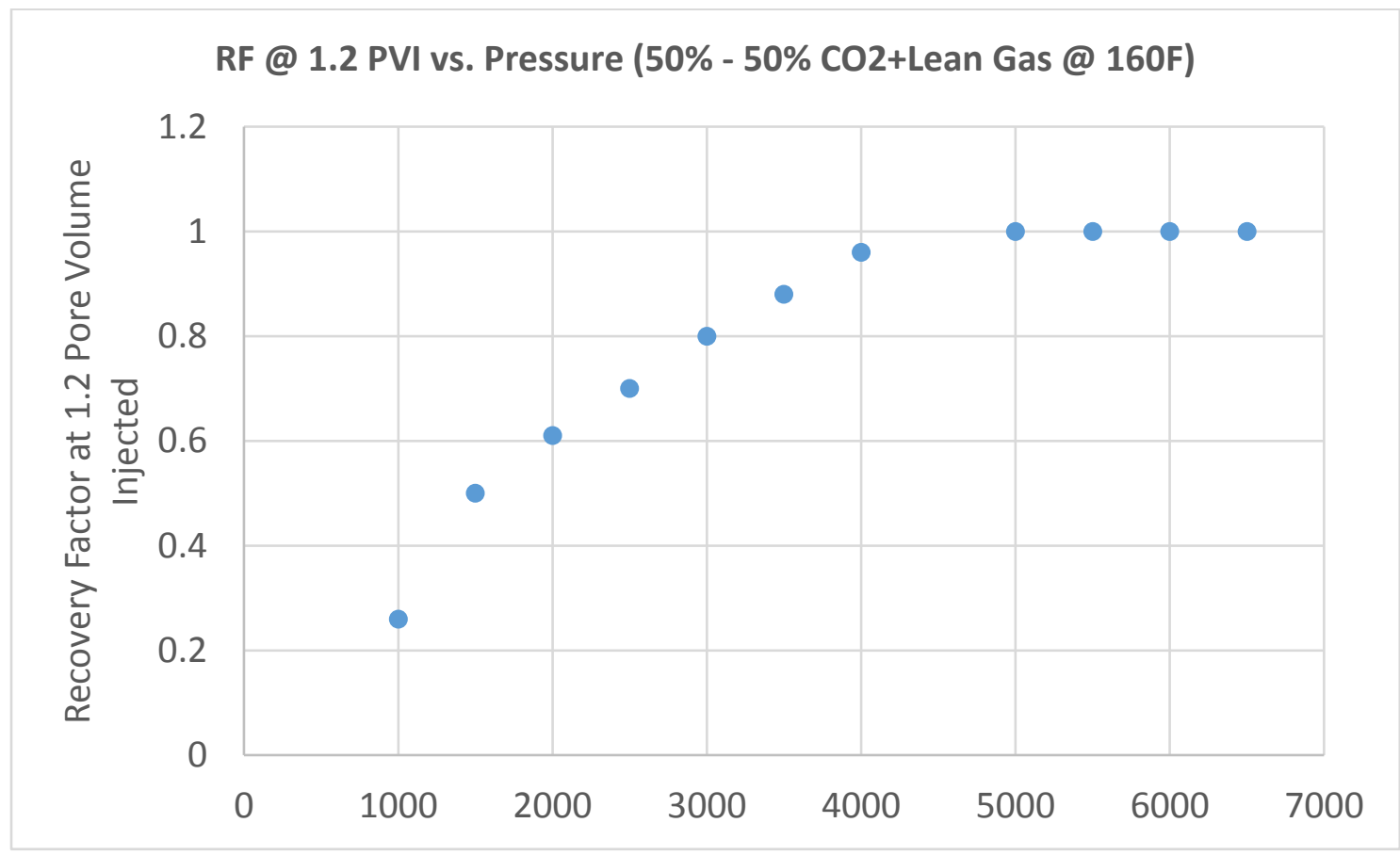

Figure 3.35 The oil recovery factor of $90 \%$ at 1.2 pore volume injected vs. the pressure (50\% carbon dioxide and 50\% at 160F) 


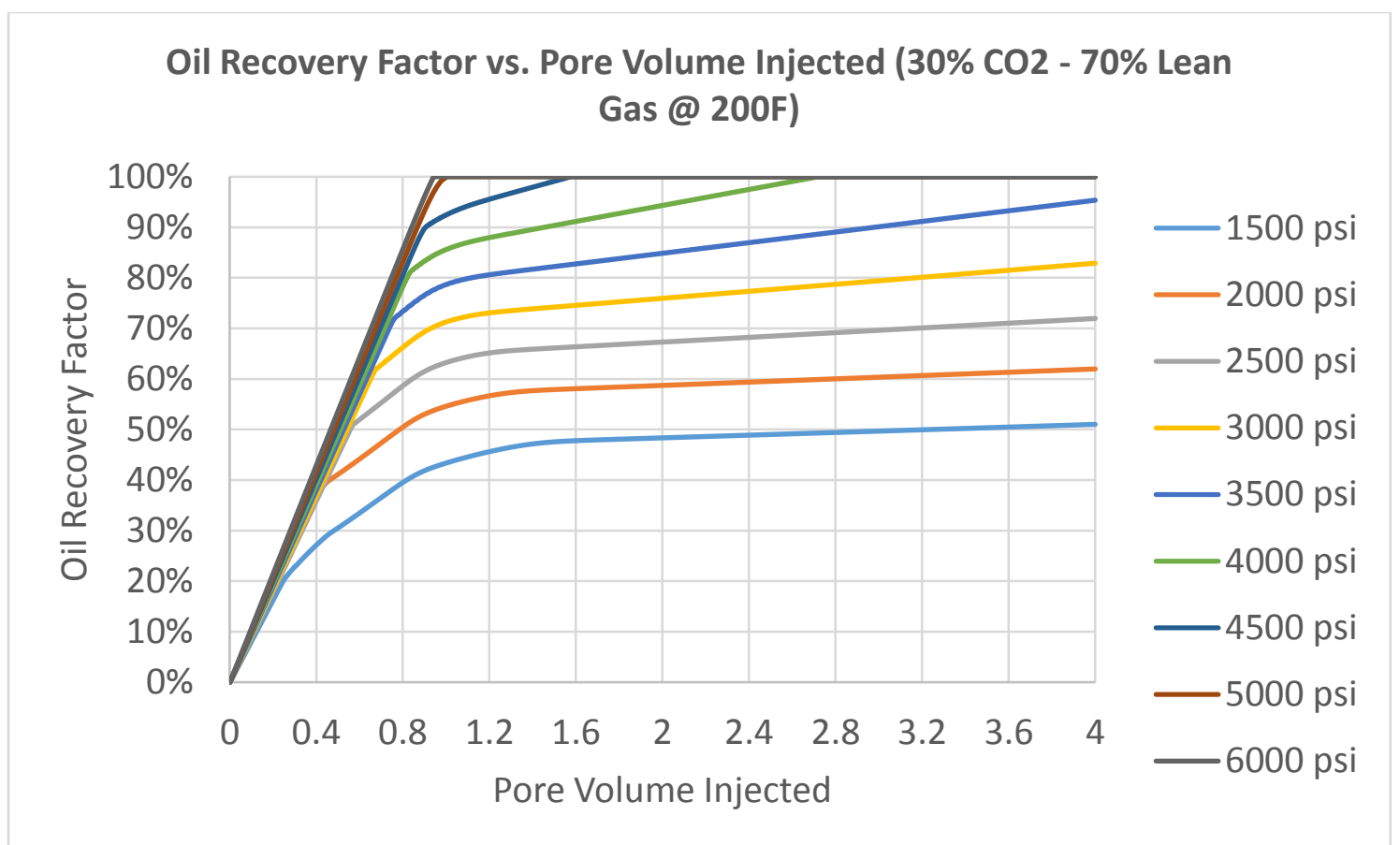

Figure 3.36 Simulator result of the minimum miscibility pressure of $30 \%$ carbon dioxide and $70 \%$ nitrogen at $200 \mathrm{~F}$.

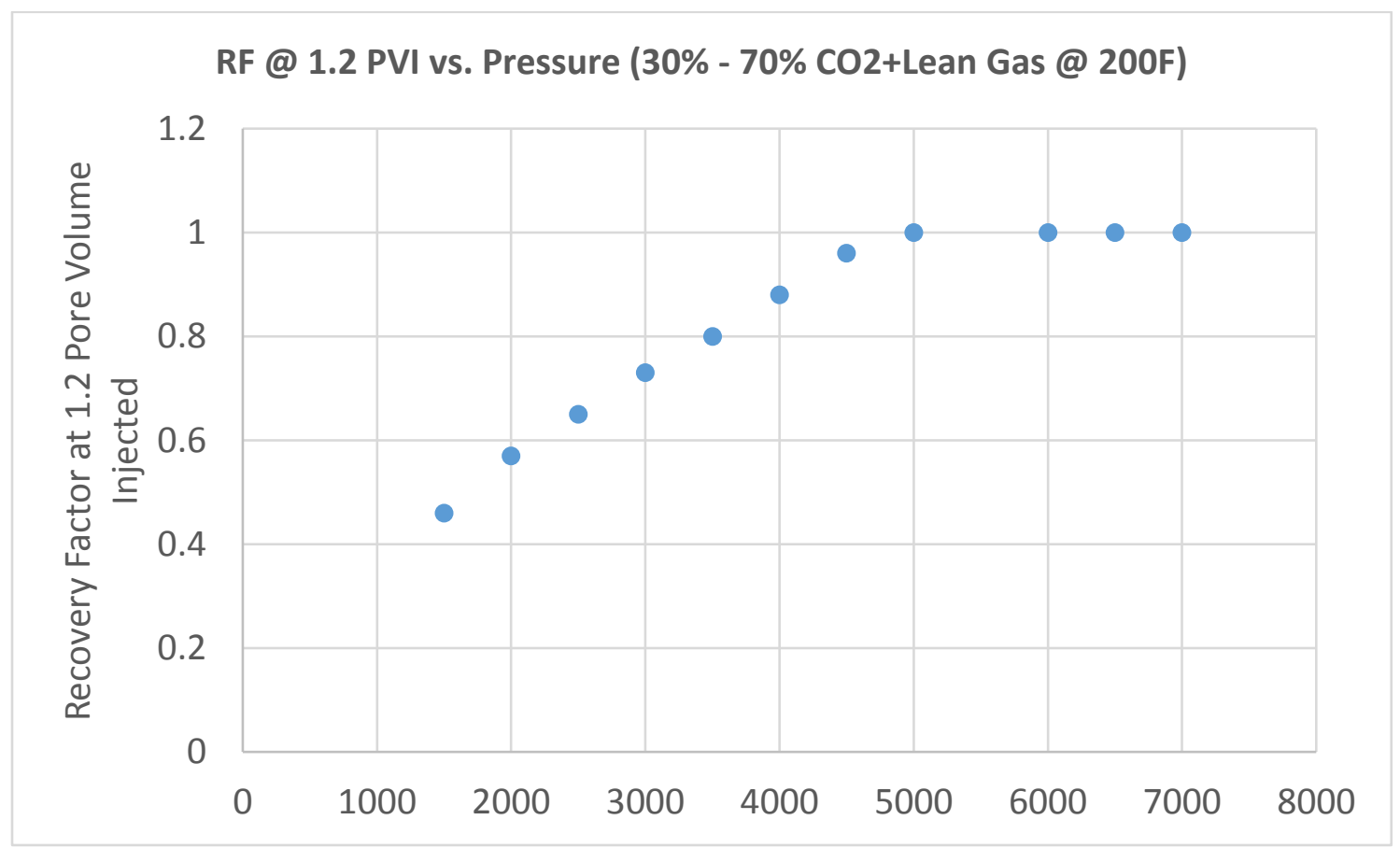

Figure 3.37 The oil recovery factor of $90 \%$ at 1.2 pore volume injected vs. the pressure (30\% carbon dioxide and $70 \%$ at 200F) 


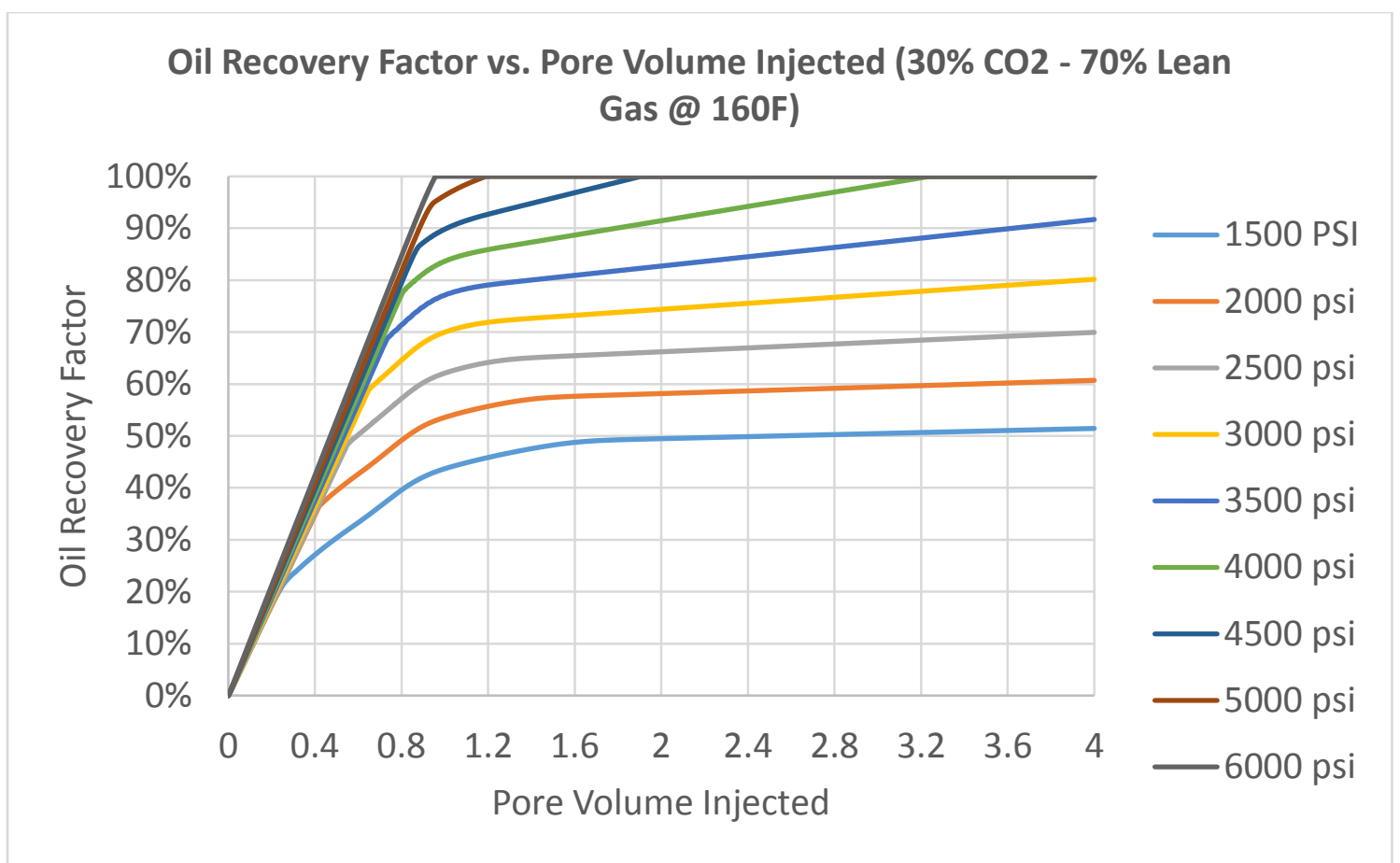

Figure 3.38 Simulator result of the minimum miscibility pressure of $30 \%$ carbon dioxide and $70 \%$ nitrogen at $160 \mathrm{~F})$.

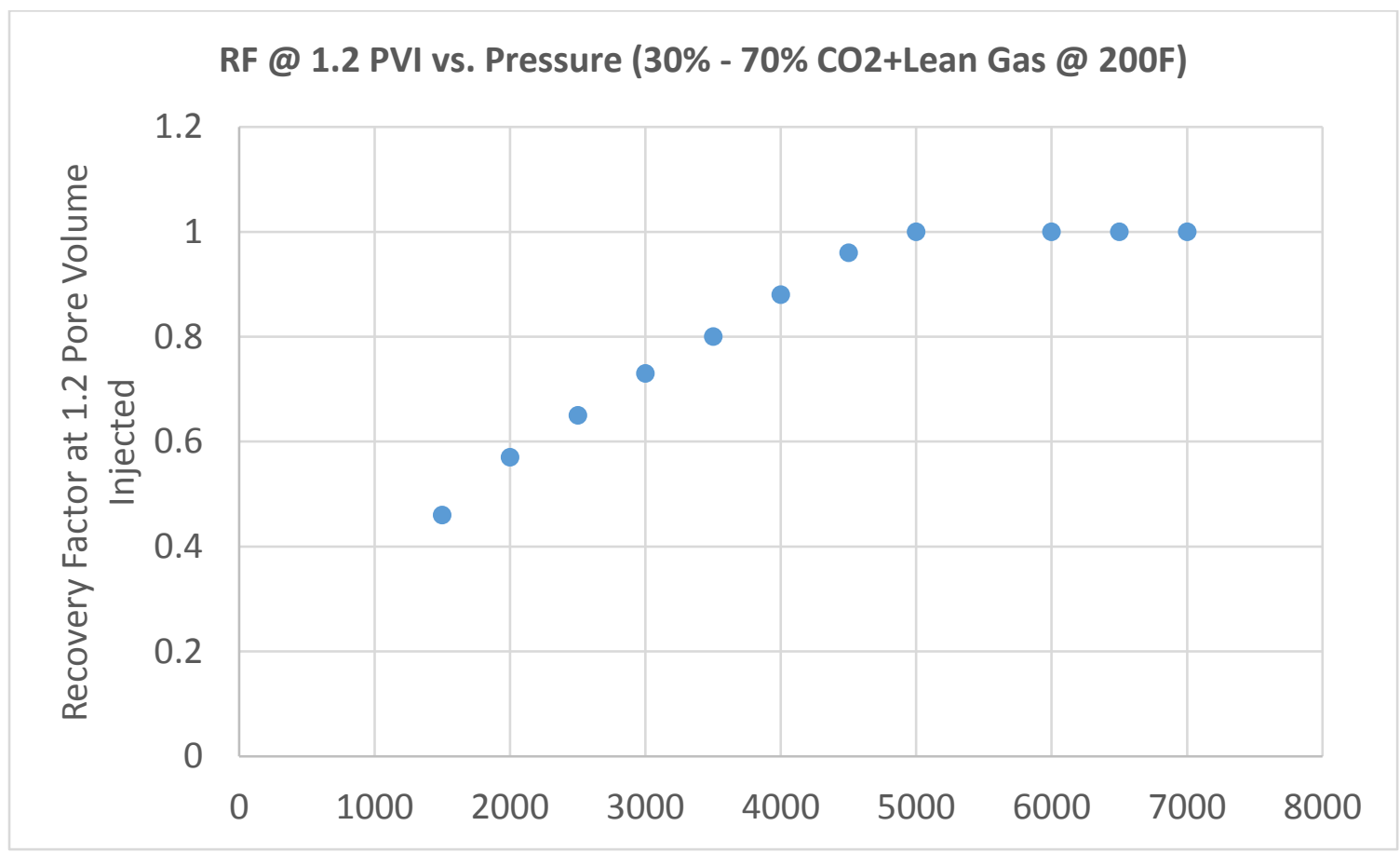

Figure 3.39 The oil recovery factor of $90 \%$ at 1.2 pore volume injected vs. the pressure (30\% carbon dioxide and $70 \%$ lean gas at 200F) 


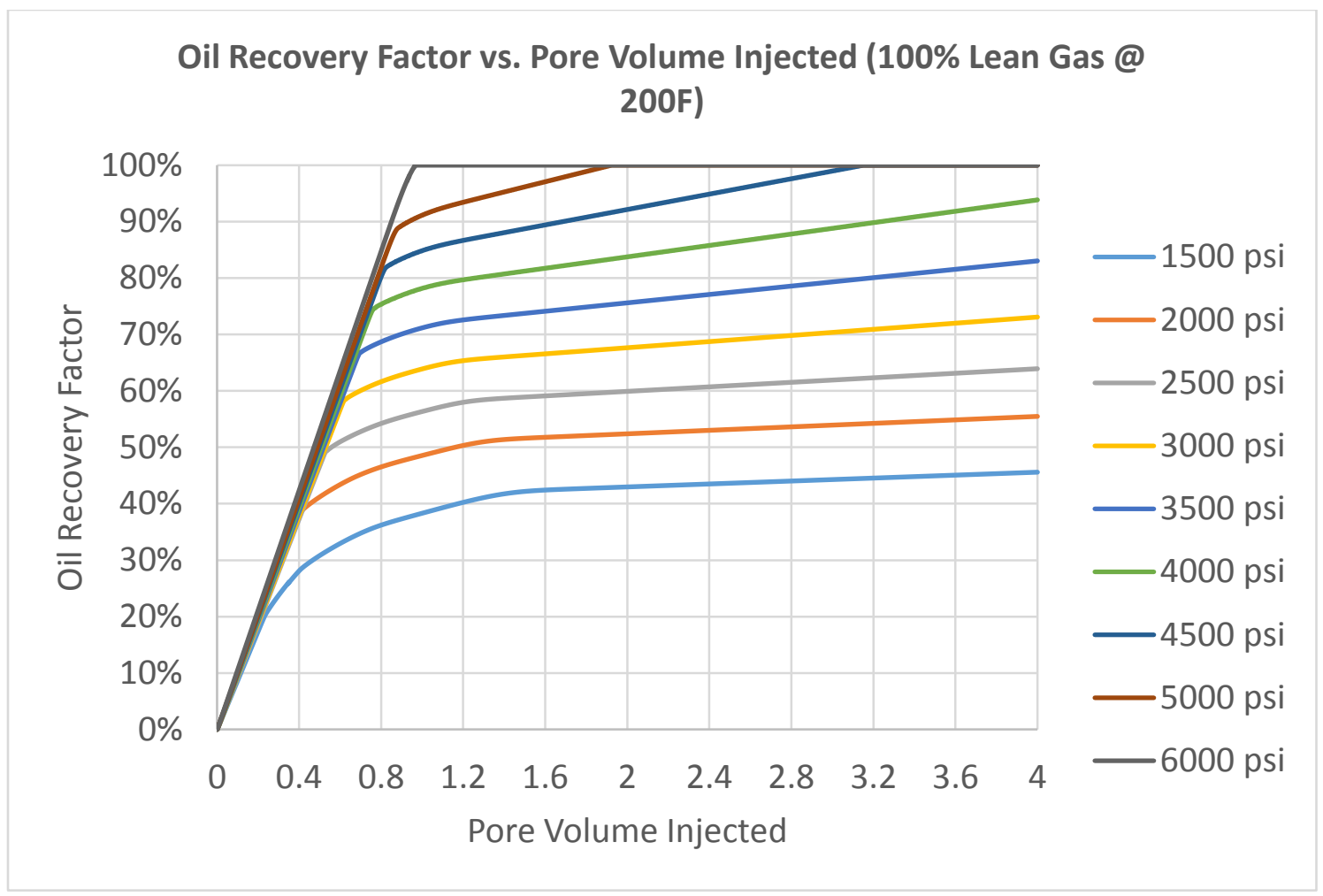

Figure 3.40 Simulator result of the minimum miscibility pressure of $100 \%$ lean gas at $200 F$.

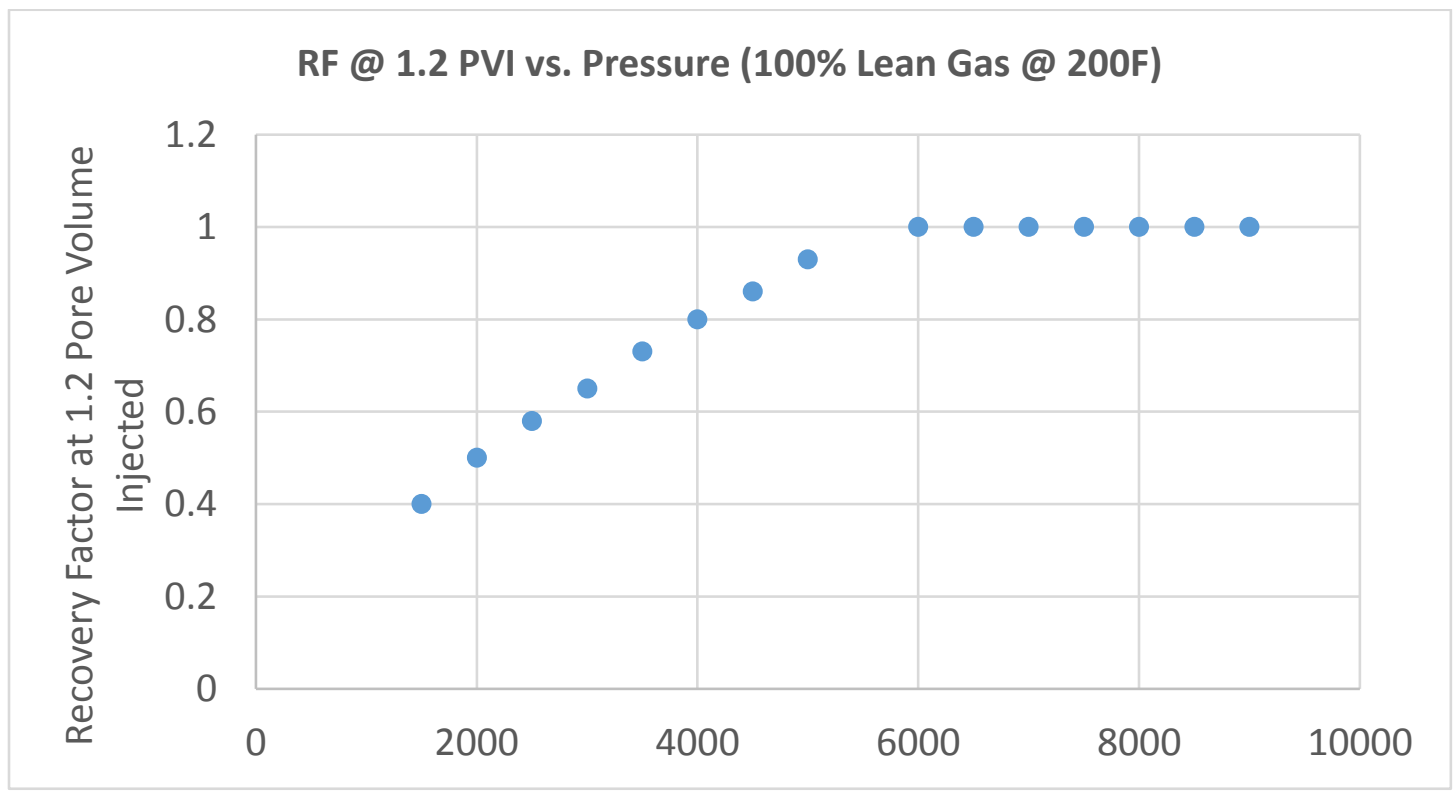

Figure 3.41 The oil recovery factor of $90 \%$ at 1.2 pore volume injected vs. the pressure (100\% lean gas at 200F) 


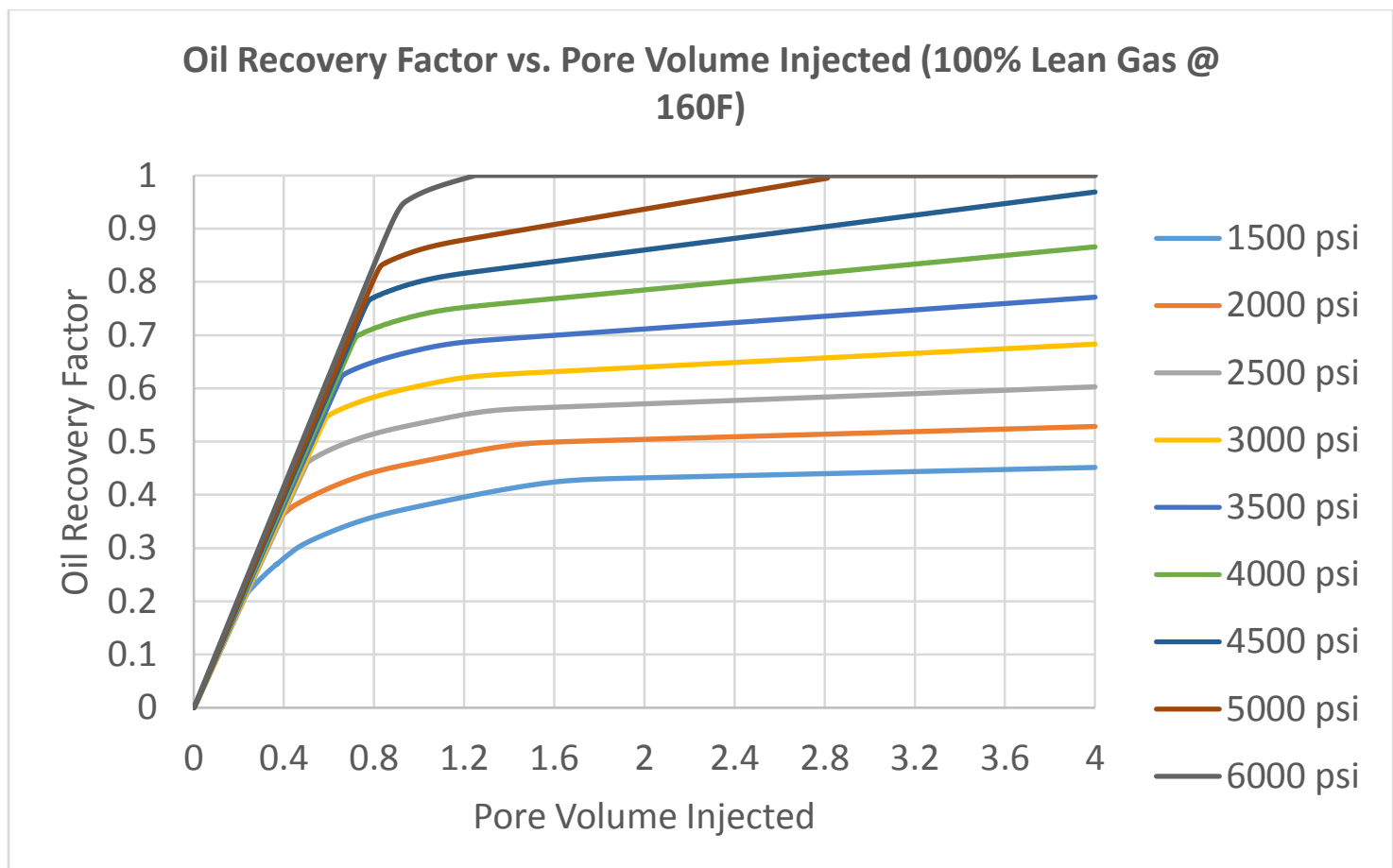

Figure 3.42 Simulator result of the minimum miscibility pressure of $100 \%$ lean gas at $160 F$.

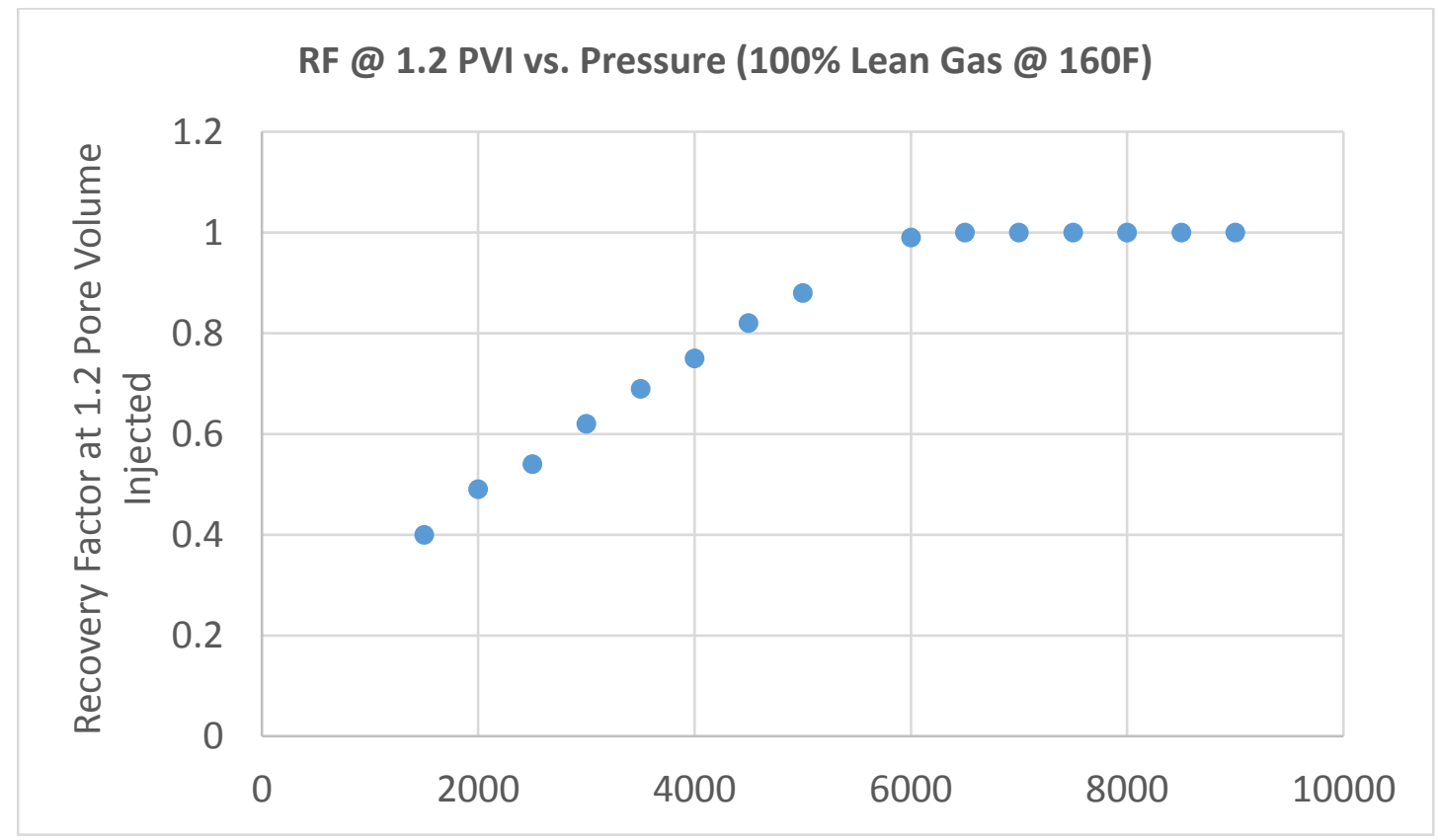

Figure 3.43 The oil recovery factor of $90 \%$ at 1.2 pore volume injected vs. the pressure (100\% lean gas at 160F) 


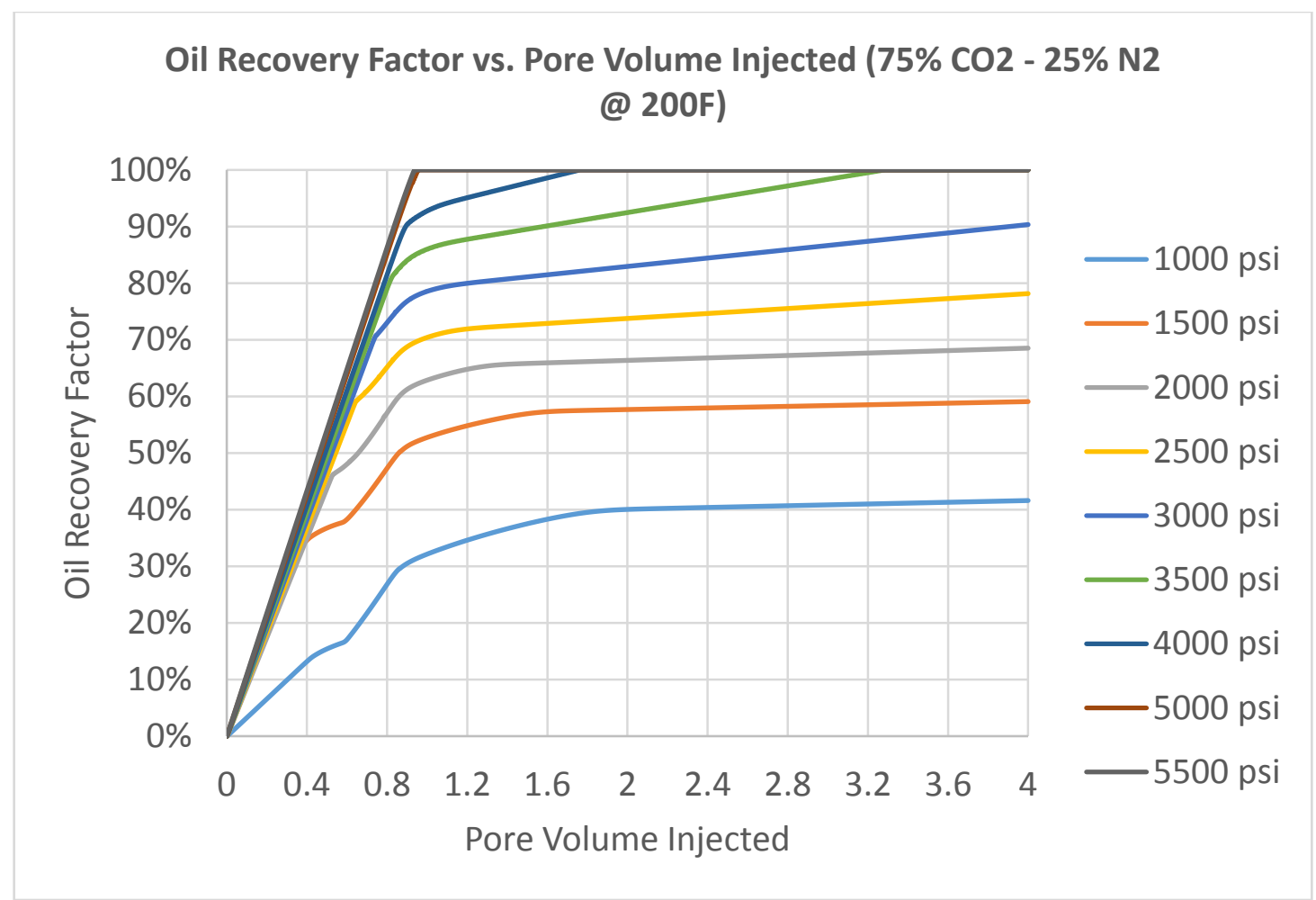

Figure 3.44 Simulator result of the minimum miscibility pressure of $25 \%$ nitrogen and $75 \%$ carbon dioxide at $200 \mathrm{~F}$

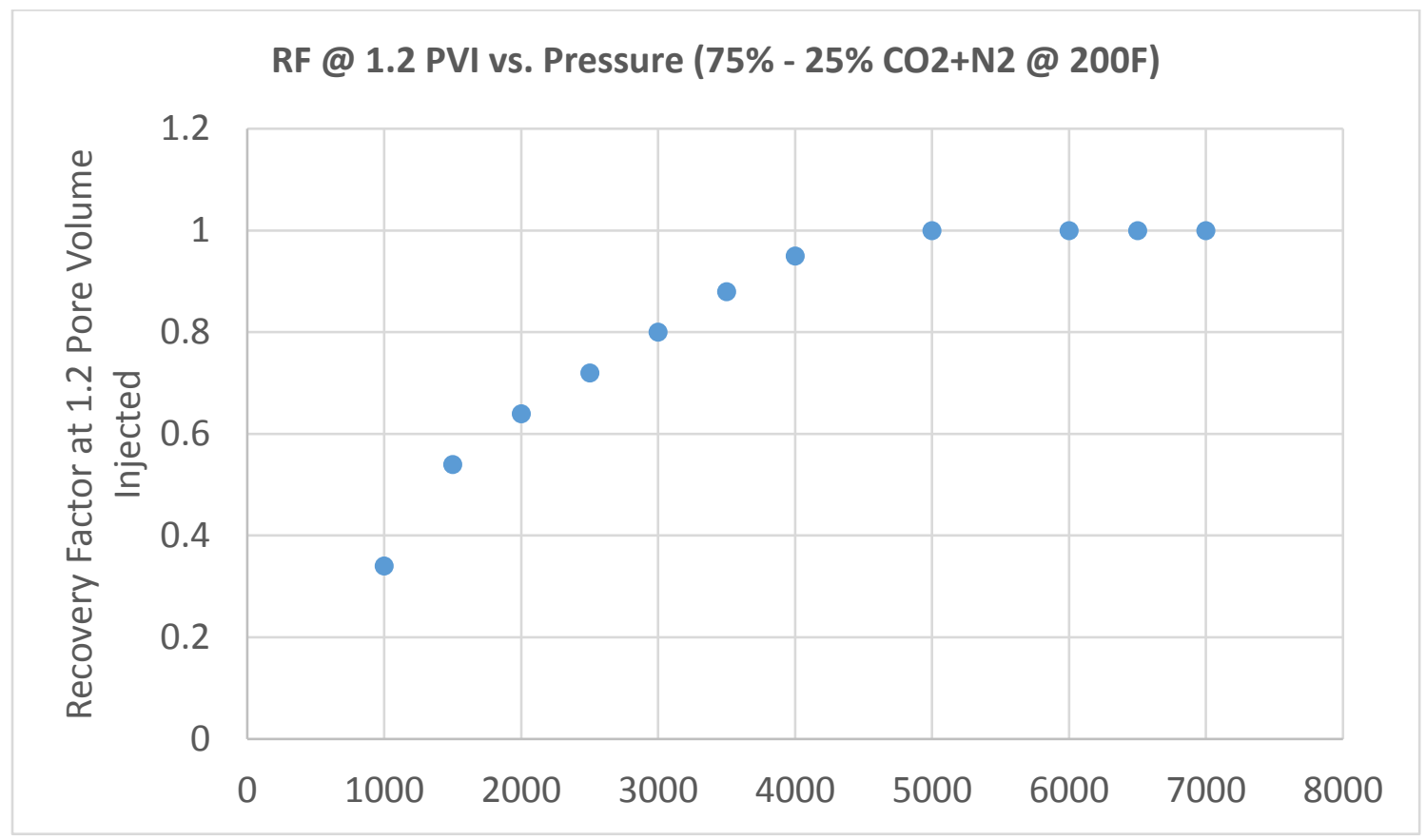

Figure 3.45 The oil recovery factor of $90 \%$ at 1.2 pore volume injected vs. the pressure (75\% carbon dioxide and 25\% nitrogen at 200F) 


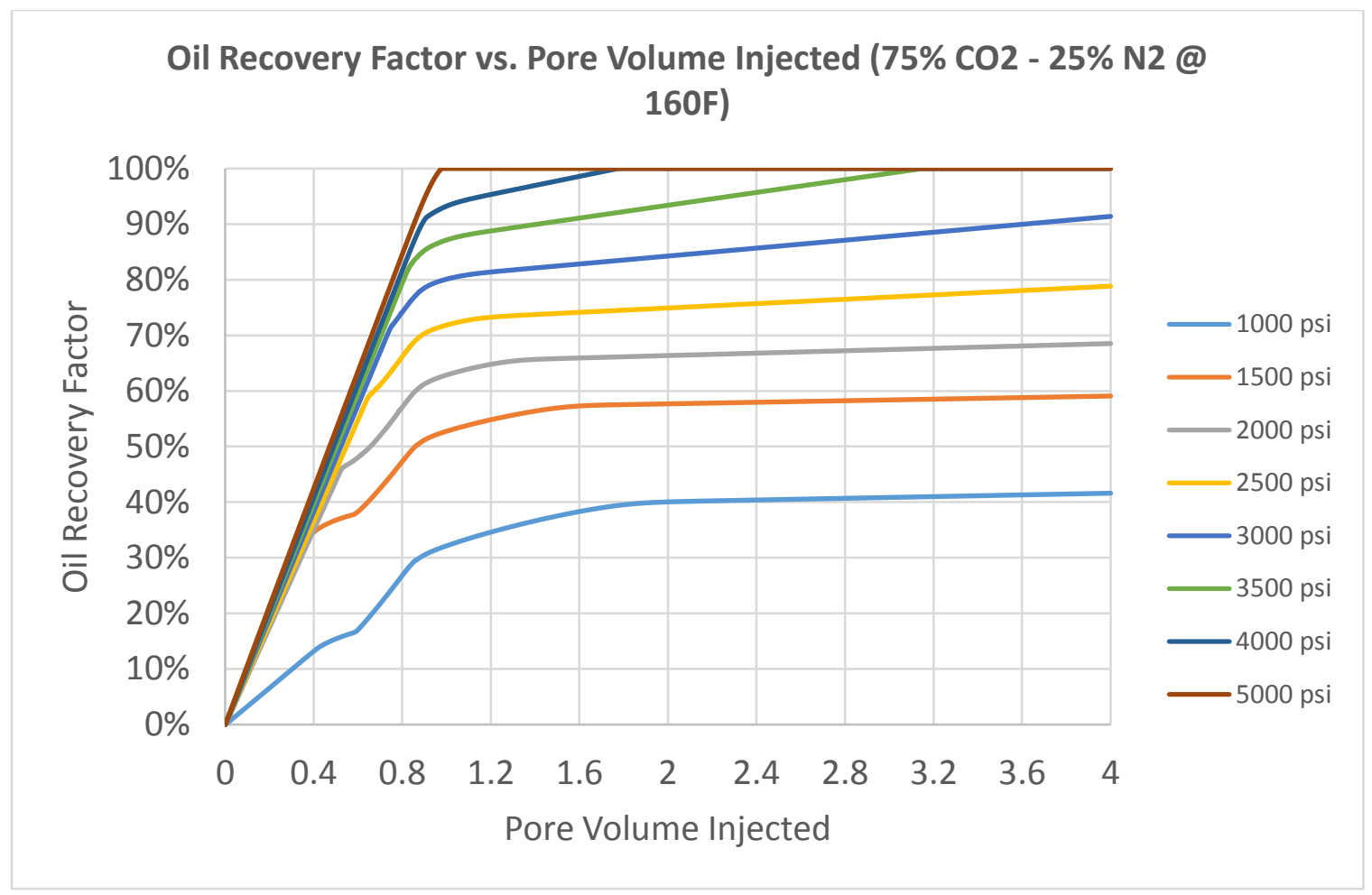

Figure 3.46 Simulator result of the minimum miscibility pressure of $25 \%$ nitrogen and 75\% carbon dioxide at $160 \mathrm{~F}$.

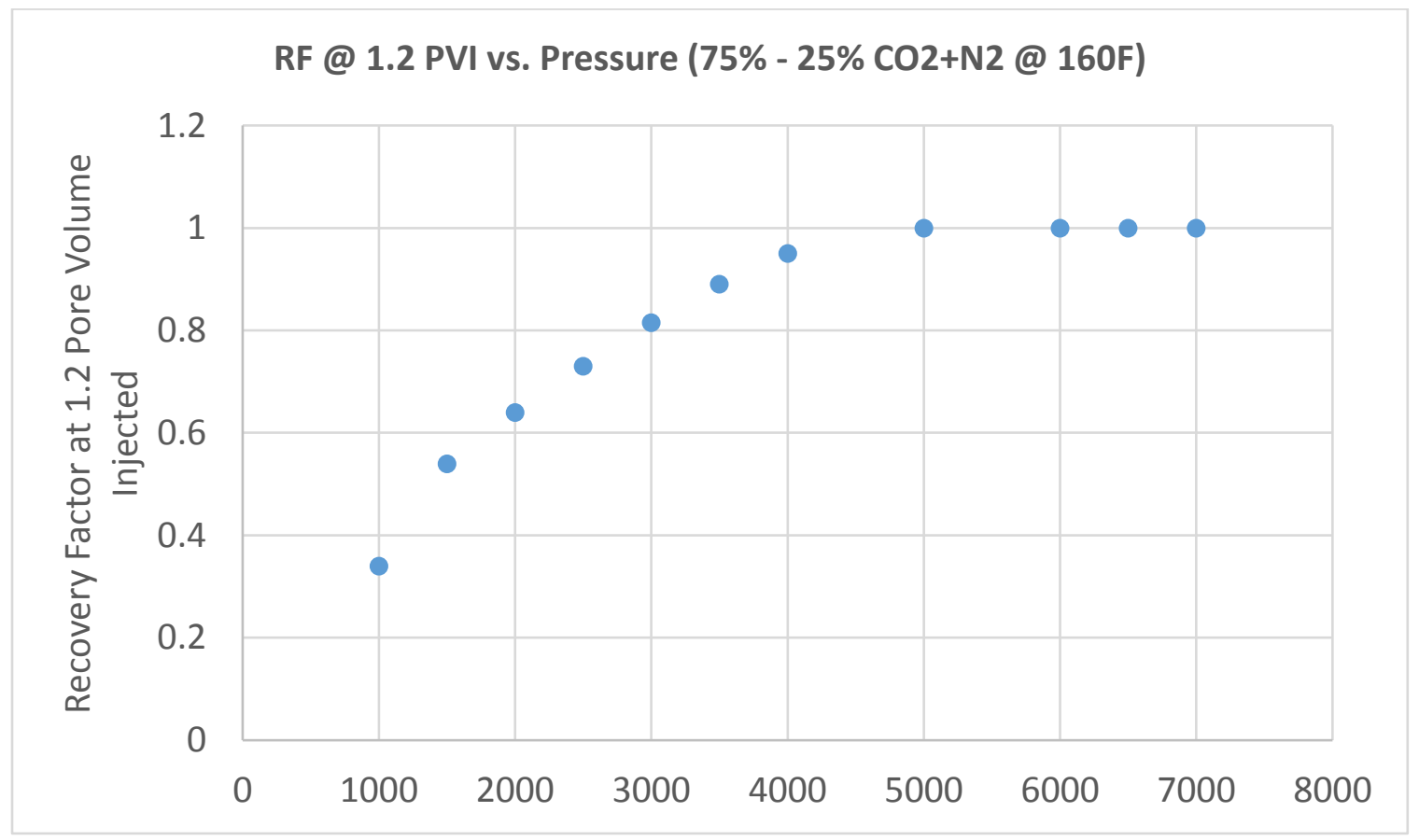

Figure 3.47 The oil recovery factor of $90 \%$ at 1.2 pore volume injected vs. the pressure (75\% carbon dioxide and 25\% nitrogen at 160F) 


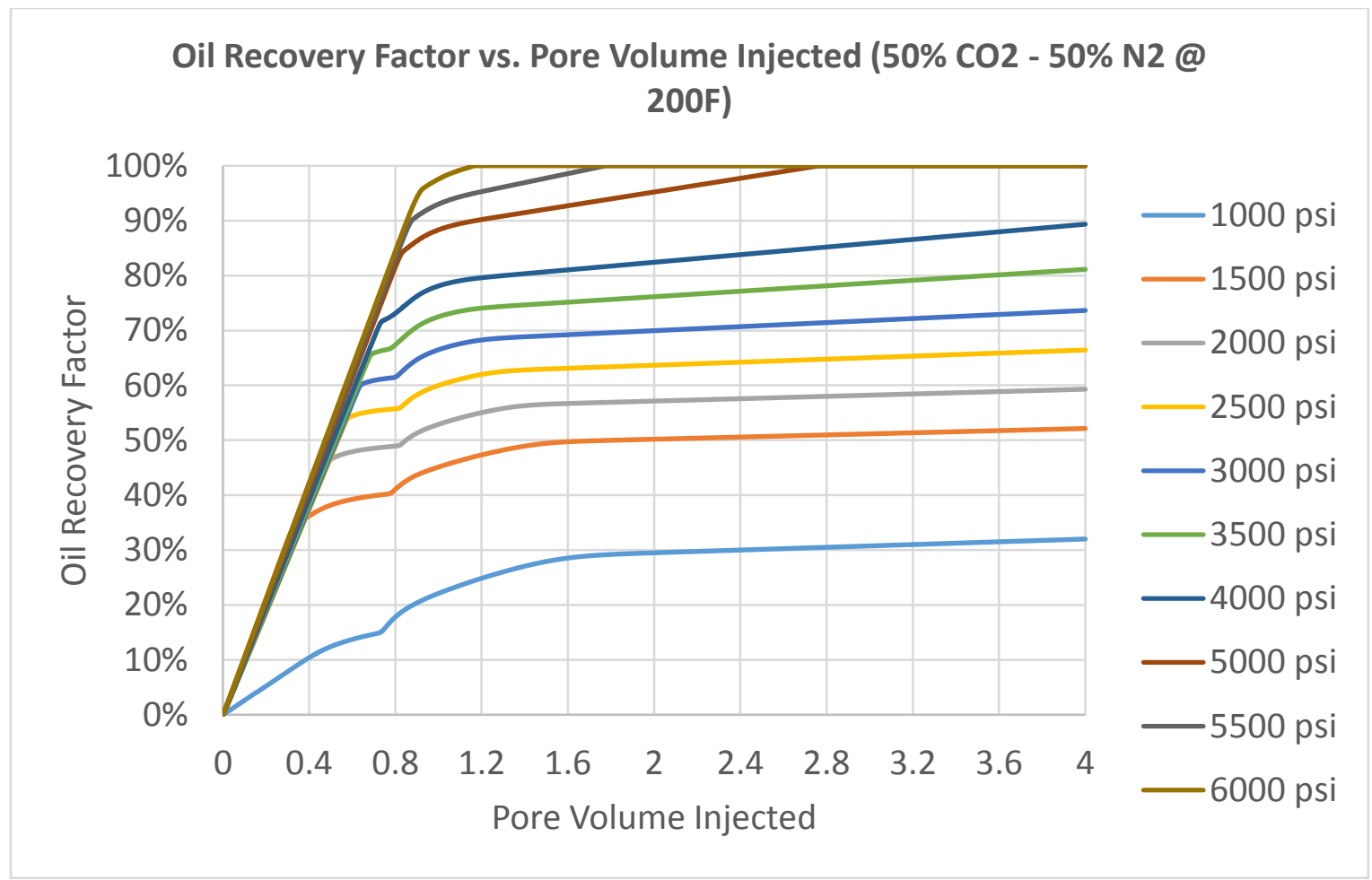

Figure 3.48 Simulator result of the minimum miscibility pressure of 50\% nitrogen and $50 \%$ carbon dioxide at $200 F$

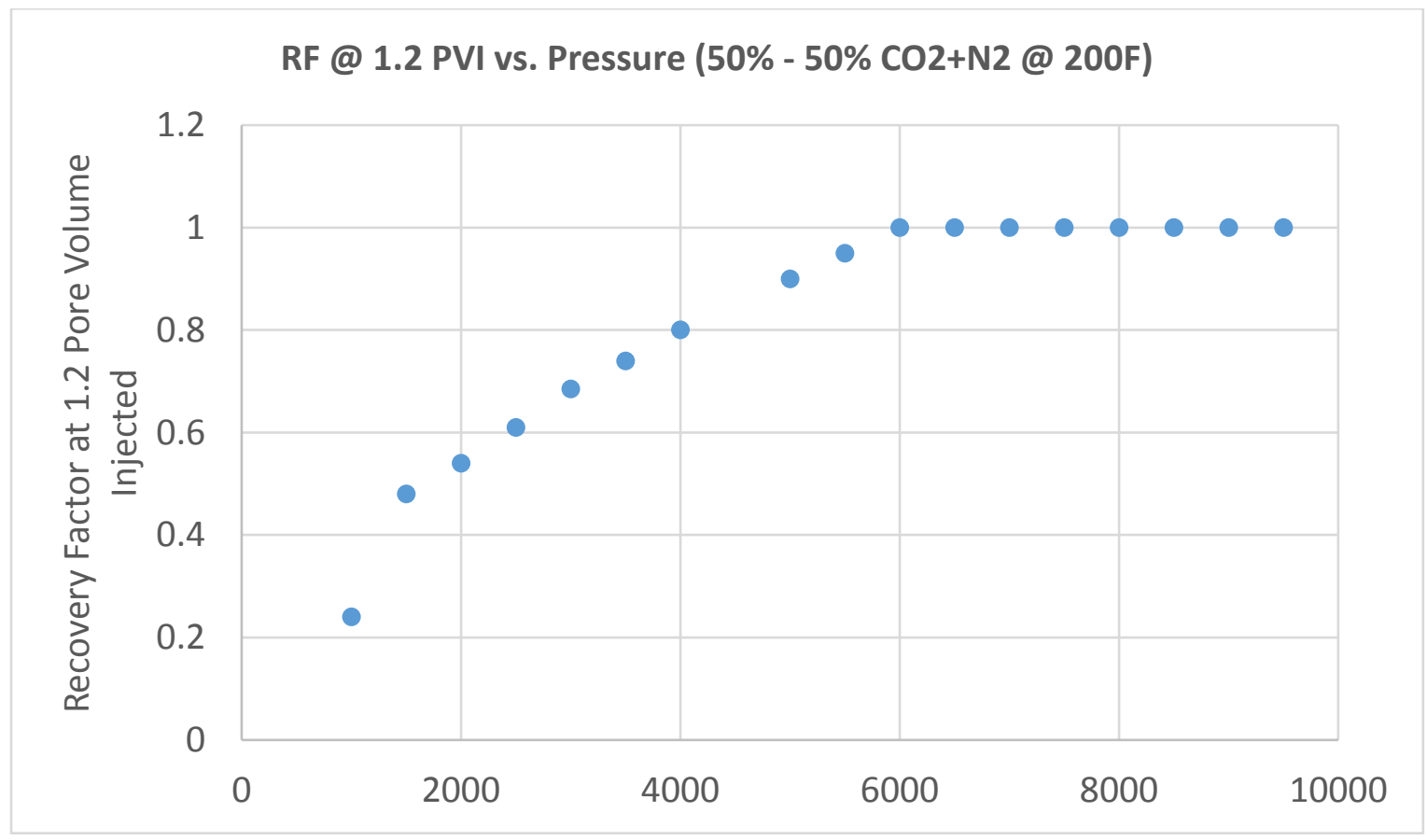

Figure 3.49 The oil recovery factor of $90 \%$ at 1.2 pore volume injected vs. the pressure (75\% carbon dioxide and 25\% nitrogen at 200F) 


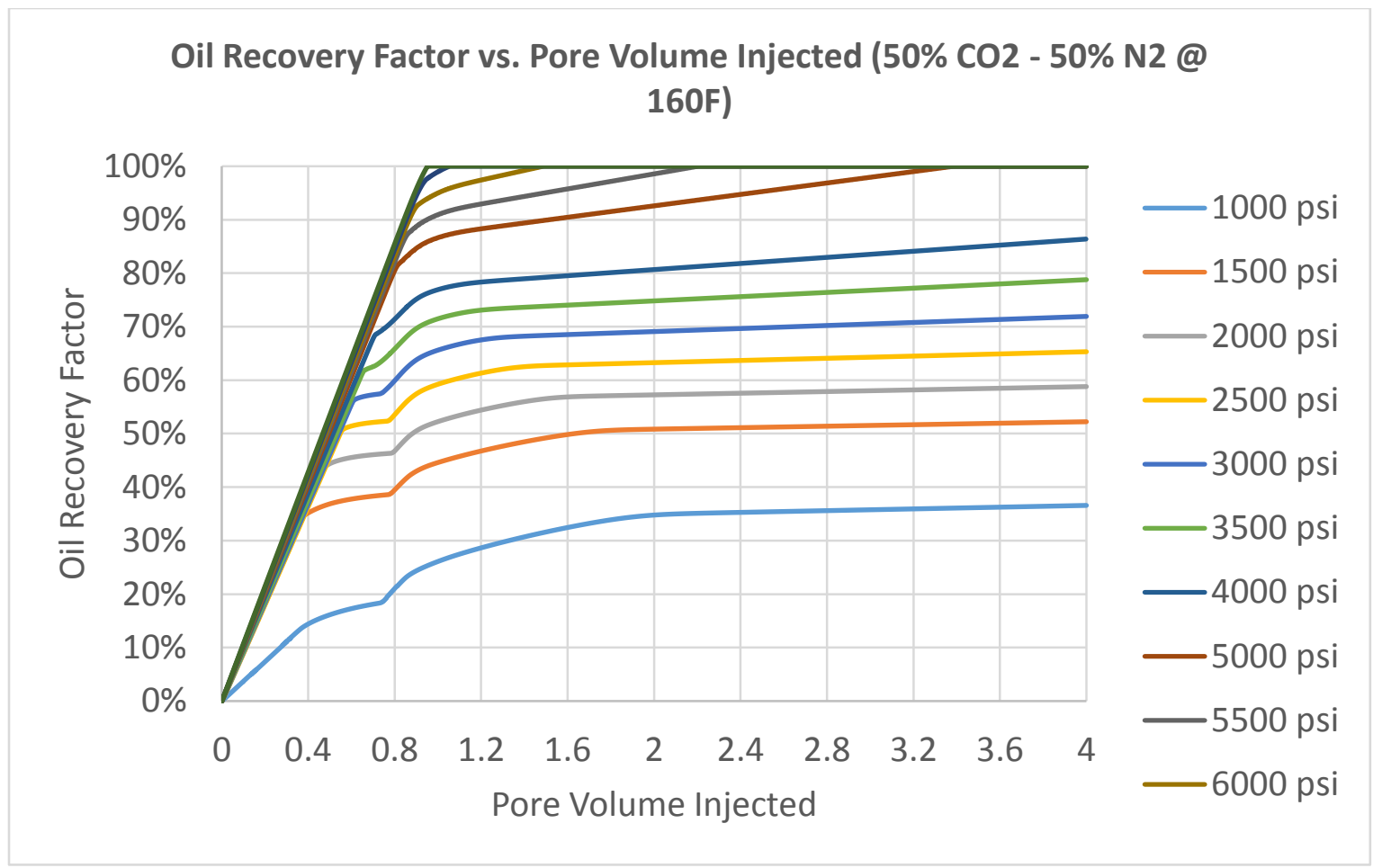

Figure 3.50 Simulator result of the minimum miscibility pressure of 50\% nitrogen and $50 \%$ carbon dioxide at 160F.

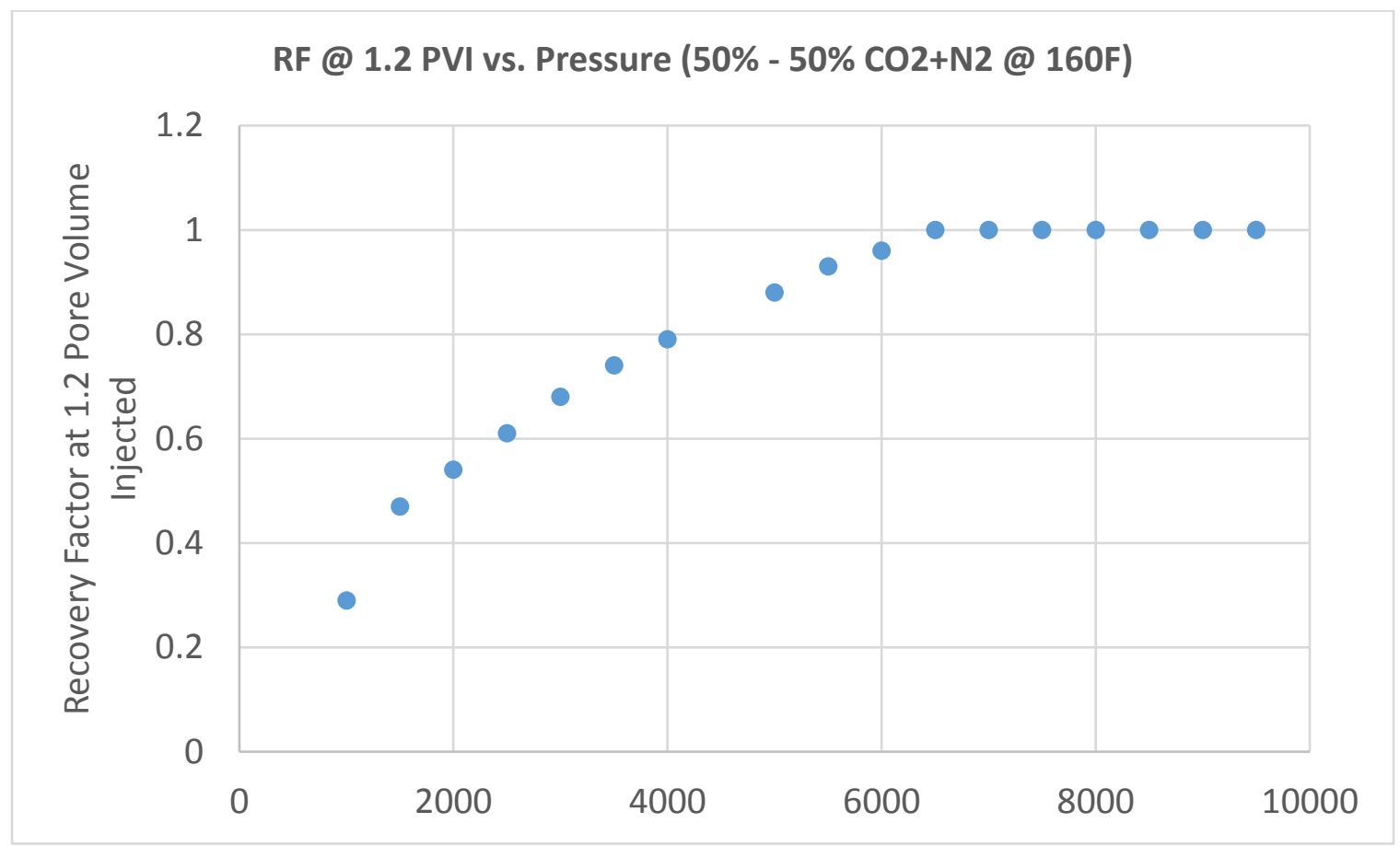

Figure 3.51 The oil recovery factor of $90 \%$ at 1.2 pore volume injected vs. the pressure (50\% carbon dioxide and 50\% nitrogen at 160F) 


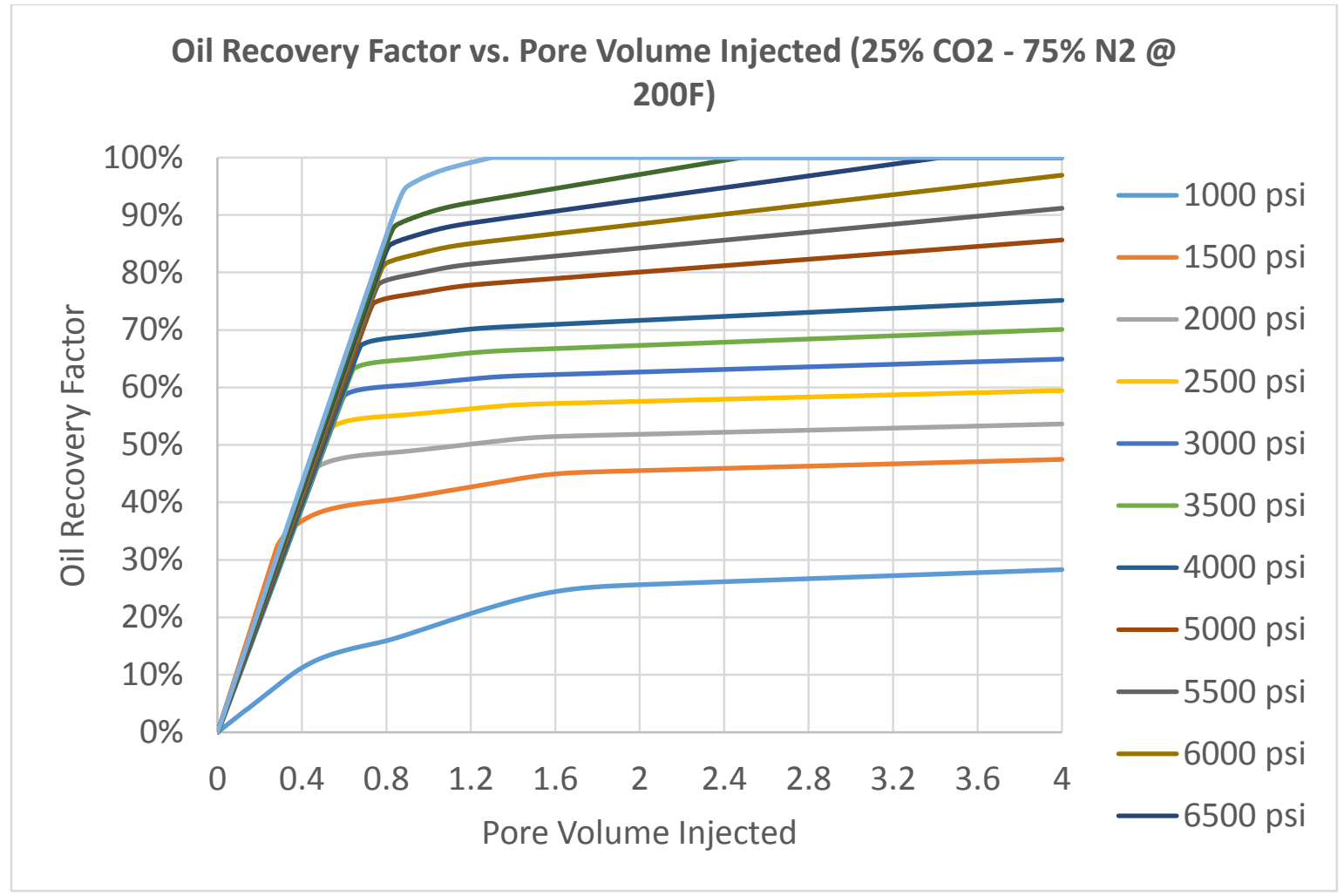

Figure 3.52 Simulator result of the minimum miscibility pressure of $75 \%$ nitrogen and $25 \%$ carbon dioxide at $200 \mathrm{~F}$

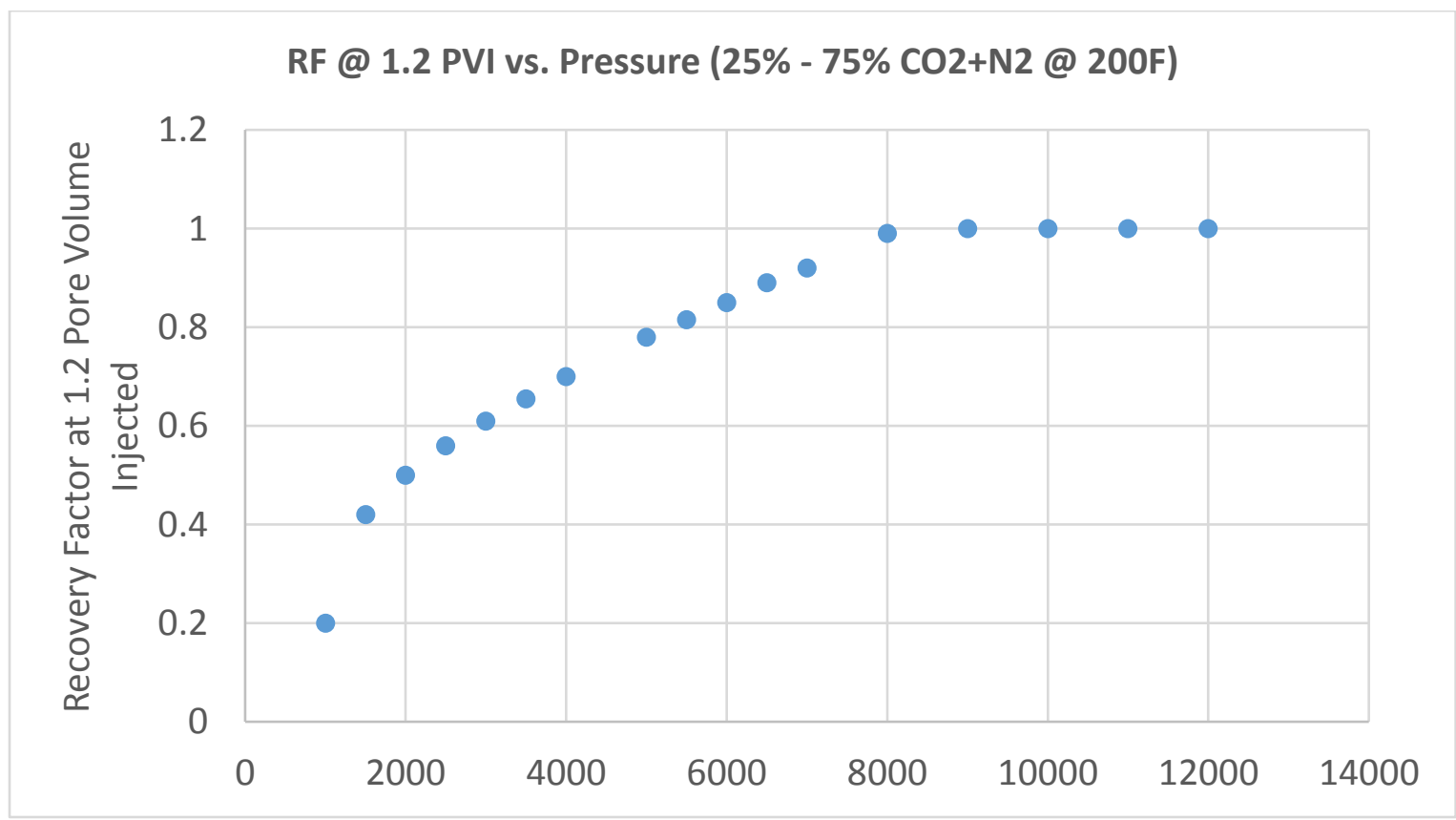

Figure 3.53 The oil recovery factor of $90 \%$ at 1.2 pore volume injected vs. the pressure (25\% carbon dioxide and $75 \%$ nitrogen at 200F) 


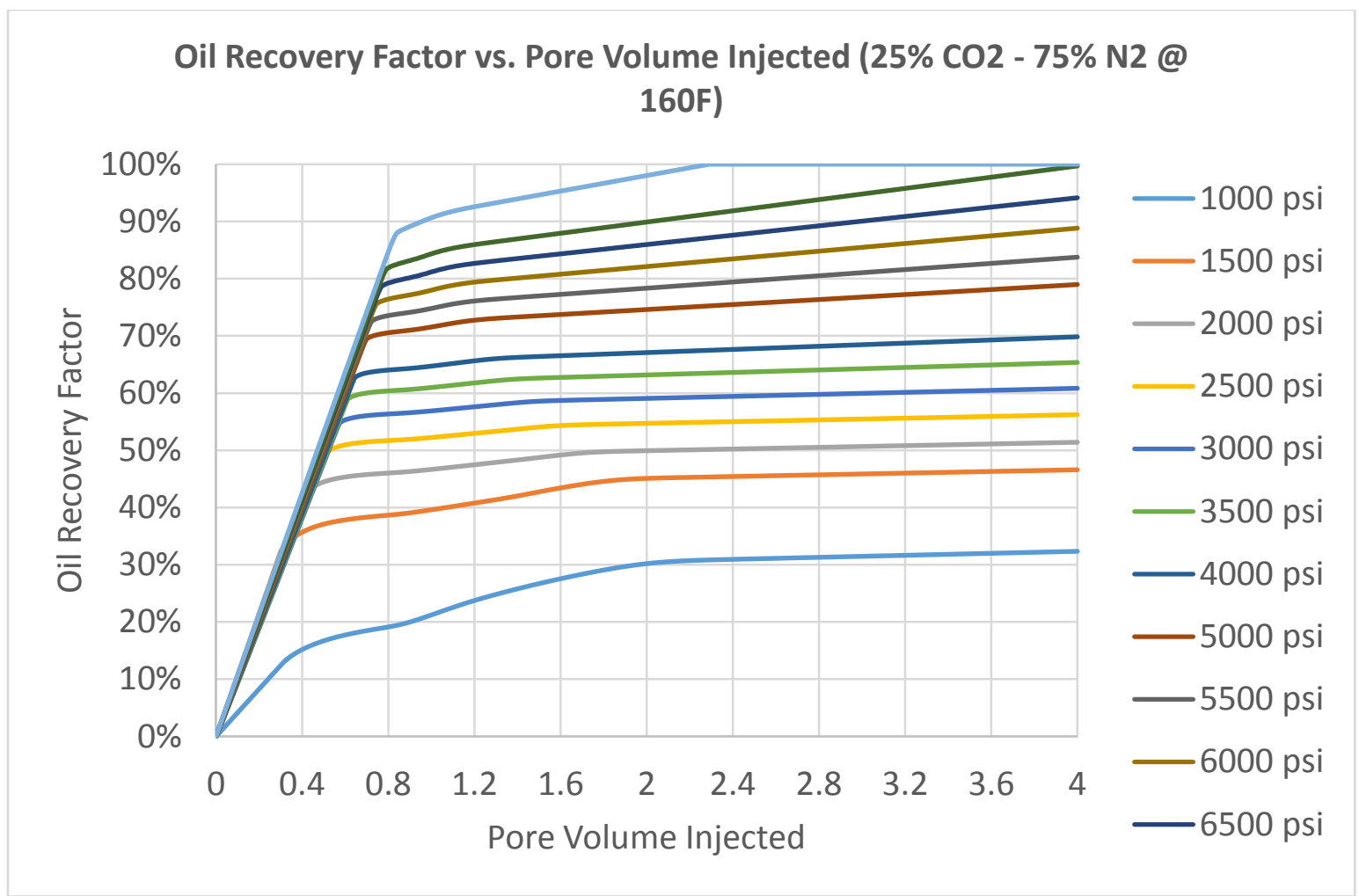

Figure 3.54 Simulator result of the minimum miscibility pressure of $75 \%$ nitrogen and $25 \%$ carbon dioxide at $160 \mathrm{~F}$.

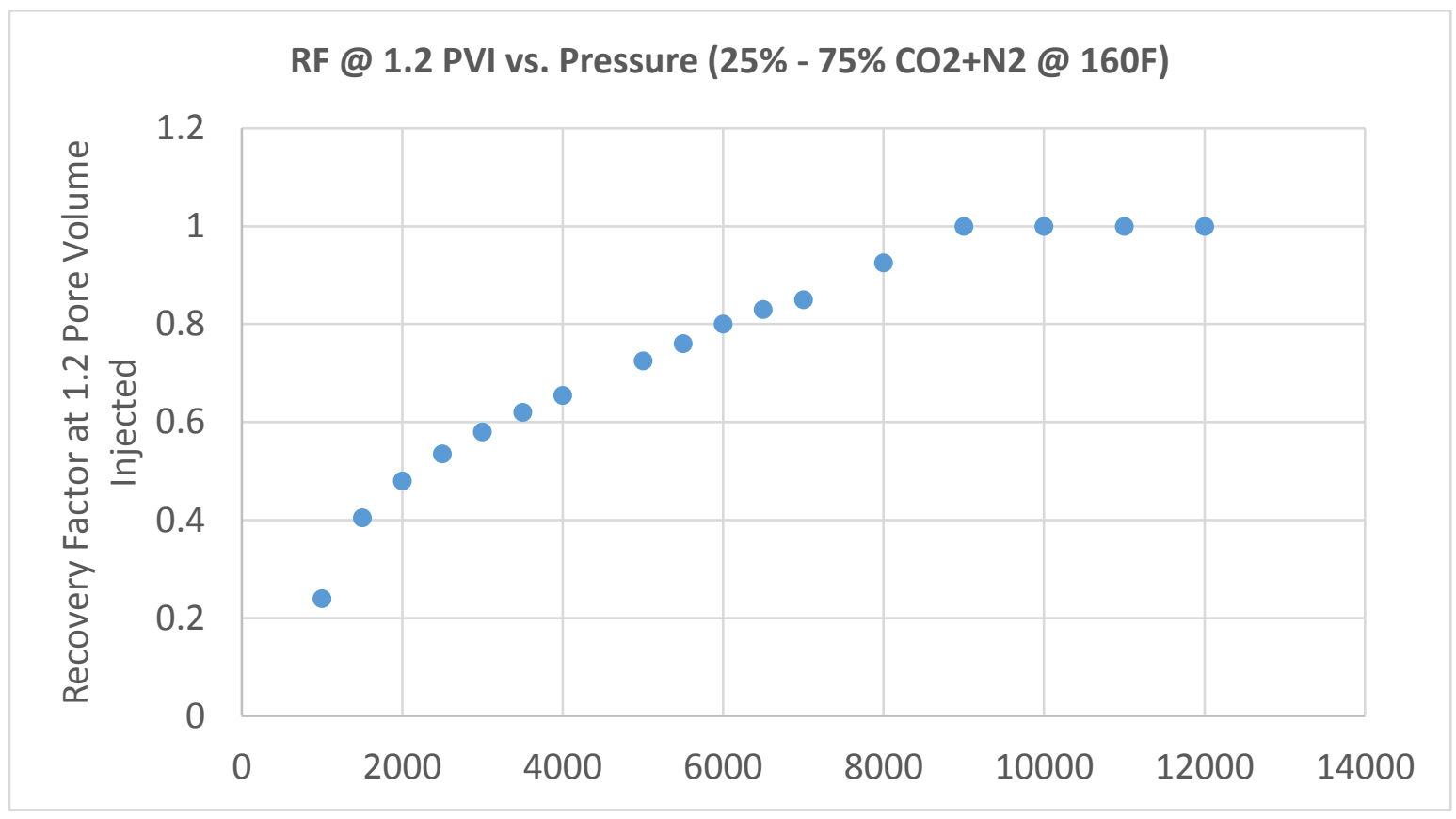

Figure 3.55 The oil recovery factor of $90 \%$ at 1.2 pore volume injected vs. the pressure (25\% carbon dioxide and $75 \%$ nitrogen at 160F) 


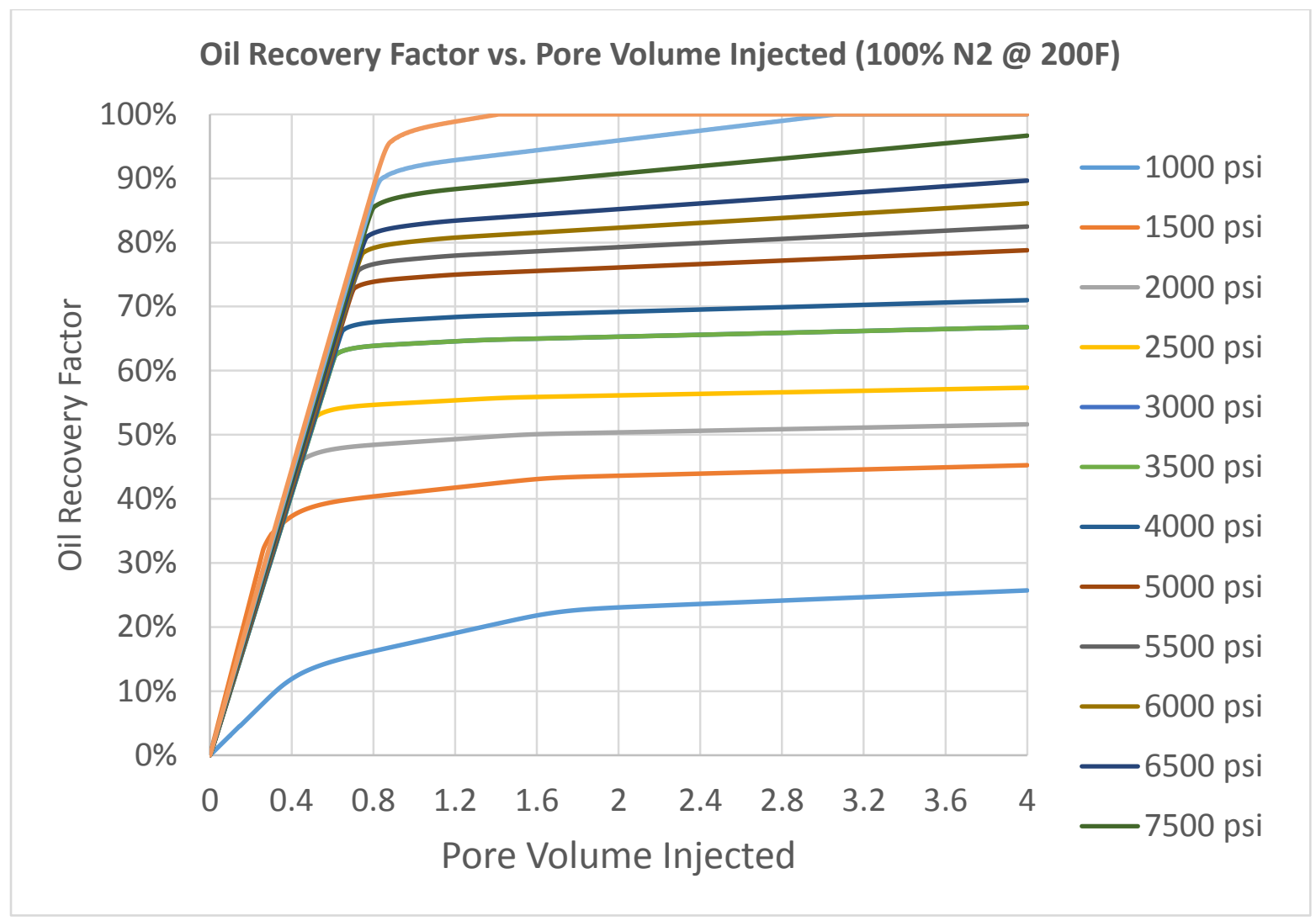

Figure 3.56 Simulator result of the minimum miscibility pressure of $100 \%$ nitrogen at $200 F$

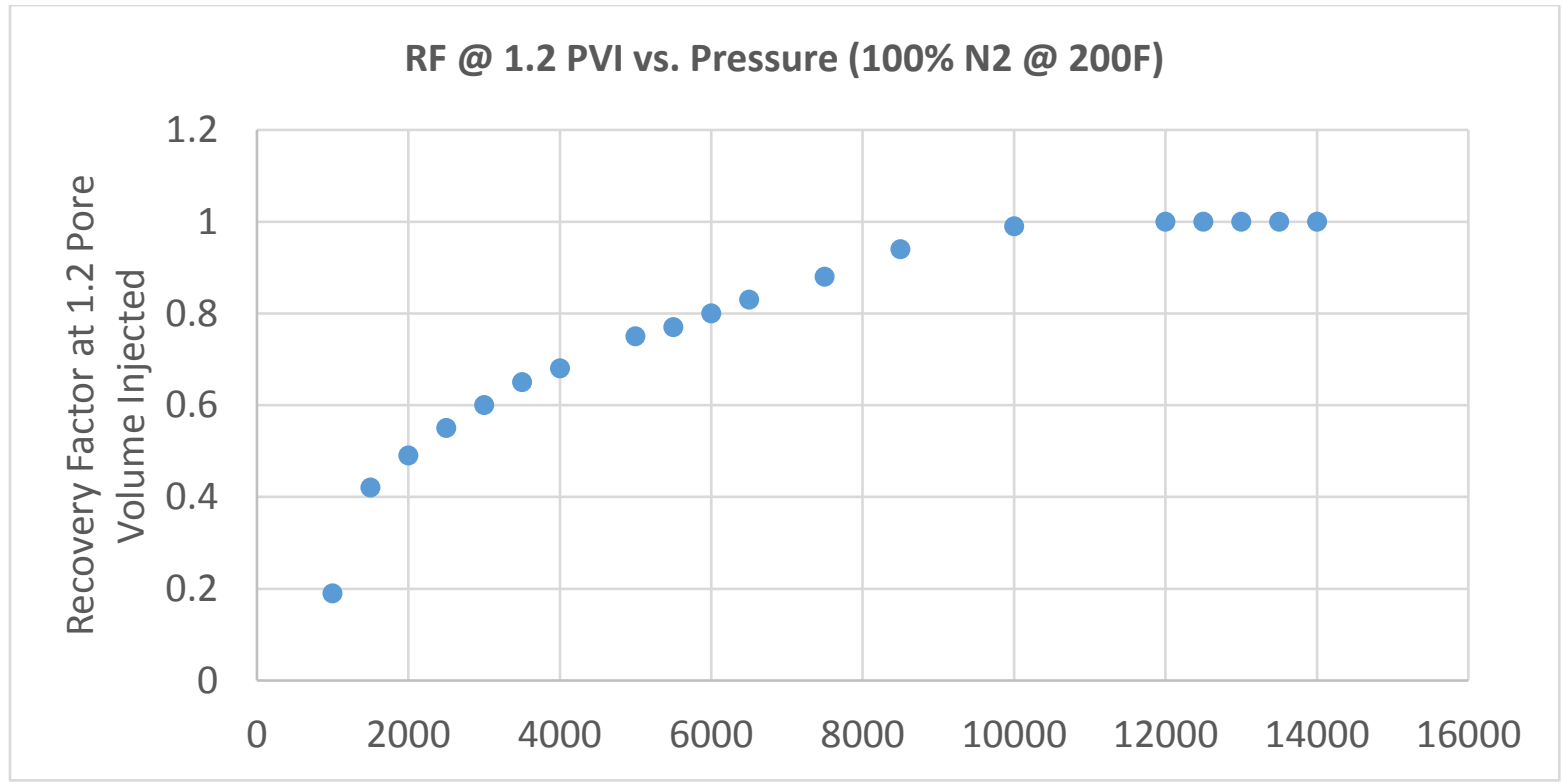

Figure 3.57 The oil recovery factor of $90 \%$ at 1.2 pore volume injected vs. the pressure (100\% nitrogen at 200F) 


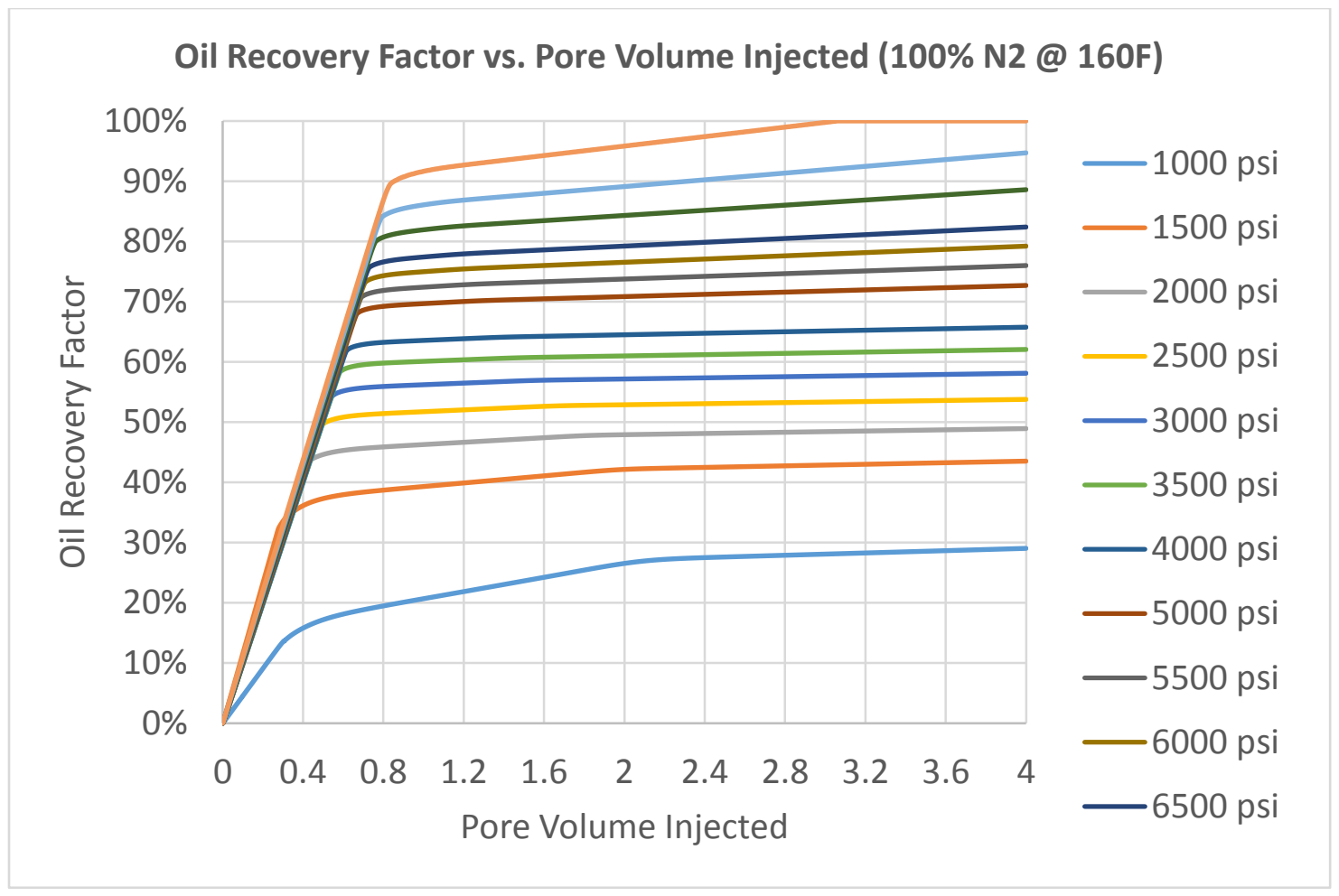

Figure 3.58 Simulator result of the minimum miscibility pressure of $100 \%$ nitrogen at $250 F$

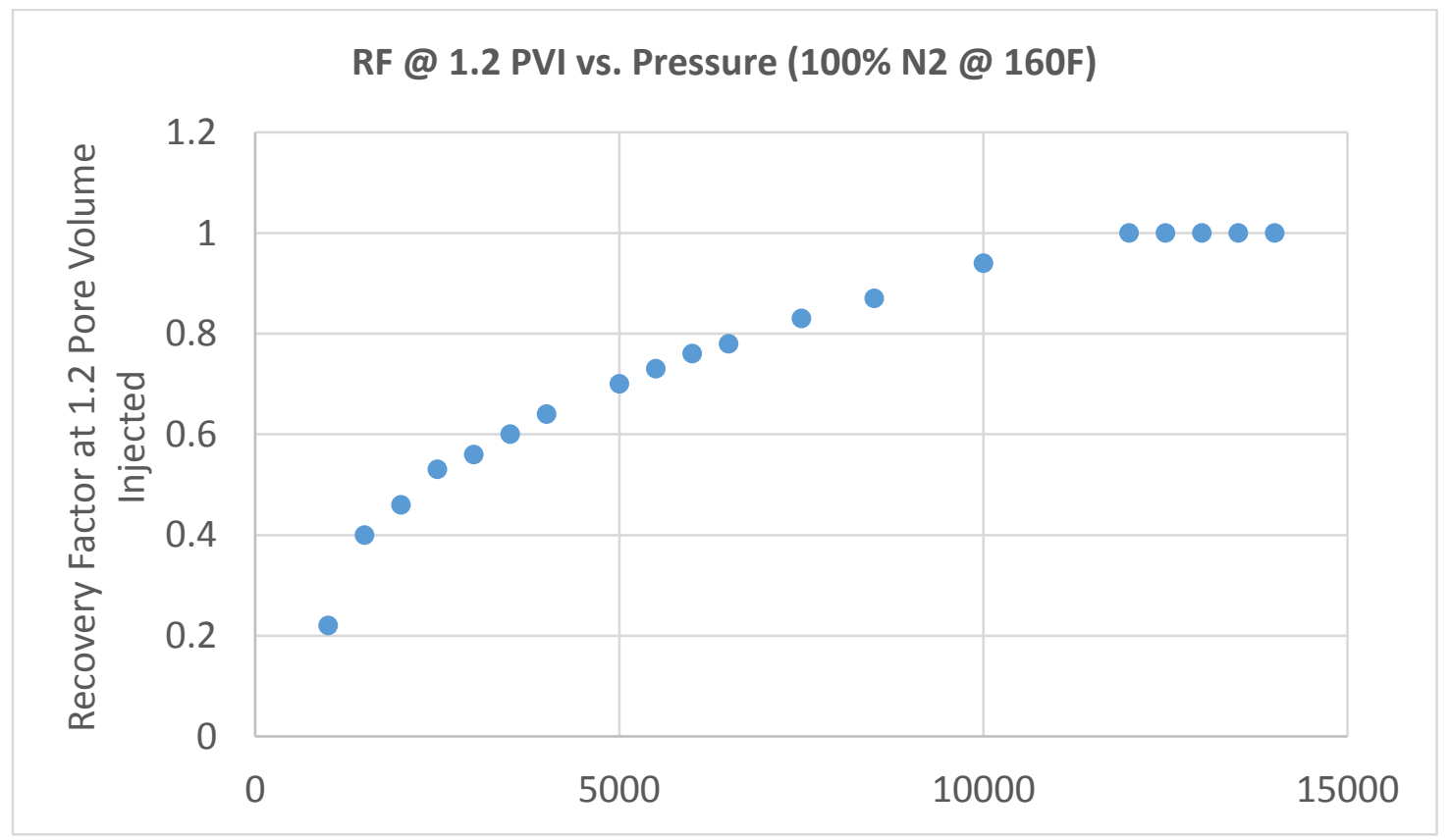

Figure 3.59 The oil recovery factor of $90 \%$ at 1.2 pore volume injected vs. the pressure (100\% nitrogen at 160F) 
Table 3.3 Carbon dioxide - lean gas mixture' minimum miscible pressure at 160F, 200F, and $250 F$

\begin{tabular}{|c|c|c|c|c|c|c|}
\hline \multicolumn{2}{|c|}{ Gas Injection Compactions } & MMP @ 160 F & MMP @ 200 F & MMP @ 250 F \\
\hline CO2 & C1 & C2 & Total & Model & Model & Model \\
\hline $0 \%$ & $98 \%$ & $2 \%$ & $100 \%$ & 5182 & 4786 & 4250 \\
\hline $30 \%$ & $68 \%$ & $2 \%$ & $100 \%$ & 4286 & 4125 & 3889 \\
\hline $50 \%$ & $48 \%$ & $2 \%$ & $100 \%$ & 3625 & 3625 & 3500 \\
\hline $80 \%$ & $18 \%$ & $2 \%$ & $100 \%$ & 2909 & 3000 & 3091 \\
\hline $100 \%$ & $0 \%$ & $0 \%$ & $100 \%$ & 2688 & 2800 & 2875 \\
\hline
\end{tabular}

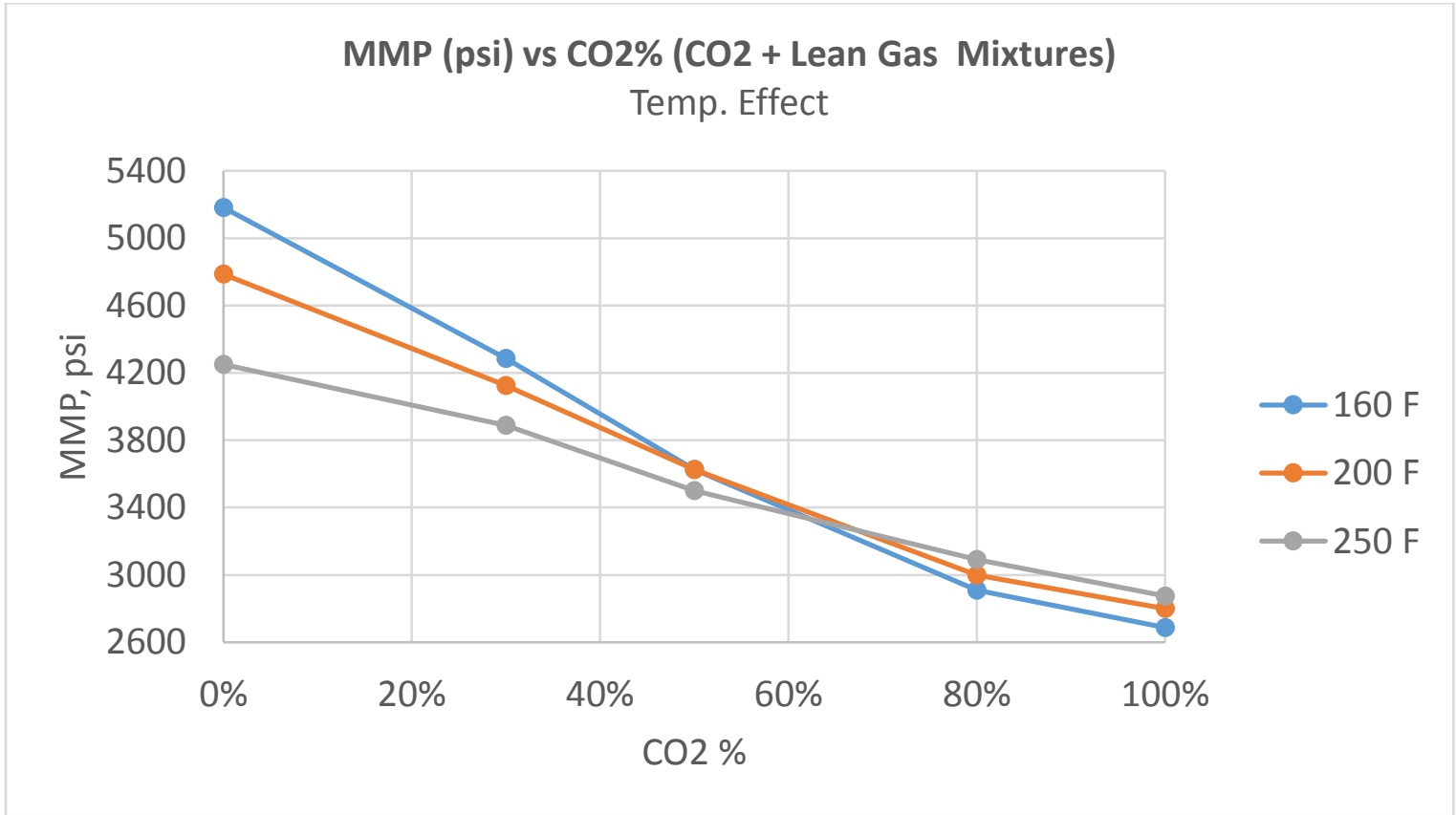

Figure 3.60 Carbon dioxide \% as a function of the minimum miscibility pressure (lean gas-carbon dioxide) with different temperatures. 
Table 3.4 Carbon dioxide - nitrogen mixture' minimum miscible pressure at 160F, 200F, and $250 F$

\begin{tabular}{|c|c|c|c|c|c|}
\hline \multicolumn{2}{|c|}{ Gas Injection Compactions } & MMP @ 160 F & MMP @ 200 F & MMP @ 250 F \\
\hline CO2 & N2 & Total & Model & Model & Model \\
\hline $0 \%$ & $100 \%$ & $100 \%$ & 9143 & 7833 & 6375 \\
\hline $25 \%$ & $75 \%$ & $100 \%$ & 7667 & 6667 & 5583 \\
\hline $50 \%$ & $50 \%$ & $100 \%$ & 5200 & 5000 & 4667 \\
\hline $75 \%$ & $25 \%$ & $100 \%$ & 3583 & 3643 & 3563 \\
\hline $100 \%$ & $0 \%$ & $100 \%$ & 2688 & 2800 & 2875 \\
\hline
\end{tabular}

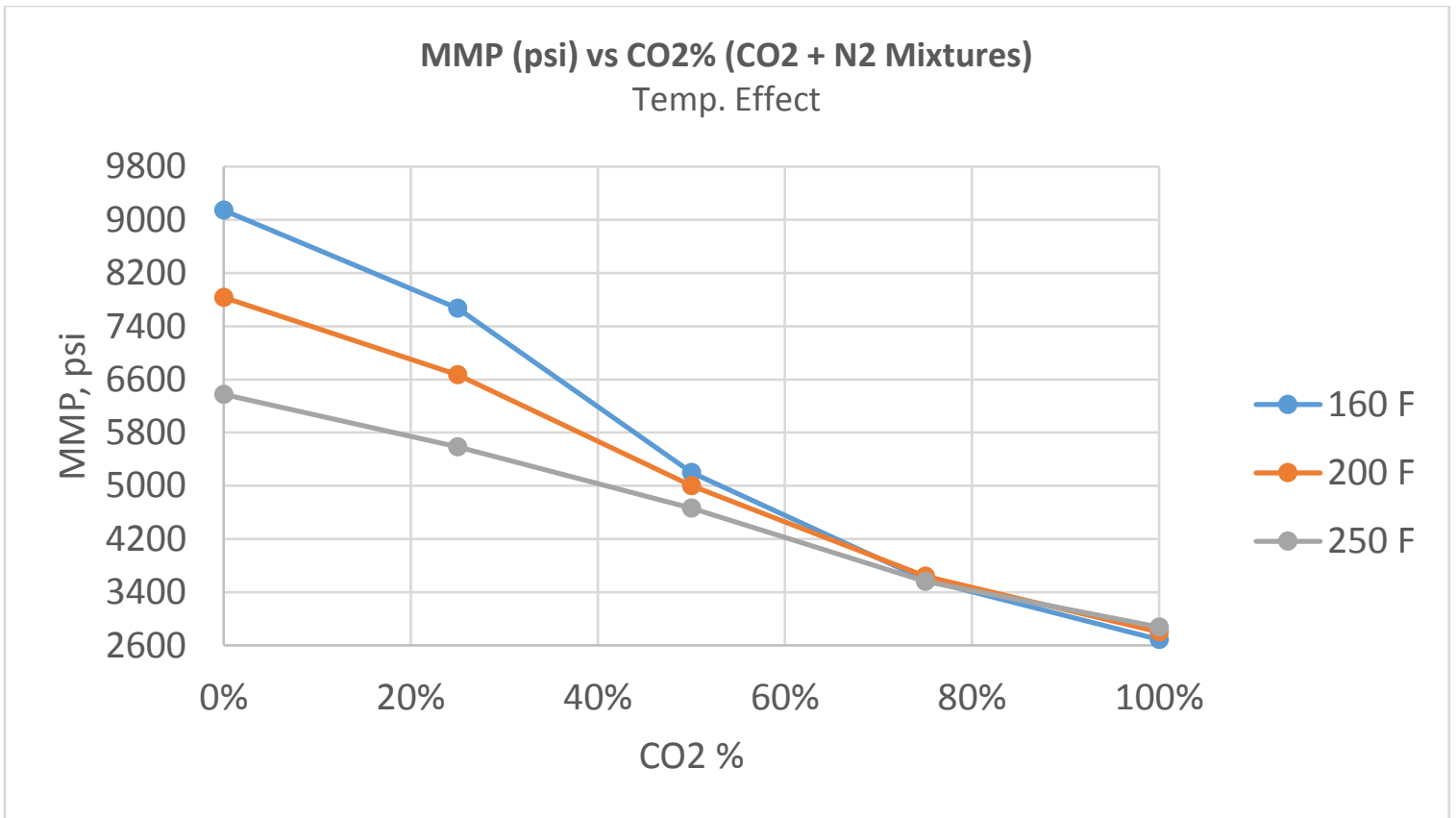

Figure 3.61 Carbon dioxide \% as a function of the minimum miscibility pressure (nitrogen-carbon dioxide) with different temperatures. 


\section{CHAPTER IV}

\section{DISCUSSION AND PROJECT APPLICATION}

\subsection{Discussion.}

Based on the criteria of the $90 \%$ oil recovery at 1.2 pore volume injected, the minimum miscibility pressure values were measured in the third chapter. One of the goals of this project is to find an answer to the following question: is mixing two gases together a good solution for gas injection project when the total amount of a certain gas is not available? Figure (4.1) shows that the minimum miscibility pressure can be lowered when carbon dioxide is added to the $100 \%$ lean gas.

Lean gas is re-injected form what is already produced from the production wells; however, carbon dioxide could be captured, stored, and transferred, which add extra cost to the gas injection project. If half of the carbon dioxide amount is used to be mixed with lean gas, the cost of the gas injection projects drops. In terms of minimum miscibility pressure, $50 \%$ carbon dioxide with $50 \%$ lean hydrocarbon gas can be considered as a good replacement of using $100 \%$ carbon dioxide. However, when $50 \%$ carbon dioxide is mixed with $50 \%$ nitrogen, the difference in the minimum miscibility pressure between the $50 \%-\% 50$ case to the $100 \%$ carbon dioxide is high, as its shown if figure (4.2). This big difference shows that using $50 \%$ lean hydrocarbon gas instead of $50 \%$ nitrogen to be mixed with $50 \%$ carbon dioxide is a better option in terms of minimum miscibility pressure value. However, mixing $25 \%$ nitrogen to $75 \%$ carbon dioxide can be considered as good replacement to the $100 \%$ carbon dioxide if the not 


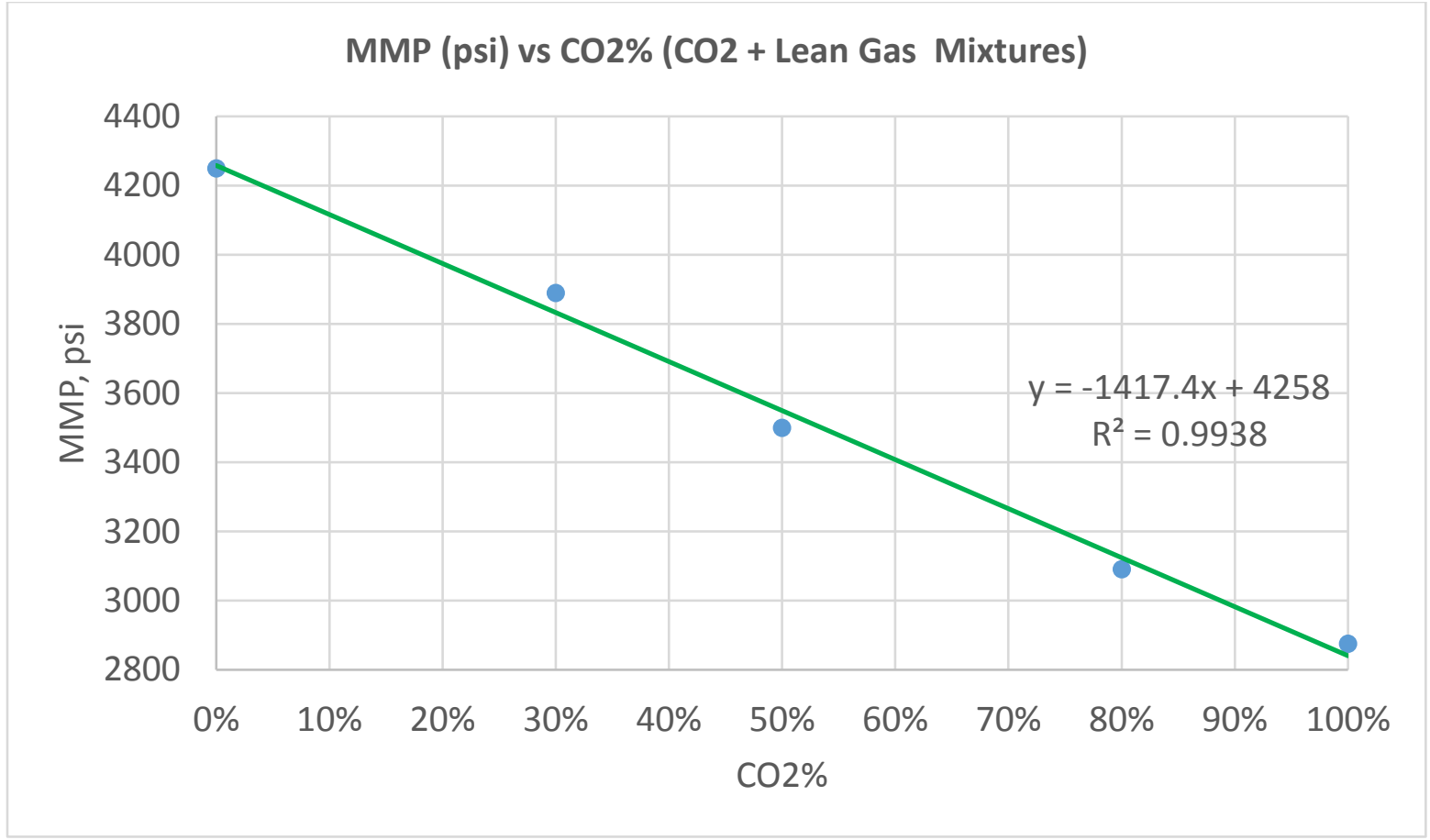

Figure 4.1 Carbon dioxide \% as a function of the minimum miscibility pressure (lean gascarbon dioxide)

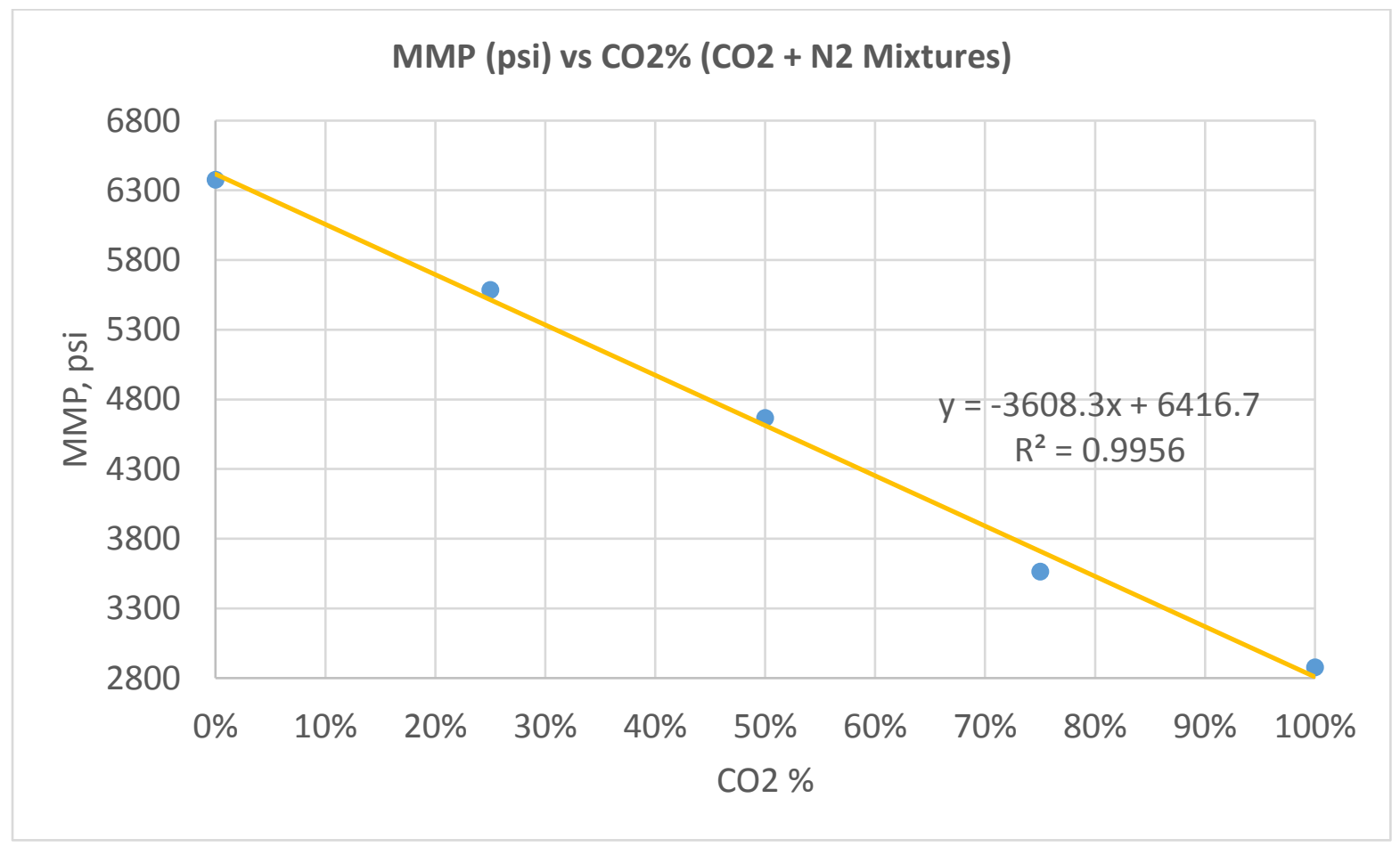

Figure 4.2 Carbon dioxide \% as a function of the minimum miscibility pressure (nitrogencarbon dioxide) 
In this part of the project, only five cases are compared based on the amount of the oil produced when 1.2 pore volume is injected (at 12 hours). The five gas injected compositions are summarized in figure (4.3) with their minimum miscibility pressure. From figure (4.4), the amount of oil recovered at 1.2 pore volume injected of using carbon dioxide only is the highest amount of all of the other injected gas mixtures followed by the gas mixture of lean gas only. Using nitrogen in general gives the lowest amount of oil produced, especially when $100 \%$ nitrogen is used. When $50 \%$ carbon dioxide is used with $50 \%$ lean hydrocarbon gas, a decent amount oil is produced. In other words, the injected gas composition of $50 \%$ carbon dioxide with $50 \%$ of lean hydrocarbon gas has a good oil produced with a low minimum miscibility pressure.

The amount of gas injected to achieve a given produced oil is also important. In figure (4.5), the amount of oil produced for each of the five cases is summarized at 1.2 pore volume injected. For an easier compression, the amount of gas injected was measured for all of the five gas mixtures that is needed to produce a fixed amount of oil (30 SCC), as its shown in figure (4.5). Then, the ratio of the amount of gas needed to the total oil produced (30 SCC in this case) is calculated. The lower the ratio is, the less amount of gasses is needed; hence, it is economically better.

The amount of gas injected is high when carbon dioxide is used as a $100 \%$. Moreover, using $100 \%$ lean gas requires a large amount of gas injected. Using $100 \%$ nitrogen or $50 \%$ nitrogen with $50 \%$ carbon dioxide to produce 30 SCC oil needs only less amount of total gas injected; however, the long period of time needed to produce 30 SCC of oil when nitrogen is used as an injected gas makes the total cost of the gas 
injection project high. For a good choice, $50 \%$ carbon dioxide and $50 \%$ lean hydrocarbon gas is a good choice in terms of the amount of total gas injected. Table (6) summarizes the results of the total gas injected and the amount of gas needed of each component in the injected gas mixture of the five cases. Also, the results of the ratio, the total gas injected to the total oil produced, are summarized in the same table.

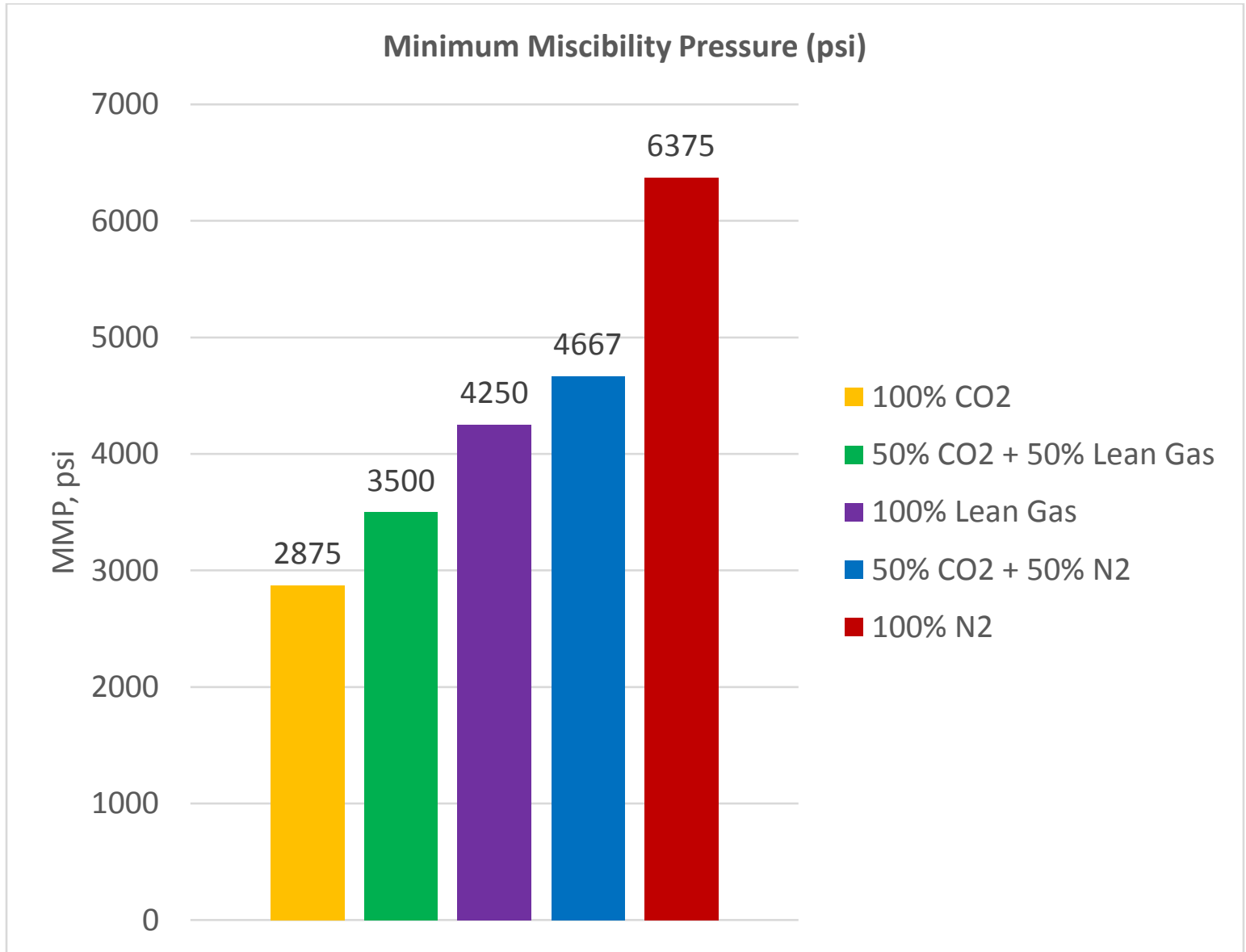

Figure 4.3 Summary of the five gas injected composition with their minimum miscibility pressure 


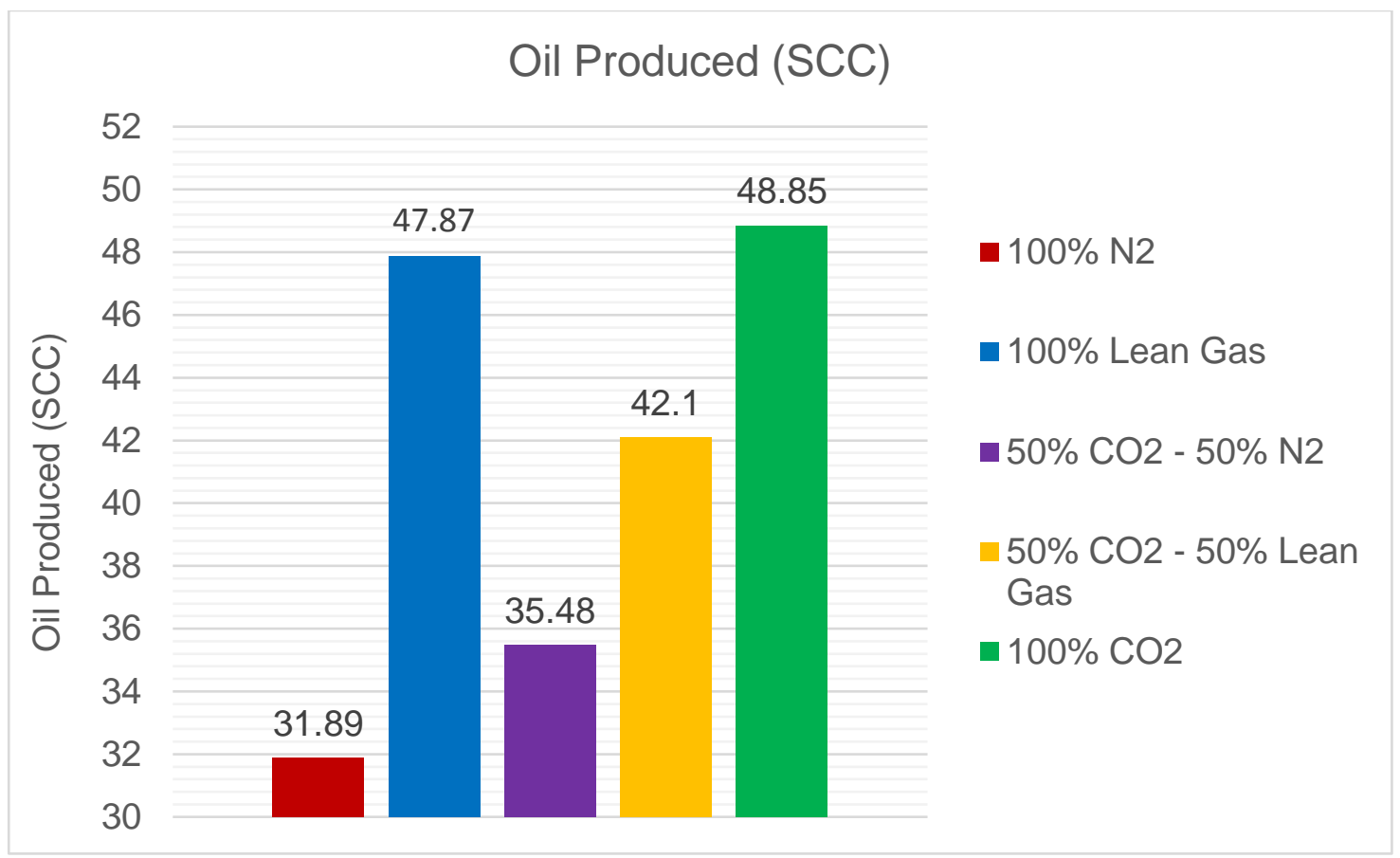

Figure 4.4 the amount oil recovered at 1.2 injected pore volume for all of the five injected gas mixture.

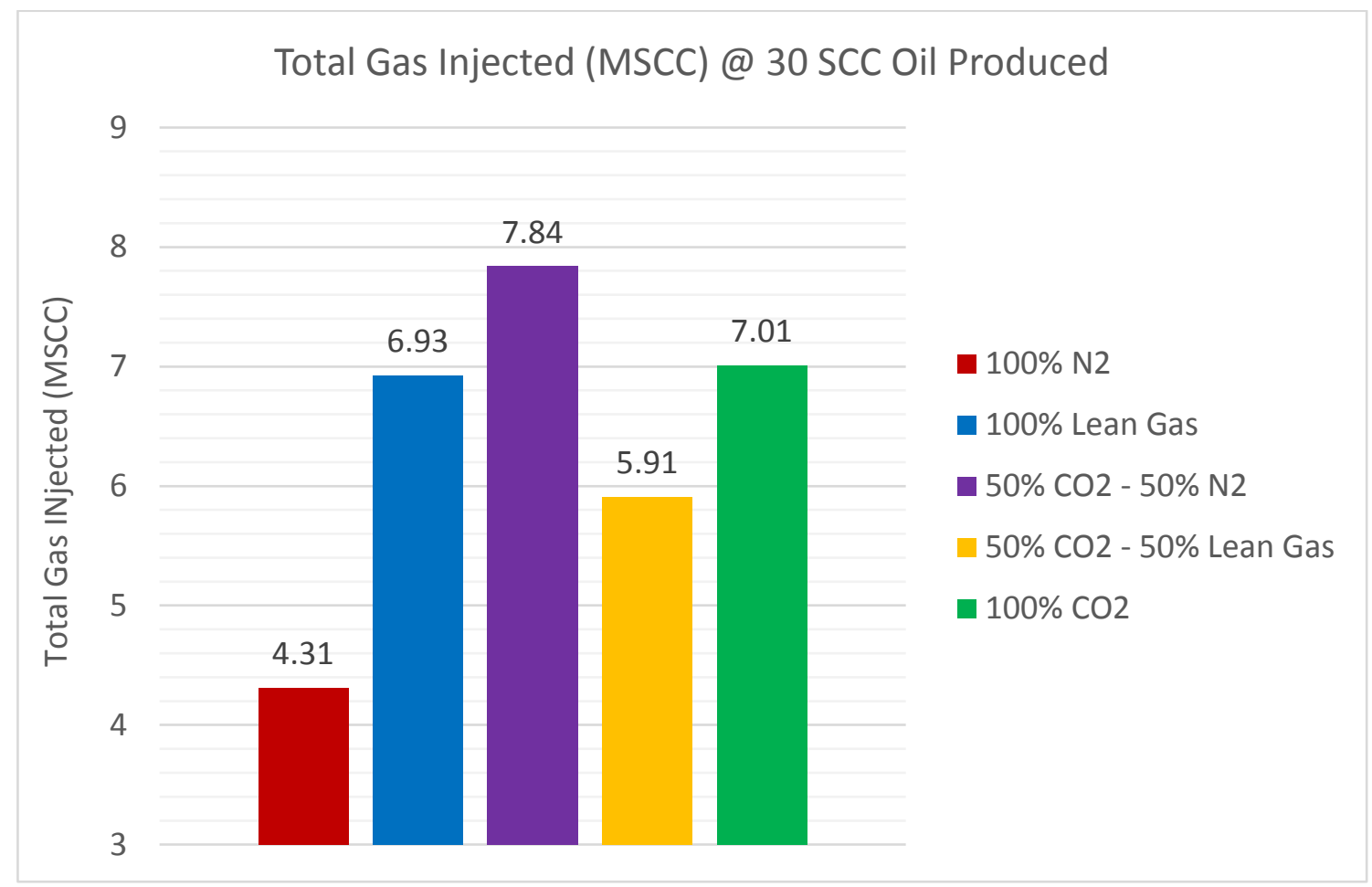

Figure 4.5 The amount of gas injected for all of the five gas mixtures that is needed to produce a fixed amount of oil (30 SCC) 
Table 4.1 Summary of the results of the total gas injected and the amount of gas needed of each component in the injected gas mixture of the five cases

\begin{tabular}{|c|c|c|c|c|c|c|c|c|c|c|}
\hline \multirow{2}{*}{$\mathrm{CO} 2$} & \multirow{2}{*}{ C1 } & \multirow{2}{*}{$\mathrm{C} 2$} & \multirow{2}{*}{ N2 } & \multirow{2}{*}{ Total } & \multirow{2}{*}{$\begin{array}{c}\text { TGI at } 30 \text { MSCC } \\
\text { Oil Produced }\end{array}$} & \multirow{2}{*}{$\begin{array}{l}\text { Ratio } \\
\text { GI/NP }\end{array}$} & $\mathrm{CO} 2$ & C1 & $\mathrm{C} 2$ & N2 \\
\hline & & & & & & & \multicolumn{4}{|c|}{ MSCC } \\
\hline $0 \%$ & $98 \%$ & $2 \%$ & $0 \%$ & $100 \%$ & 6.93 & 0.23 & 0.00 & 6.79 & 0.14 & 0.00 \\
\hline $0 \%$ & $0 \%$ & $0 \%$ & $100 \%$ & $100 \%$ & 4.31 & 0.14 & 0.00 & 0.00 & 0.00 & 4.31 \\
\hline $50 \%$ & $48 \%$ & $2 \%$ & $0 \%$ & $100 \%$ & 5.91 & 0.20 & 2.95 & 2.84 & 0.12 & 0.00 \\
\hline $50 \%$ & $0 \%$ & $0 \%$ & $50 \%$ & $100 \%$ & 7.84 & 0.26 & 3.92 & 0.00 & 0.00 & 3.92 \\
\hline $100 \%$ & $0 \%$ & $0 \%$ & $0 \%$ & $100 \%$ & 7.01 & 0.23 & 7.01 & 0.00 & 0.00 & 0.00 \\
\hline
\end{tabular}

\subsection{Project Application.}

Based on the discussion above, the best gas injected mixture can be decided based on: the minimum miscibility pressure value, the total amount of gas injected, the amount of each gas in the injected mixture, and the total oil produced at 1.2 pore volume injected. Table (7) helps to simplify the results. Based on the results, the best option that can be used as an injected gas mixture is the $50 \%$ carbon dioxide and the $50 \%$ lean hydrocarbon gas due to the following reasons:

1. Closest minimum miscibility pressure to $100 \%$ carbon dioxide ( 2875 psi) compared to the other compositions of 3500 psi. Hence, less pressure is needed to injected the gas at the surface.

2. It needs a very small amount of total gas injected of $5.91 \mathrm{MSCC}$, which is generally accepted compared to the other gas injected mixtures.

3. It has an average oil produced when 1.2 pore volume is injected

All of these are factors of choosing $50 \%$ carbon dioxide and $50 \%$ lean hydrocarbon gas in gas injection project for this specific oil composition. When the 
whole amount of carbon dioxide is available, or the cost of having the whole amount of carbon dioxide is not economical, lean hydrocarbon gas can be mixed with the available amount of carbon dioxide for a good performance.

Table 4.2 Minimum miscibility pressure result simplification.

\begin{tabular}{|c|c|c|c|c|c|c|c|}
\hline $\mathrm{CO} 2$ & C1 & C2 & N2 & Total & MMP & $\begin{array}{c}\text { Oil Produced @ } \\
1.2 \text { IPV }\end{array}$ & $\begin{array}{c}\text { Total Gas } \\
\text { Injected (MSCC) } \\
\text { @ } 30 \text { SCC NP }\end{array}$ \\
\hline & & & & & Model & SCC & MSCC \\
\hline $0 \%$ & $98 \%$ & $2 \%$ & $0 \%$ & $100 \%$ & 4250 & $\underline{18.29}$ & 6.93 \\
\hline $0 \%$ & $0 \%$ & $0 \%$ & $100 \%$ & $100 \%$ & 6375 & 11.47 & $\underline{4.31}$ \\
\hline $50 \%$ & $48 \%$ & $2 \%$ & $0 \%$ & $100 \%$ & $\underline{3500}$ & 13.02 & $\underline{5.91}$ \\
\hline $50 \%$ & $0 \%$ & $0 \%$ & $50 \%$ & $100 \%$ & 4667 & 11.79 & 7.84 \\
\hline $100 \%$ & $0 \%$ & $0 \%$ & $0 \%$ & $100 \%$ & 2875 & 17.32 & 7.01 \\
\hline
\end{tabular}




\section{CHAPTER V}

\section{CONCLUSION AND RECOMMENDATIONS}

\subsection{Conclusion.}

Minimum Miscible Pressure Conclusion:

- The lowest minimum miscible pressure is obtained when $100 \%$ carbon dioxide is used as an injection gas mixture.

- The highest minimum miscibility pressure was obtained when $100 \%$ nitrogen is used as an injected gas mixture.

- The use of $50 \%$ nitrogen mixed with $50 \%$ carbon dioxide also gives a high minimum miscibility pressure.

- A gas mixture of $100 \%$ lean gas has a higher minimum miscible pressure than $100 \%$ carbon dioxide gas mixture, but it is less than a $100 \%$ nitrogen gas mixture.

50\% Carbon dioxide and 50\% lean gas conclusion:

- Even though its environmental to inject carbon dioxide and lowering its concentration from the atmosphere; re-injecting lean hydrocarbon gas could be more economical than injecting carbon dioxide due to the cost of capturing and storing it.

- Adding amount of lean gas to the available amount of carbon dioxide drops the cost of the gas injection project. 
- $\quad 50 \%$ carbon dioxide with $50 \%$ lean hydrocarbon gas or can be considered as a good replacement of using $100 \%$ carbon dioxide.

50\% Carbon dioxide and 50\% nitrogen conclusion:

- For this given oil composition, when $50 \%$ carbon dioxide is mixed with $50 \%$ nitrogen, the difference in the minimum miscible pressure between the $50 \%-50 \%$ case to the $100 \%$ carbon dioxide is high.

- This big difference shows that using $50 \%$ lean hydrocarbon gas instead of $50 \%$ nitrogen mixed with $50 \%$ carbon dioxide is a better option in terms of minimum miscible pressure value.

- $\quad 75 \%$ carbon dioxide with $25 \%$ nitrogen can be considered as a good replacement of using $100 \%$ carbon dioxide.

Oil production conclusion:

- The amount of oil recovered at 1.2 pore volume injected of using carbon dioxide only is the highest.

- When $50 \%$ carbon dioxide is used with $50 \%$ lean hydrocarbon gas, a good amount of oil is produced.

- Using nitrogen in general gives the lowest amount of oil produced, especially when $100 \%$ nitrogen is used.

\section{$\underline{\text { Total gas injected conclusion: }}$}

- The amount of gas injected is high when carbon dioxide is used as a $100 \%$. 
- $\quad 100 \%$ lean gas requires a large amount of gas injected too.

- Using $100 \%$ nitrogen or $50 \%$ nitrogen with $50 \%$ carbon dioxide to produce 30 SCC oil needs only a few amount of total gas injected.

- Long period of time is needed to produce $30 \mathrm{SCC}$ of oil when nitrogen is used as an injected gas, which makes the total cost of the gas injection project high.

Final gas mixture selection conclusion:

- The best option that can be used as an injected gas mixture is the $50 \%$ carbon dioxide and the $50 \%$ lean hydrocarbon gas due to the following reasons:

1. Closest minimum miscibility pressure to $100 \%$ carbon dioxide (2875 psi) compared to the other compositions of 3500 psi. Hence, less pressure is needed to injected the gas at the surface.

2. It needs a very small amount of total gas injected of $5.91 \mathrm{MSCC}$, which can be considered a good amount compared to the other gas injected mixtures.

3. It has an average oil produced when 1.2 pore volume is injected. 


\subsection{Recommendations.}

- More than 5 gas injection component percentages (100\% - 80\% - 50\% $30 \%-0 \%)$ should be considered; It would give better accuracy of the minimum miscible pressure variation as the gas mixture changes. For example, the following gas injection component percentages (100\% - 90\% - $80 \%-70 \%-60 \%$ etc.) can be used for a better result.

- Using other methods of measuring the minimum miscible pressure rather than using the intersection of the two straight lines for validation purposes.

- Using more temperature points rather than using three points only.

- Studying the effect of changing the oil composition from heavy API oil to a light API oil.

- Conducting slim tube experiment in the lab using nitrogen, carbon dioxide and lean gas- carbon dioxide mixtures to compare to the simulation results.

- Developing a correlation that includes the injected gas mixture's components to a quick approximation of the minimum miscible pressure. 


\section{BIBLIOGRAPHY}

Adel, Imad A., Francisco D. Tovar, and David S. Schechter. "Fast-Slim Tube: A Reliable and Rapid Technique for the Laboratory Determination of MMP in CO2 - Light Crude Oil Systems." SPE Improved Oil Recovery Conference (2016): n. pag. Web.

Ahmadi, Kaveh, and Russell Taylor Johns. "Multiple Mixing-Cell Method for MMP Calculations." SPE Annual Technical Conference and Exhibition (2008): n. pag. Web.

Alomair, Osamah, and Maqsood Iqbal. "CO2 Minimum Miscible Pressure (MMP) Estimation Using Multiple Linear Regression (MLR) Technique." SPE Saudi Arabia Section Technical Symposium and Exhibition (2014): n. pag. Web.

Firoozabadi, Abbas, and Aziz Khalid. "Analysis and Correlation of Nitrogen and Lean-Gas Miscibility Pressure (includes Associated Paper 16463)." SPE Reservoir Engineering 1.06 (1986): 575-82. Web.

Amao, Abiodun Matthew, Shameem Siddiqui, and Habib Menouar. "A New Look at the Minimum Miscibility Pressure (MMP) Determination from Slimtube Measurements." SPE Improved Oil Recovery Symposium (2012): n. pag. Web.

Ayirala, Subhash, and Dandina Rao. "Comparative Evaluation of a New MMP Determination Technique." Proceedings of SPE/DOE Symposium on Improved Oil Recovery (2006): n. pag. Web.

Beare, P., and A. Cockin. "Simulation Analysis of Lean Alternating Rich Gas Injection in a Massive Turbidite Reservoir." Proceedings of SPE Asia Pacific Improved Oil Recovery Conference (1999): n. pag. Web.

Belhaj, Hadi, Hadil Abu Abu Khalifeh, and Khalid Javid. "Potential of Nitrogen Gas Miscible Injection in South East Assets, Abu Dhabi." North Africa Technical Conference and Exhibition (2013): n. pag. Web.

Bonet-Cunha, Luciane. "Technology Focus: EOR Operations (June 2011)." Journal of Petroleum Technology 63.06 (2011): 82. Web.

Bybee, Karen. "EOR/IOR: Displacement Optimization in Hydrocarbon Reservoirs." Journal of Petroleum Technology 56.01 (2004): 45-46. Web.

Dzulkarnain, Iskandar, Mariyamni Bt. Awang, and Ahmad Muzakkir Mohamad.

"Uncertainty in MMP Prediction from EOS Fluid Characterization." SPE Enhanced Oil Recovery Conference (2011): n. pag. Web. 
Eakin, B.e., and F.j. Mitch. "Measurement and Correlation of Miscibility Pressures of Reservoir Oils." Proceedings of SPE Annual Technical Conference and Exhibition (1988): n. pag. Web.

Felber, Betty. "Overview: EOR/IOR (January 2001)." Journal of Petroleum Technology 53.01 (2001): 48. Web.

Firoozabadi, Abbas, and Aziz Khalid. "Analysis and Correlation of Nitrogen and Lean-Gas Miscibility Pressure (includes Associated Paper 16463)." SPE Reservoir Engineering 1.06 (1986): 575-82. Web.

Hagedorn, K.d., and F.m. Orr. "Component Partitioning in CO2/Crude Oil Systems: Effects of Oil Composition on CO2 Displacement Performance." SPE Advanced Technology Series 2.02 (1994): 177-84. Web.

Hanssen, J.e. "Nitrogen as a Low-Cost Replacement for Natural Gas Reinjection Offshore." Proceedings of SPE Gas Technology Symposium (1988): n. pag. Web.

Hite, J. Roger, S.m. Avasthi, and Paul L. Bondor. "Planning Successful EOR Projects." Journal of Petroleum Technology 57.03 (2005): 28-29. Web.

Jiang, Haifeng, Lily Nuryaningsih, and Hertanto Adidharma. "The Influence of O2 Contamination on MMP and Core Flood Performance in Miscible and Immiscible CO2 WAG." SPE Improved Oil Recovery Symposium (2012): n. pag. Web.

Kossack, Charles. "EOR Processes -Miscible Gas Injection." Web.

Mihcakan, Metin. "Minimum Miscibility Pressure, Rising Bubble Apparatus, and Phase Behavior." Proceedings of SPE/DOE Improved Oil Recovery Symposium (1994): n. pag. Web.

Rao, Dandina. "Gas Injection EOR- A New Meaning in the New Millennium." Journal of Canadian Petroleum Technology 40.02 (2001): n. pag. Web.

Sebastian, H.m., and D.d. Lawrence. "Nitrogen Minimum Miscibility Pressures." SPE/DOE Enhanced Oil Recovery Symposium (1992): n. pag. Web.

Alston, R.b., G.p. Kokolis, and C.f. James. "CO2 Minimum Miscibility Pressure: A Correlation for Impure CO2 Streams and Live Oil Systems." Society of Petroleum Engineers Journal 25.02 (1985): 268-74. Web.

Vahidi, Akram, and Ghassem Zargar. "Sensitivity Analysis of Important Parameters Affecting Minimum MiscibilityPressure (MMP) of Nitrogen Injection into 
Conventional Oil Reservoirs." Proceedings of SPE/EAGE Reservoir Characterization and Simulation Conference (2007): n. pag. Web.

Yuan, H., R.t. Johns, A.m. Egwuenu, and B. Dindoruk. "Improved MMP Correlations for CO2 Floods Using Analytical Gas Flooding Theory." SPE/DOE Symposium on Improved Oil Recovery (2004): n. pag. Web. 


\section{APPENDIX A}

-->Simulation of a 10 metre slimtube using lab units

-- 5 components

-- Peng-Robinson EoS

-- Grid dimensions 200x1×1

-- FULLIMP solution method

-- LAB units

-- OIL GAS only, no water

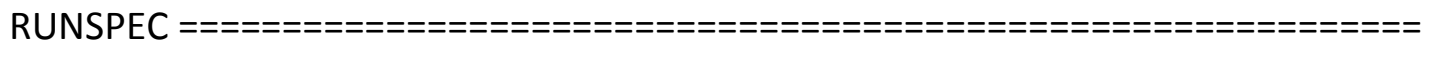

OIL

GAS

FULLIMP

DIMENS

$20011 /$

-- Cartesian co-ord system

CART

-- Units: Lab

$\mathrm{LAB}$

-- Number of components: implies compositional run

COMPS

5 /

MISCIBLE

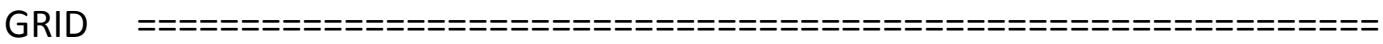

DX

200*5 / 


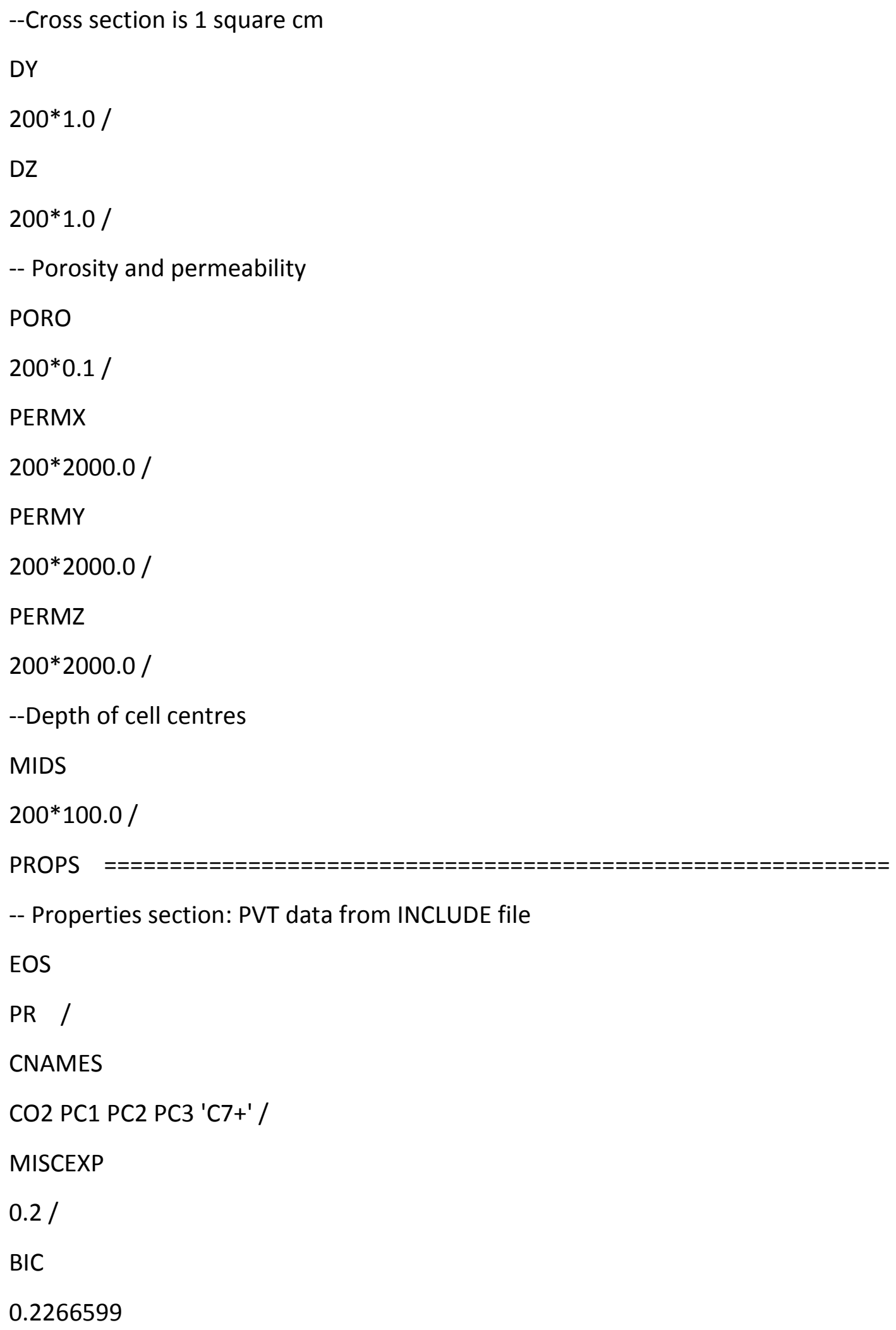




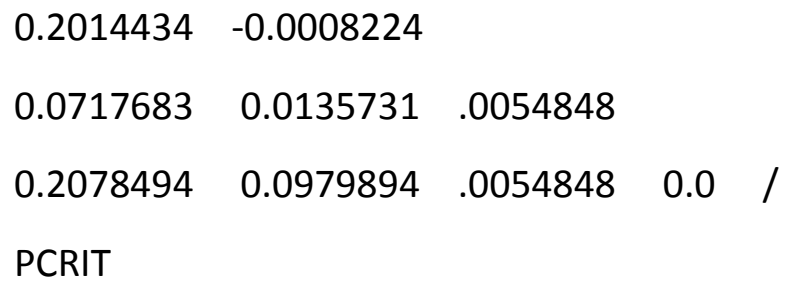


-- Rock and properties

ROCK

$136.00 .000004 /$

SGFN

0.000 .00000 .0

0.100 .01560 .0

0.200 .06250 .0

0.300 .14060 .0

$0.400 .2500 \quad 0.0$

0.500 .39060 .0

0.600 .56250 .0

0.700 .76560 .0

$0.801 .00000 .0 /$

SOF2

0.200 .0000

0.300 .0278

0.400 .1109

0.500 .2500

0.600 .4444

0.700 .6944

0.750 .8403

$0.801 .0000 /$

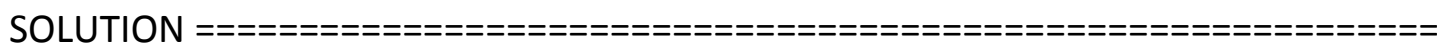

-- Solution section: define explicitly

PRESSURE

$200 * 102.0 /$

SGAS

200*0.0 / 


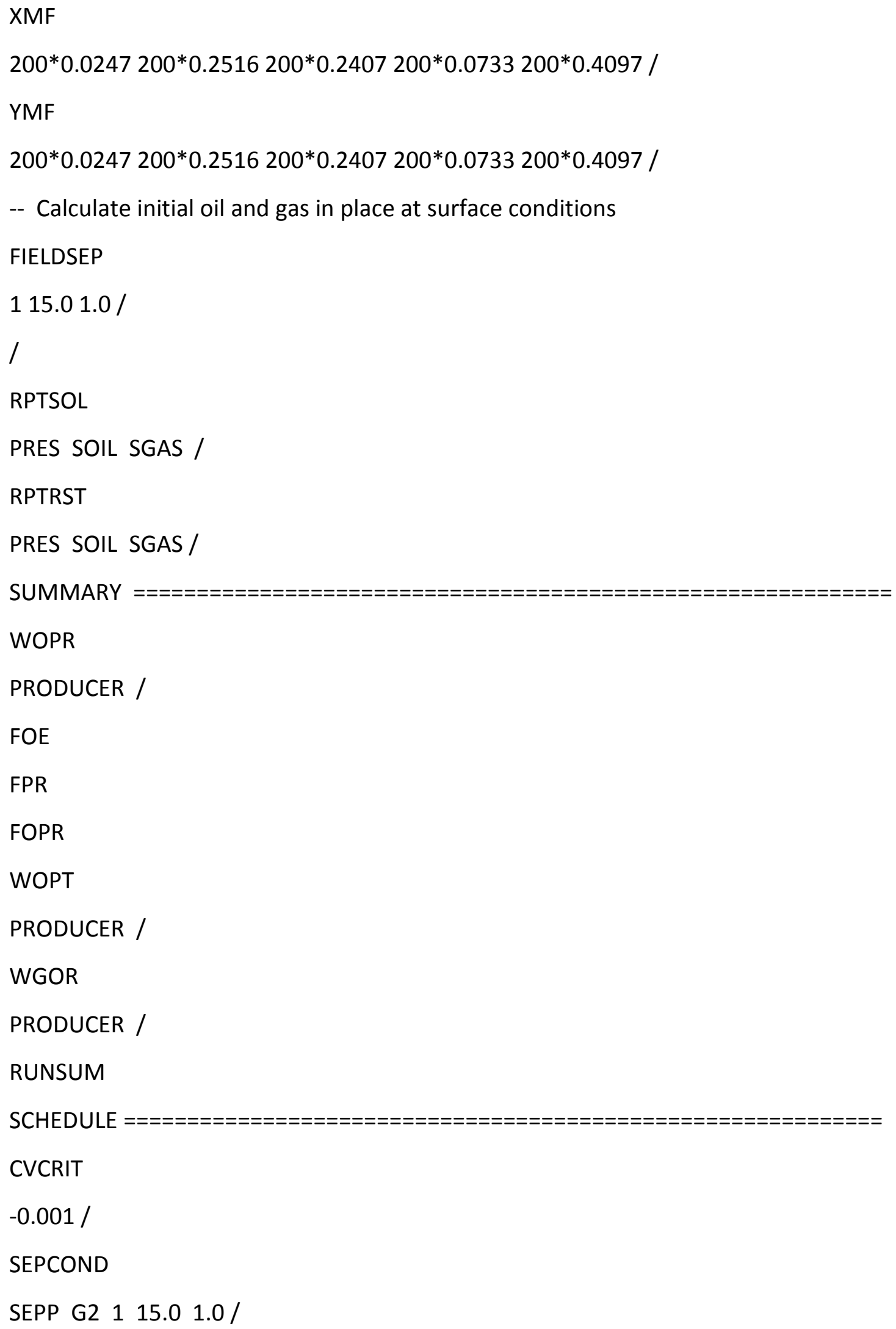




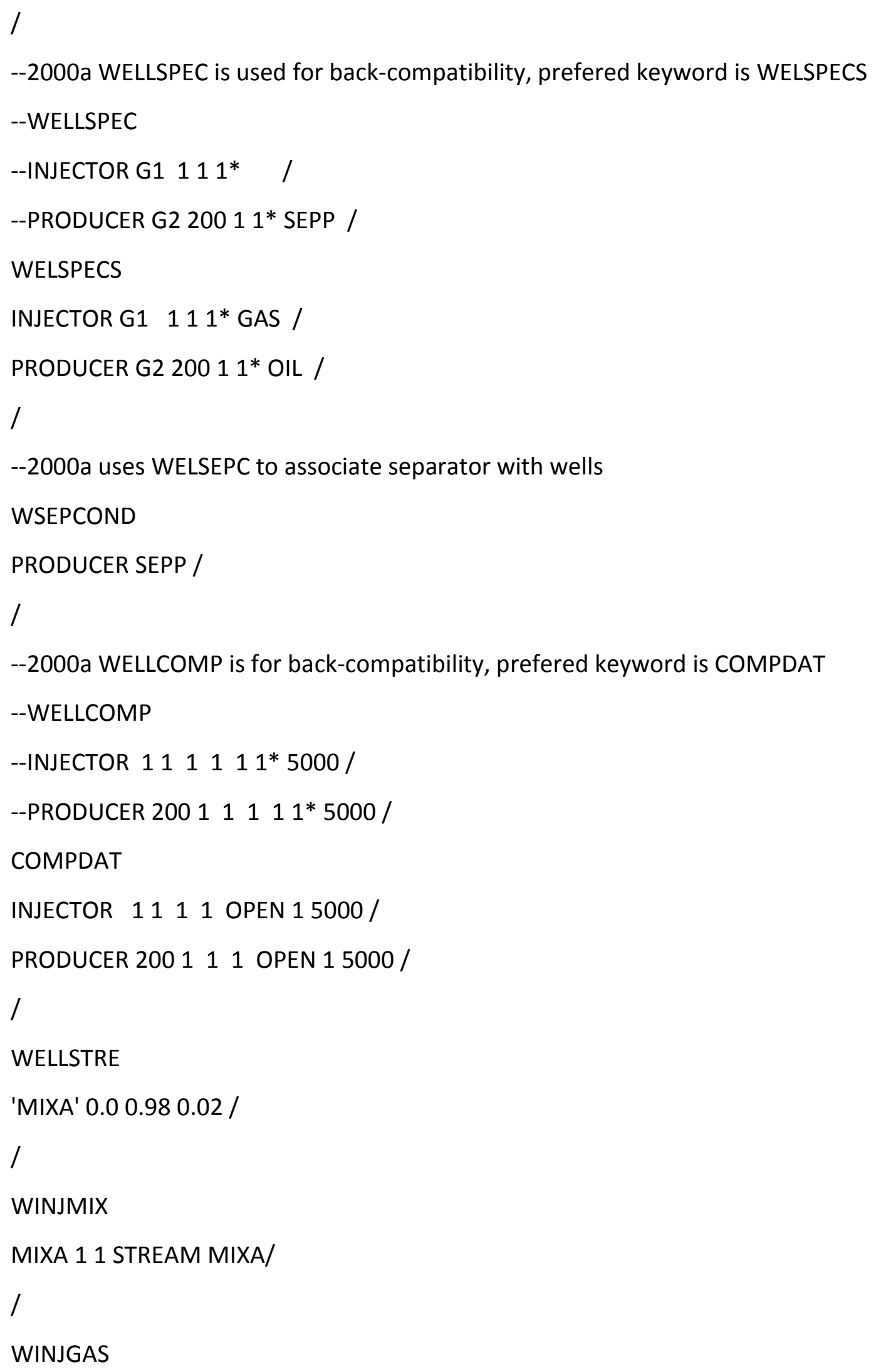




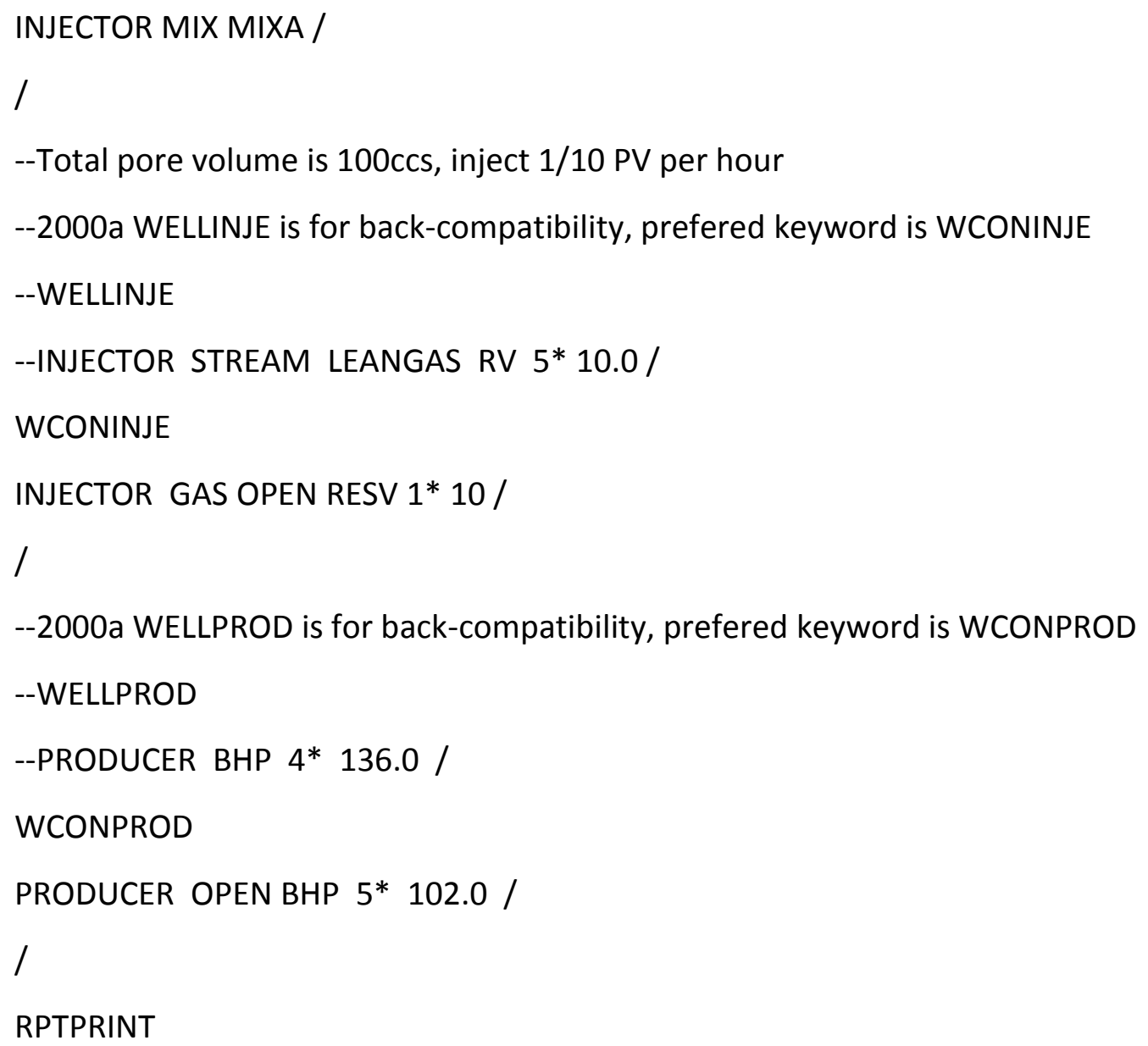




\section{APPENDIX B}

\begin{tabular}{|c|c|c|c|c|c|c|}
\hline $\mathrm{CO} 2$ & $\begin{array}{c}\text { Lean } \\
\text { Gas }\end{array}$ & N2 & Temp & $\mathbf{R F}$ & MMP & \multirow[t]{2}{*}{ MMP Rate of Change } \\
\hline & $\%$ & & $\mathrm{~F}$ & $\mathrm{v} / \mathrm{v}$ & psi & \\
\hline $100 \%$ & $0 \%$ & & 250 & $90 \%$ & 2875 & 0 \\
\hline $80 \%$ & $20 \%$ & & 250 & $90 \%$ & 3091 & 216 \\
\hline $50 \%$ & $50 \%$ & & 250 & $90 \%$ & 3500 & 409 \\
\hline $30 \%$ & $70 \%$ & & 250 & $90 \%$ & 3889 & 389 \\
\hline $0 \%$ & $100 \%$ & & 250 & $90 \%$ & 4250 & 361 \\
\hline $100 \%$ & & $0 \%$ & 250 & $90 \%$ & 2875 & 0 \\
\hline $75 \%$ & & $25 \%$ & 250 & $90 \%$ & 3563 & 688 \\
\hline $50 \%$ & & $50 \%$ & 250 & $90 \%$ & 4667 & 1104 \\
\hline $25 \%$ & & $75 \%$ & 250 & $90 \%$ & 5583 & 917 \\
\hline $0 \%$ & & $100 \%$ & 250 & $90 \%$ & 6375 & 792 \\
\hline $100 \%$ & $0 \%$ & & 200 & $90 \%$ & 2800 & 0 \\
\hline $80 \%$ & $20 \%$ & & 200 & $90 \%$ & 3000 & 200 \\
\hline $50 \%$ & $50 \%$ & & 200 & $90 \%$ & 3625 & 625 \\
\hline $30 \%$ & $70 \%$ & & 200 & $90 \%$ & 4125 & 500 \\
\hline $0 \%$ & $100 \%$ & & 200 & $90 \%$ & 4786 & 661 \\
\hline $100 \%$ & & $0 \%$ & 200 & $90 \%$ & 2800 & 0 \\
\hline $75 \%$ & & $25 \%$ & 200 & $90 \%$ & 3643 & 843 \\
\hline $50 \%$ & & $50 \%$ & 200 & $90 \%$ & 5000 & 1357 \\
\hline $25 \%$ & & $75 \%$ & 200 & $90 \%$ & 6667 & 1667 \\
\hline $0 \%$ & & $100 \%$ & 200 & $90 \%$ & 7833 & 1167 \\
\hline $100 \%$ & $0 \%$ & & 160 & $90 \%$ & 2688 & 0 \\
\hline $80 \%$ & $20 \%$ & & 160 & $90 \%$ & 2909 & 222 \\
\hline $50 \%$ & $50 \%$ & & 160 & $90 \%$ & 3625 & 716 \\
\hline $30 \%$ & $70 \%$ & & 160 & $90 \%$ & 4286 & 661 \\
\hline $0 \%$ & $100 \%$ & & 160 & $90 \%$ & 5182 & 896 \\
\hline $100 \%$ & & $0 \%$ & 160 & $90 \%$ & 2688 & 0 \\
\hline $75 \%$ & & $25 \%$ & 160 & $90 \%$ & 3583 & 896 \\
\hline $50 \%$ & & $50 \%$ & 160 & $90 \%$ & 5200 & 1617 \\
\hline $25 \%$ & & $75 \%$ & 160 & $90 \%$ & 7667 & 2467 \\
\hline $0 \%$ & & $100 \%$ & 160 & $90 \%$ & 9143 & 1476 \\
\hline
\end{tabular}

